Análise de dados por meio de agrupamento fuzzy semi-supervisionado e mineração de textos

\author{
Debora Maria Rossi de Medeiros
}



Data de Depósito:

Assinatura:

\title{
Análise de dados por meio de agrupamento fuzzy semi-supervisionado e mineração de textos ${ }^{1}$
}

\author{
Debora Maria Rossi de Medeiros
}

Orientador: Prof. Dr. André C. P. L. F. de Carvalho

Tese apresentada ao Instituto de Ciências Matemáticas e de Computação - ICMC-USP, como parte dos requisitos para obtenção do título de Doutor em Ciências - Ciências de Computação e Matemática Computacional.

USP - São Carlos

Agosto de 2010 

Em carinhosa memória de minha avó Therezinha Rossi, com amor, saudades e gratidão por seu carinho e aconchegante presença ao longo dos anos em que tive o privilégio de desfrutar de sua companhia. 


\section{Agradecimentos}

Agradeço primeiramente a meus pais, Araceli e Max, pela orientação, pelo porto seguro, por conseguirem ser tão preocupados e divertidos ao mesmo tempo e pelo amor incondicional a vida toda. Agradeço também a minha irmã, Marianna que apesar dos desentendimentos inerentes a toda relação, no fim o que conta é o amor, o companheirismo, a preocupação, os momentos divertidos e a dedicação nos momentos críticos. Também agradeço a minha avó Eva, mesmo distante, os raros momentos juntos em família fazem com que o carinho permaneça.

Agradeço especialmente ao meu orientador André, que possui uma incrivel capacidade de motivação e compreensão. Também agradeço a ele por estar sempre presente, mesmo quando longe.

Agradeço ao Thiago, por estar do meu lado, principalmente na fase mais crítica, pela paciência, pela ajuda técnica, por ser um manual de linux humano, pelo carinho e por me ajudar a manter as emoções controladas nos momentos de extrema preocupação.

Agradeço à minha, para sempre amiga, Paula, pessoa capaz de saber o que eu sinto e preciso, sem que eu precise falar ou mesmo estar perto.

Agradeço à minha amiga Carolzinha, pelo carinho, dedicação, lealdade e por sempre estar presente, independente da distância.

Agradeço ao Bruno Feres, que acompanhou este trabalho desde o começo e acabou tornando-se um importante colega e grande amigo. Agradeço a ele por toda a ajuda e importantes conversas ao longo do desenvolvimento desse trabalho.

Agradeço à minha nova e já grande amiga Rosane, por ser tão carinhosa e companheira. Agradeço também a seus pais, que de certa forma já são meus pais também.

Agradeço às professoras Roseli Francelin, Graça Nunes, Solange Rezende e Carolina Monard por terem me orientado e ensinado muito do que sei hoje.

Agradeço à Camila Martins, pela sua amizade, no verdadeiro sentido da palavra e pelas divertidas corridas, saladas e barzinhos.

Agradeço à Anielli, que em tão pouco tempo se tornou um porto seguro para mim, por me fazer praticar exercícios, por ser tão prática, e me ajudar a ser também, e tão carinhosa e atenciosa ao mesmo tempo. 
Agradeço a Murilo e Kemilly, amigos sempre prontos para todos os momentos, de conforto, conselhos, diversão e por serem um porto seguro para mim.

Agradeço à minha segunda família, Marinez, Evano, Tiago e Juliana, por serem tão especiais, tão super-pessoas, tão leais, tão eternos na minha vida.

Agradeço à nossa vizinha Maria Helena, por ser tão atenciosa, prestativa e carinhosa.

Agradeço à Nola, por ter sido uma mãe e amiga em Edmonton e ter me inserido em sua família em proporcionando essa incrivel oportunidade de ver de perto o cotidiano de uma família canadense. Agradeço a seus filhos Carol, Brady e nora Abby, por terem sido como "tios" para mim.

Agradeço ao professor Witold Pedrycz, por ter me aceitado como sua aluna e ter me ensinado coisas fundamentais para o desenvolvimento deste trabalho.

Ao colega Renato Ishi e ao professor Rodrigo Melo por colaborarem com a configuração do servidor de experimentos.

Agradeço as minhas amigas Gabi, Mel, Nazira, Alessandra, Kemelli, Carol Reis, Juliana Santos, Kamila Sauer, Carol Scarton, Vanessa, personagens importantíssimas em diferentes momentos dessa história.

Agradeço ao meu colega e amigo Mario, com quem compartilhei tantos momentos bons e momentos difíceis.

Agradeço a Adriana Alves e Sabrina Senatore por terem sido tão especiais e atenciosas em Edmonton.

Aos amigos que ganhei no Biocomp, Cerri, Pablo, Márcio, Danilo, Lucas, Luiz, Jonathan, Marcelo Silva, Marcelo Albertini, André Rossi, Augusto, Lilian, Mariá, Rodrigo Calvo, por todos os momentos, sérios de conversas sobre pesquisa, descontraídos nos churrascos e barzinhos, enfim, pessoas com lugar garantido no meu coração para sempre, e às amigas que acabei ganhando por tabela, Talita, Carol e Madaleine.

Aos colegas da época de Labic, Lorena, Katti, Cris Imamura, Patrícia, Gedson, Zé Flávio, Cláudia Martins, Eduardo Spinosa, Eduardo Costa, Marcílio, Ronaldo Prati, Gustavo, Cláudia Milaré, Gustavo Batista, Edson Takashi, pela amizade

Agradeço as professoras de inglês e amigas, Doca e Jane.

Agradeço aos colegas do Nilc, pessoas com quem tive o prazer de conviver por um tempo.

Agradeço aos amigos da Comp2k e da PGCompUSP04 pela parceria em todos os momentos.

Agradeço especialmente a todos os professores e funcionários do ICMC, em especial as meninas da Seção de Pós, pessoas com papel fundamental neste trabalho e na minha vida.

Agradeço a meus amigos Vladimir, Dalton, Marcos Pacheco, Marcos Turci, Joana, Heider por sempre torcerem por mim e terem me desejado o melhor, de verdade.

Agradeço à Capes, pelo suporte financeiro durante o estágio no exterior.

Agradeço à FAPESP, pelo suporte financeiro essencial a este trabalho. 


\section{Resumo}

Esta Tese apresenta um conjunto de técnicas propostas com o objetivo de aprimorar processos de Agrupamento de Dados (AD). O principal objetivo é fornecer à comunidade científica um ferramental para uma análise completa de estruturas implícitas em conjuntos de dados, desde a descoberta dessas estruturas, permitindo o emprego de conhecimento prévio sobre os dados, até a análise de seu significado no contexto em que eles estão inseridos. São dois os pontos principais desse ferramental. $\mathrm{O}$ primeiro se trata do algoritmo para $\mathrm{AD}$ fuzzy semi-supervisionado SSL+P e sua evolução SSL+P*, capazes de levar em consideração o conhecimento prévio disponível sobre os dados em duas formas: rótulos e níveis de proximidade de pares de exemplos, aqui denominados Dicas de Conhecimento Prévio (DCPs). Esses algoritmos também permitem que a métrica de distância seja ajustada aos dados e às DCPs. O algoritmo SSL+P* também busca estimar o número ideal de clusters para uma determinada base de dados, levando em conta as DCPs disponiveis. Os algoritmos SSL+P e SSL+P* envolvem a minimização de uma função objetivo por meio de um algoritmo de Otimização Baseado em População (OBP). Esta Tese também fornece ferramentas que podem ser utilizadas diretamente neste ponto: as duas versões modificadas do algoritmo Particle Swarm Optimization (PSO), DPSO-1 e DPSO-2 e 4 formas de inicialização de uma população inicial de soluções. O segundo ponto principal do ferramental proposto nesta Tese diz respeito à análise de clusters resultantes de um processo de $\mathrm{AD}$ aplicado a uma base de dados de um domínio específico. É proposta uma abordagem baseada em Mineração de Textos (MT) para a busca em informações textuais, disponibilizadas digitalmente e relacionadas com as entidades representadas nos dados. Em seguida, é fornecido ao pesquisador um conjunto de palavras associadas a cada cluster, que podem sugerir informações que ajudem a identificar as relações compartilhadas por exemplos atribuídos ao mesmo cluster. 


\section{Abstract}

This Thesis presents a whole set of techniques designed to improve the data clustering proccess. The main goal is to provide to the scientific community a tool set for a complete analyses of the implicit structures in datasets, from the identification of these structures, allowing the use of previous knowledge about the data, to the analysis of its meaning in their context. There are two main points involved in that tool set. The first one is the semi-supervised clustering algorithm SSL+P and its upgraded version SSL+P*, which are able of take into account the available knowlegdge about de data in two forms: class labels and pairwise proximity levels, both refered here as hints. These algorithms are also capable of adapting the distance metric to the data and the available hints. The SSL+P* algorithm searches the ideal number of clusters for a dataset, considering the available hints. Both SSL+P and SSL+P* techniques involve the minimization of an objective function by a Population-based Optimization algorithm (PBO). This Thesis also provides tools that can be directly employed in this area: the two modified versions of the Particle Swarm Optimization algorithm (PSO), DPSO- 1 and DPSO-2, and 4 diferent methods for initializing a population of solutions. The second main point of the tool set proposed by this Thesis regards the analysis of clusters resulting from a clustering process applied to a domain specific dataset. A Text Mining based approach is proposed to search for textual information related to the entities represented by the data, available in digital repositories. Next, a set of words associated with each cluster is presented to the researcher, which can suggest information that can support the identification of relations shared by objects assigned to the same cluster. 


\section{Lista de Figuras}

2.1 Agrupamento hierárquico de genes. . . . . . . . . . . 6

2.2 Ilustração da abordagem SEEDED- $k$-médias, onde os símbolos "+" e "-" representam exemplos rotulados de cada uma das duas classes. . . . . . . . . . . . . . . . 10

2.3 Agrupamentos utilizando restrições e generalizações espaciais das restrições (Figura adaptada de (Klein et al., 2002)). . . . . . . 12

3.1 Lei de Zipf e Curvas de Luhn. . . . . . . . . . . . . . . . . . . 22

3.2 Comparação de dois textos no espaço de vetores. . . . . . . . . . 23

3.3 Hidden Markov Model para frases (Yandell e Majoros, 2002). . . . 26

3.4 Extração de informação. Adaptado de Yandell e Majoros (2002). . 27

4.1 Estruturas utilizadas como partícula do PSO, onde $N$ é o número de objetos na base de dados, $C$ é o número de clusters e $D$ é o número de atributos da base de dados. . . . . . . . . . . . . . . . . 39

4.2 Conteúdo da partícula. . . . . . . . . . . . . . . . . 42

4.3 O conteúdo da partícula (solução candidata do algoritmo PSO). $H$ representa o número de classes e $N$ o número de elementos na base de dados . . . . . . . . . . . . . . . . . 44 44

4.4 Esquema de rotulação dos textos. . . . . . . . . . . . . . . 48

5.1 Gráficos das bases de dados Sintética-1 e Sintética-2 . . . . . . . . . 50

5.2 Gráfico do Erro de Proximidade para as bases Sintética-1 em função do número de clusters para os critérios de aptidão: Silhueta, VRC, Xie-Beni, FDB e Reconstrução com representação de protótipos baseada em centróides e medóides. . . . . . . . . . . . . . 52

5.3 Gráfico do Erro de Proximidade para a base Sintética-2 em função do número de clusters para os critérios de aptidão: Silhueta, VRC, Xie-Beni, FDB e Reconstrução, com representação de protótipos baseada em centróides e medóides. . . . . . . . . . . . . . . 53 
5.4 Gráfico do Erro de Proximidade para a base Diabetes em função do número de clusters para os critérios de aptidão: Silhueta, VRC, Xie-Beni, FDB e Reconstrução, com representação de protótipos baseada em centróides e medóides. . . . . . . . . . . . . . 53

5.5 Gráfico do Erro de Proximidade para a base Glass em função do número de clusters para os critérios de aptidão: Silhueta, VRC, Xie-Beni, FDB e Reconstrução, com representação de protótipos baseada em centróides e medóides.

5.6 Gráfico do Erro de Proximidade para a base Wine em função do número de clusters para os critérios de aptidão: Silhueta, VRC, Xie-Beni, FDB e Reconstrução com representação de protótipos baseada em centróides e medóides.

5.7 Gráficos das bases de dados Sintética-3 e Sintética-4. . . . . . . . . . . 58

5.8 Gráfico do Erro de Classificação para a base Sintética-1 com a técnica SSL+P em função dos valores de $\alpha$ e $\beta$ para as variações de métrica de distância (euclidiana (EUC), euclidiana ponderada (DIAG) e completamente adaptativa (FULL)), função não-supervisionada ( $N S$ ), quantidades de dicas $(0.1 N$ e $0.5 N)$ e forma de produção das dicas, em comparação com as técnicas propostas por Basu et al. (2002) e Bouchachia e Pedrycz (2003). . . . . . . . . . . . . . . . .

5.9 Gráfico do Erro de Classificação para a base Sintética-3 com a técnica SSL+P em função dos valores de $\alpha$ e $\beta$ para as variações de métrica de distância (euclidiana (EUC), euclidiana ponderada (DIAG) e completamente adaptativa (FULL)), função não-supervisionada ( $N S$ ), quantidades de dicas $(0.1 N$ e $0.5 N)$ e forma de produção das dicas, em comparação com as técnicas propostas por Basu et al. (2002) e Bouchachia e Pedrycz (2003). . . . . . . . . . . . . . .

5.10Gráfico do Erro de Classificação para a base Sintética-4 com a técnica SSL+P em função dos valores de $\alpha$ e $\beta$ para as variações de métrica de distância (euclidiana (EUC), euclidiana ponderada (DIAG) e completamente adaptativa (FULL)), função não-supervisionada ( $N S$ ), quantidades de dicas $(0.1 N$ e $0.5 N)$ e forma de produção das dicas, em comparação com as técnicas propostas por Basu et al. (2002) e Bouchachia e Pedrycz (2003). . . . . . . . . . . . . . . 
5.11 Gráfico do Erro de Classificação para a base Sintética-4 com a técnica SSL+P* em função dos valores de $\alpha$ e $\beta$ para as variações de métrica de distância (euclidiana (EUC), euclidiana ponderada (DIAG) e completamente adaptativa (FULL)), quantidades de dicas $(0.1 N \mathrm{e}$ $0.5 N$ ) e forma de produção das dicas (aleatória ou baseada nos rótulos disponíveis), em comparação com as técnicas propostas por Basu et al. (2002) e Bouchachia e Pedrycz (2003).

5.12 Gráfico dos números de clusters estimados pela técnica $\mathrm{SSL}+\mathrm{P}^{*}$ para a base Sintética-4 em função dos valores de $\alpha$ e $\beta$ para as variações quantidades de DCPs $(0.1 N$ e $0.5 N)$ e forma de produção delas (aleatória ou baseada nos rótulos disponíveis). . . . . . . . . . .

5.13 Gráfico do Erro de Classificação para a base Íris com a técnica SSL+P* em função dos valores de $\alpha$ e $\beta$ para as variações de métrica de distância (euclidiana (EUC), euclidiana ponderada (DIAG) e completamente adaptativa (FULL)), quantidades de dicas $(0.1 N$ e $0.5 N)$ e forma de produção das dicas (aleatória ou baseada nos rótulos disponiveis), em comparação com as técnicas propostas por Basu et al. (2002) e Bouchachia e Pedrycz (2003). . . . . . . . . . . . . . . . .

5.14 Gráfico dos números de clusters estimados pela técnica SSL+P* para a base Íris em função dos valores de $\alpha$ e $\beta$ para as variações de quantidades de dicas $(0.1 N$ e $0.5 N)$ e forma de produção das dicas (aleatória ou baseada nos rótulos disponíveis). . . . . . . . . . .

5.15Gráfico do Erro de Classificação para a base Sintética-3 com a técnica SSL+P* em função dos valores de $\alpha$ e $\beta$ para as variações de métrica de distância (euclidiana (EUC), euclidiana ponderada (DIAG) e completamente adaptativa (FULL)), quantidades de dicas $(0.1 N \mathrm{e}$ $0.5 N$ ) e forma de produção das dicas (aleatória ou baseada nos rótulos disponíveis), em comparação com as técnicas propostas por Basu et al. (2002) e Bouchachia e Pedrycz (2003). . . . . . . . . . . . . . . . . . .

5.16 Gráfico dos números de clusters estimados pela técnica SSL+P* para a base Sintética-3 em função dos valores de $\alpha$ e $\beta$ para as variações de quantidades de dicas $(0.1 N$ e $0.5 N)$ e forma de produção das dicas (aleatória ou baseada nos rótulos disponíveis). . . . . . . . . . . . .

5.17Gráfico do Erro de Classificação para a base Wine com a técnica SSL+P* em função dos valores de $\alpha$ e $\beta$ para as variações de métrica de distância (euclidiana (EUC), euclidiana ponderada (DIAG) e completamente adaptativa (FULL)), quantidades de dicas $(0.1 N$ e $0.5 N$ ) e forma de produção das dicas (aleatória ou baseada nos rótulos disponíveis), em comparação com as técnicas propostas por Basu et al. (2002) e Bouchachia e Pedrycz (2003). . . . . . . . . . . . . . . 
5.18 Gráfico dos números de clusters estimados pela técnica SSL+P* para a base Wine em função dos valores de $\alpha$ e $\beta$ para as variações de quantidades de dicas $(0.1 N$ e $0.5 N)$ e forma de produção das dicas (aleatória ou baseada nos rótulos disponíveis). . . . . . . . . . . . . . . 68

5. 19 Gráfico da base de dados Sintética-5. . . . . . . . . . . . . 71

5.20 Gráficos da medida de avaliação Erro de Proximidade para a base Sintética-1 em função do número de clusters. . . . . . . . . . . . . 74

5.21 Gráficos da medida de avaliação Erro de Proximidade para a base Sintética 2 em função do número de clusters . . . . . . . . . . . . 75

6.1 Contribuições da Tese. . . . . . . . . . . . . . . . 89

A.1 Comparação do erro de classificação entre os algoritmos Bouchachia e Pedrycz (Bouchachia e Pedrycz, 2006a), Constrained e seeded $k$-médias com SSL+P na base de dados Sintética-1. . . . . . . . . . . . . . . . . . 102

A.2 Comparação do erro de classificação entre os algoritmos Bouchachia e Pedrycz (Bouchachia e Pedrycz, 2006a), Constrained e Seeded $k$-médias com SSL+P na base de dados Sintética-3. . . . . . . . . . . . . . . 103

A.3 Comparação do erro de classificação entre os algoritmos Bouchachia e Pedrycz (Bouchachia e Pedrycz, 2003), Constrained e Seeded $k$-médias com SSL+P na base de dados Sintética-4. . . . 104

A.4 Comparação do erro de classificação entre os algoritmos Bouchachia e Pedrycz (Bouchachia e Pedrycz, 2003), Constrained e Seeded $k$-médias com SSL+P* na base de dados Iris. . . . . . . . 105

A.5 Comparação do erro de classificação entre os algoritmos Bouchachia e Pedrycz (Bouchachia e Pedrycz, 2003), Constrained e Seeded $k$-médias com SSL+P* na base de dados Sintética-3. . . 106

A.6 Comparação do erro de classificação entre os algoritmos Bouchachia e Pedrycz (Bouchachia e Pedrycz, 2003), Constrained e Seeded $k$-médias com SSL+P* na base de dados Sintética-4. . . 107

A.7 Comparação do erro de classificação entre os algoritmos Bouchachia e Pedrycz (Bouchachia e Pedrycz, 2003), Constrained e Seeded $k$-médias com SSL+P* na base de dados Wine. . . . . . . 108

A.8 Número de clusters estimados pelo algoritmo SSL+P* na base de dados Iris. . . . . . . . . . . . . . . . . . . . 108

A.9 Número de clusters estimados pelo algoritmo SSL+P* na base de dados Sintética-3. . . . . . . . . . . . . . . 109

A.10Número de clusters estimados pelo algoritmo SSL+P* na base de dados Sintética-4. . . . . . . . . . . . . . 109 
A.11Número de clusters estimados pelo algoritmo SSL+P* na base de dados Wine. . . . . . . . . . . . . . . . . . . . . . 109 


\section{Lista de Tabelas}

5.1 Configurações para criação das bases de dados sintéticas. . . . . 50

5.2 Principais características das bases de dados utilizadas. . . . . . 51

5.3 Tabela de vitórias/empates/derrotas das variações listadas na primeira coluna, em relação àquelas listadas na primeira linha. 55

5.4 Resultados dos testes estatísticos de Friedman e Nemenyi (“+” significa diferença estatística 90\% e “*” 95\%). . . . . . . . . . . . 55

5.5 Principais características das bases de dados utilizadas. . . . . 58

5.6 Números de clusters empregados para cada base de dados. . . . . 59

5.7 Tabela de vitórias/empates/derrotas das técnicas listadas na primeira coluna, em relação àquelas listadas na primeira linha comparando as técnicas de referência e as variações do SSL+P utilizando de dicas deduzidas. . . . . . . . . . . . . . . . . 62

5.8 Tabela de vitórias/empates/derrotas das técnicas listadas na primeira coluna, em relação àquelas listadas na primeira linha comparando as técnicas de referência e as variações do SSL+P utilizando de dicas aleatórias. . . . . . . . . . . . . . . . 63

5.9 Testes estatísticos de Friedman e Nemenyi dos resultados das técnicas de referência e das variações do SSL+P utilizando de dicas deduzidas. (“+” significa diferença estatística 90\% e “*” 95\%). 63

5.10Testes estatísticos de Friedman e Nemenyi dos resultados das técnicas de referência e das variações do SSL+P utilizando de dicas aleatórias (“+” significa diferença estatística 90\% e “*” 95\%). 64

5.11 Tabela de vitórias/empates/derrotas das técnicas listadas na primeira coluna, em relação àquelas listadas na primeira linha comparando as técnicas de referência e as variações do SSL+P* utilizando de dicas aleatórias. . . . . . . . . . . . . . . 69

5.12 Tabela de vitórias/empates/derrotas das técnicas e variações do SSL+P* listadas na primeira coluna, em relação àquelas listadas na primeira linha no caso de utilização de dicas aleatórias. . . . . 69 
5.13Testes estatísticos de Friedman e Nemenyi dos resultados das técnicas de referência e das variações do SSL+P* utilizando de dicas deduzidas ("+" significa diferença estatística 90\% e “*” 95\%). 69

5.14Testes estatísticos de Friedman e Nemenyi dos resultados das técnicas de referência e das variações do SSL+P* utilizando de dicas aleatórias ("+" significa diferença estatística 90\% e “*” 95\%). 70

5.15Configurações para criação da base de dados Sintética-5 . . . . 70

5.16 Comparação das formas de inicialização para base de dados Sintética-1, onde os melhores resultados estão destacados. . . . . 72

5.17 Comparação das formas de inicialização para base de dados Sintética-5, onde os melhores resultados estão destacados. . . . . 73

5.18Tabela de vitórias/empates/derrotas das versões do PSO listadas na primeira coluna, em relação àquelas listadas na primeira linha. 75 5.19 Clusters de genes definidos no trabalho de Eisen et al. (1998). . . 77

5.20 Coleção de textos sobre os genes dos clusters de Eisen et al. (1998). 77

5.21 Taxas de acerto (média e desvio padrão entre os folds) e número de atributos. . . . . . . . . . . . . . . . 79

5.22 Taxas de acerto (média e desvio padrão entre os folds) e números de atributos. . . . . . . . . . . . . . . . 79

5.23 Performance do treinamento das regras de decisão. . . . . . . . 80

5.24 Palavra consideradas relevantes. . . . . . . . . . . . 82

5.25 Médias de acerto por cluster e total. . . . . . . . . . . . . 83

5.26 Sub-árvores relevantes. . . . . . . . . . . . . . . . 83

5.27 Novas palavras relevantes. . . . . . . . . . . . 84

5.28 Nova sub-árvore e sub-árvore antiga modificada . . . . . . . . 84 


\section{Lista de Abreviaturas}

$\begin{array}{ll}\text { AD } & \text { Agrupamento de Dados } \\ \text { AG } & \text { Algoritmo Genético } \\ \text { AM } & \text { Aprendizagem de Máquina } \\ \text { ART } & \text { Adaptive Resonance Theory } \\ \text { DCPs } & \text { Dicas de Conhecimento Prévio } \\ \text { DPSO } & \text { Dynamic Particle Swarm Optimization } \\ \text { EI } & \text { Extração de Informação } \\ \text { FCM } & \text { Fuzzy-c-means } \\ \text { FDB } & \text { Davies-Bouldin fuzzy } \\ \text { MD } & \text { Mineração de Dados } \\ \text { MT } & \text { Mineração de textos } \\ \text { OBP } & \text { Otimização baseada em população } \\ \text { PSO } & \text { Particle Swarm Optimization } \\ \text { RNAs } & \text { Redes Neurais Artificiais } \\ \text { SOM } & \text { Self Organizing Maps } \\ \text { SSL+P } & \text { Semi-supervised labels+proximity } \\ \text { SVM } & \text { Support Vector Machine }\end{array}$




\section{Sumário}

1 Introdução 1

2 Agrupamento de Dados 5

2.1 Considerações Iniciais . . . . . . . . . . . . . . . . . 5

2.2 Agrupamento não-supervisionado . . . . . . . . . . . 5

2.3 Agrupamento semi-supervisionado . . . . . . . . . . . . . . 9

2.4 Medidas de validação . . . . . . . . . . . . . . . . . . 14

2.5 Aplicação em dados de biologia molecular . . . . . . . . . . . 15

2.6 Considerações Finais . . . . . . . . . . . . . . . . . 17

3 Mineração de textos biomédicos 19

3.1 Considerações iniciais . . . . . . . . . . . . . . . . . . . 19

3.2 Mineração de textos . . . . . . . . . . . . . . . . . 20

3.2.1 Recuperação de informação . . . . . . . . . . . . 20

3.2.2 Processamento de língua natural (PLN) . . . . . . . . . 25

3.2.3 Avaliação e interpretação dos resultados . . . . . . . . . . 28

3.3 Mineração de textos em Bioinformática . . . . . . . . . . . . . . . . 29

3.3.1 Agrupamento de genes e descoberta do significado dos clusters ................... . 29

3.3.2 Descoberta de relacionamentos entre genes . . . . . . 31

3.4 Recursos para mineração de textos . . . . . . . . . . . . 33

3.4.1 Biblioteca Libbow . . . . . . . . . . . . . . . . 33

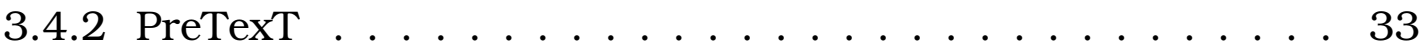

3.4.3 General Text Parser . . . . . . . . . . . . . . 34

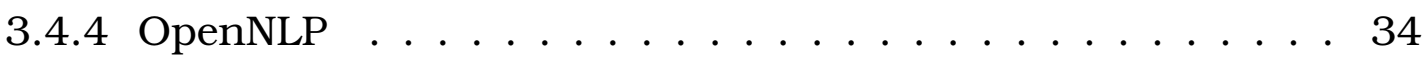

3.4 .5 Mallet ...................... 34

3.4.6 Natural Language Toolkit . . . . . . . . . . . . . . . . . . 35

3.4 .7 JavaNLP . . . . . . . . . . . . . . . . . 35

3.5 Considerações finais . . . . . . . . . . . . . . 35 
4 Abordagens propostas $\quad 37$

4.1 Considerações iniciais . . . . . . . . . . . . . . . 37

4.2 Agrupamento de dados não-supervisionado . . . . . . . . . . 38

4.3 Agrupamento de dados semi-supervisionado . . . . . . . . . . 40

4.3.1 SSL+P: Unindo rótulos e proximidade de pares de exemplos 40

4.3.2 SSL+P*: Otimização do número de clusters . . . . . . . . 43

4.4 Otimização baseada em população . . . . . . . . . . . . 44

4.4.1 Produção da população inicial de soluções . . . . . . . . . 45

4.4 .2 Modificações do PSO . . . . . . . . . . . . . . . . . 46

4.5 Análise automática de clusters de dados biomédicos . . . . . . . . 47

4.6 Considerações finais . . . . . . . . . . . . . . . . . . . 48

5 Experimentos $\quad 49$

5.1 Considerações iniciais . . . . . . . . . . . . . . . . . 49

5.2 Agrupamento de dados não-supervisionado . . . . . . . . . . . 49

5.2 .1 Bases de dados . . . . . . . . . . . . . . 50

5.2 .2 Metodologia . . . . . . . . . . . . . . . 51

5.2 .3 Resultados . . . . . . . . . . . . . . . . . . 52

5.3 Agrupamento de dados semi-supervisionado . . . . . . . . . 56

5.3 .1 Bases de dados . . . . . . . . . . . . . . . 56

5.3 .2 Metodologia . . . . . . . . . . . . . . . 58

5.3 .3 Resultados . . . . . . . . . . . . . . . . 60

5.4 Otimização baseada em população $\ldots \ldots \ldots \ldots$. . . . . 70

5.4 .1 Bases de dados . . . . . . . . . . . . . . 70

5.4 .2 Metodologia . . . . . . . . . . . . . . 71

5.4 .3 Resultados . . . . . . . . . . . . . . . . . . 72

5.5 Análise automática de clusters de dados biomédicos . . . . . . . 76

5.5 .1 Bases de dados . . . . . . . . . . . . . . . 76

5.5 .2 Metodologia . . . . . . . . . . . . . . . 77

5.5 .3 Resultados . . . . . . . . . . . . . . . . 79

5.6 Considerações finais . . . . . . . . . . . . . . . . . . 85

6 Conclusões $\quad 87$

6.1 Contribuições. . . . . . . . . . . . . . . . 87

6.2 Trabalhos futuros . . . . . . . . . . . . . . . 89

$\begin{array}{ll}\text { Referências Bibliográficas } & 91\end{array}$

A Resultados completos dos experimentos em AD $\begin{array}{ll}\text { semi-supervisionado } & 101\end{array}$

B Resumo sobre o algoritmo PSO (Particle Swarm Optimization) 111 


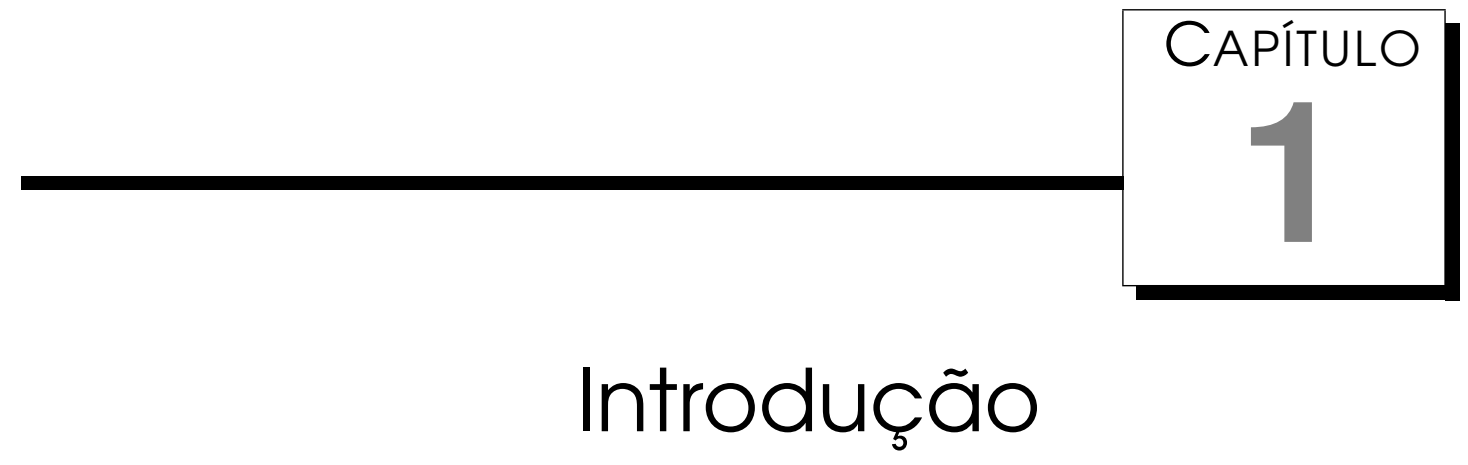

Nas últimas décadas, tem havido um considerável aumento na disponibilização de dados provindos de diversas áreas como biologia, medicina, marketing, engenharia, etc. Esses dados podem estar organizados de diferentes maneiras, desde a forma mais comum, conhecida como tabelas de atributo-valor, até conjuntos de textos e bancos de dados relacionais. Este grande volume de dados cria uma demanda de desenvolvimento de ferramentas computacionais destinadas a analisá-los com o objetivo de encontrar padrões que sugiram novas informações, úteis para domínio de conhecimento.

A área de descoberta de conhecimento em bases de dados (KDD, do inglês Knowledge Discovery in Databases) propõe uma sequência de etapas para a análise desses dados (Fayyad, 1996; Fayyad et al., 1996). Uma das principais é a Mineração de Dados (MD), que utiliza algoritmos de Aprendizado de Máquina (AM) para a descoberta automática de conhecimento nos dados. Estes algoritmos são capazes de aprender os padrões contidos nestes dados.

AM é uma área da Inteligência Artificial cujo objetivo é o desenvolvimento de técnicas computacionais capazes de adquirir conhecimento automaticamente (Mitchell, 1997). O conhecimento, geralmente, é obtido por meio de indução, ou seja, são formuladas hipóteses a partir de inferências sobre um conjunto de exemplos fornecido ao algoritmo de aprendizado (Rezende, 2003). As tarefas de AM podem ser divididas em preditivas, quando o objetivo é gerar um modelo capaz de prever um rótulo para cada item de dado, e descritivas, quando a meta é descrever um conjunto de dados.

Em tarefas preditivas, os rótulos podem representar classes em que os dados foram previamente organizados e o algoritmo deve aprender, com base 
nesses dados, para serem capazes de atribuir rótulos a dados novos ainda não classificados, sendo assim chamados de algoritmos de classificação. Os rótulos também podem ser valores em uma faixa contínua e os algoritmos designados para aprender a atribuir esse tipo de rótulo são chamados de algoritmos de regressão.

Em se tratando das tarefas descritivas, podemos citar como exemplo os algoritmos de aprendizado de regras de associação, cujo o objetivo é encontrar, em um conjunto de dados, regras que associem um subconjunto de atributos a outro. Outro exemplo de tarefa descritiva, mais relevante para este trabalho, são os algoritmos de agrupamento de dados (AD) onde a meta é encontrar grupos nos dados.

$\mathrm{AD}$ (Duda et al., 2001; Jain et al., 1999) é uma área de pesquisa fundamental em análise de dados. Em linhas gerais, o objetivo de um processo de $\mathrm{AD}$ é a descoberta de estruturas implícitas em uma base de dados, denomidadas clusters de dados. Esses clusters contém exemplos de dados similares entre si de acordo com alguma métrica de semelhança pré-definida. Alguns dos algoritmos de AD mais conhecidos estão normalmente relacionados com uma busca local no espaço de soluções guiada por uma determinada função objetivo, como é o caso do algoritmo $k$-médias (Maçueen, 1967) e do FCM (do inglês Fuzzy C-Means) (Bezdek, 1981). Como um espaço de soluções pode conter ótimos locais, é inerente a um processo de busca local o perigo de alcançar uma dessas regiões. Levando essa limitação em consideração, tem havido um crescente interesse em explorar mecanismos de Otimização Baseada em População (OBP), para evitar o problema dos ótimos locais, intrínsecos aos métodos de busca local. Exemplos clássicos de algoritimos de OBP são Algoritmos Genéticos, AGs (Goldberg, 1989) e Particle Swarm Optimization, PSO (Kennedy e Eberhart, 2001).

Dados de diversos domínios de conhecimento são frequentemente analisados por algoritmos de $\mathrm{AD}$. Um exemplo cada vez mais evidente são dados de biologia molecular. Com o advento das tecnologias de Microarray, tornou-se possivel medir os niveis de expressão de milhares de genes simultaneamente (Shatkay et al., 2000). Esses experimentos produzem uma enorme quantidade de dados. A análise cuidadosa desses dados pode contribuir para o desenvolvimento de medicamentos, aprimoramento de diagnósticos, prognósticos, etc. Com a grande quantidade de pesquisas dedicadas ao agrupamento de dados biológicos, surgiu uma nova demanda na comunidade científica: desenvolvimento de técnicas para associar significado biológico aos clusters descobertos, por exemplo, identificar se entidades biológicas pertencentes a um mesmo cluster compartilham alguma função 
no organismo a que pertencem (Shatkay et al., 2000). Atualmente, atenção especial tem sido dada à tentativa de facilitar esse trabalho, resultando no surgimento de várias abordagens para extração de informação da literatura relacionada ao assunto (Masys et al., 2001; Blaschke et al., 2001; Oliveros et al., 2000; Tanabe et al., 1999; Jenssen et al., 2001; Shatkay et al., 2000). Publicações científicas contêm as descobertas biológicas mais significativas, como funções de genes em organismos. Porém, esta é uma fonte de informação não estruturada e para analisá-la é necessária a aplicação de métodos de Mineração de Textos (MT) (Fayyad, 1996; Fayyad et al., 1996; Weiss e Indurkhya, 1998) que buscam converter os textos para formas estruturadas de dados e, delas, extrair informação útil.

Motivado pelo exposto, a pesquisa desenvolvida neste trabalho de Doutorado visa contribuir tanto com a área de $\mathrm{AD}$ com $\mathrm{OBP}$, quanto com a área de descoberta de significado de clusters de dados biológicos.

As investigações realizadas na área de $\mathrm{AD}$ se concentraram na utilização de algoritmos de OBP em conjunto com critérios de aptidão formulados para avaliar um conjunto de clusters. O principal foco dessas investigações é a utilização de supervisão parcial por algoritmos de $\mathrm{AD}$, permitindo assim a incorporação de conhecimento prévio disponível sobre os dados no processo de formação dos clusters. Foram desenvolvidas duas técnicas de $\mathrm{AD}$ semi-supervisionado fuzzy, SSL+P (Semi-supervised Labels + Proximity) e SSL+P* (Semi-supervised Labels + Proximity incrementado), capazes de utilizar conhecimento prévio disponível em diferentes formas, adaptar uma matriz de distância aos dados e buscar o número ideal de clusters para uma determinada base de dados. A diferença entre essas duas técnicas é que a SSL+P* possui a funcionalidade de estimar o número ideal de clusters de uma base de dados, enquanto a SSL+P necessita que este valor seja informado. Ainda na área de $\mathrm{AD}$, realizou-se neste trabalho uma análise da utilização de algoritmos de OBP em conjunto com índices de validação de clusters (Pal e Bezdek, 1995; Faceli et al., 2005). Também foram realizadas algumas contribuições na área de OBP, como a proposta de duas versões modificadas do algoritmo Particle Swarm Optimization (PSO) (Kennedy e Eberhart, 2001), denominadas DPSO-1 e DPSO-2 (Dynamic Particle Swarm Optimization) (Medeiros e Carvalho, 2010), em que alguns parâmetros do PSO tradicional são modificados dinamicamente durante a execução do algoritmo. Ainda na área de OBP, outras contribuições foram realizadas na maneira de inicializar a população inicial de soluções.

As contribuições na área de extração de informação de textos biomédicos para descoberta de significado de clusters de dados biológicos se concentraram na proposta da utilização de algoritmos de AM supervisionados simbólicos 
para este fim. Esses algoritmos são classificadores que armazenam o conhecimento aprendido em formas de dados compreensíveis pelo ser humano, por exemplo árvores e regras de decisão (Quinlan, 1988). Em linhas gerais, a proposta consiste em aplicar um algoritmo de aprendizado de regras de decisão para classificar textos sobre as entidades biológicas agrupadas em clusters. Os nomes dos clusters são utilizados como rótulos para os textos e as regras resultantes contêm palavras-chave que podem ajudar a definir o sentido biológico de cada cluster.

Esta Tese está organizada da seguinte maneira:

- Capítulo 2: é dada uma introdução da área de $\mathrm{AD}$ contendo alguns dos principais algoritmos encontrados na literatura. São também apresentadas algumas técnicas de $\mathrm{AD}$ semi-supervisionada, entre elas, as técnicas implementadas e utilizadas como base para comparação nos experimentos com as abordagens propostas. Também são apresentados alguns trabalhos que aplicam abordagens de $\mathrm{AD}$ a dados biológicos.

- Capítulo 3: apresenta uma introdução da área de MT contendo as principais etapas de um processo de MT, bem como algumas ferramentas disponíveis para a realização de experimentos nesta área. Também é fornecida uma revisão de alguns dos mais importantes trabalhos que aplicam essas técnicas em textos biomédicos.

- Capítulo 4: são detalhadas as contribuições desta Tese, que são a análise de funções de validação de $\mathrm{AD}$ utilizadas como critério de aptidão para algoritmos de OBP; as investigações relacionadas com a proposta de uma técnica de $\mathrm{AD}$ fuzzy multi-objetivo que permite a utilização de conhecimento prévio sobre os dados disponíveis em duas formas diferentes: dados rotulados e proximidade entre exemplos; as investigações e propostas no sentido de aprimorar a utilização e funcionamento de algoritmos de OBP e a proposta de uma abordagem de MT para a análise de clusters em dados biomédicos.

- Capítulo 5: são descritos os experimentos realizados para analisar e avaliar as propostas e conceitos apresentados no Capítulo 4.

- Capítulo 6: exibe as conclusões deste trabalho, resumindo os principais resultados obtidos e os próximos passos para a continuidade da pesquisa. 


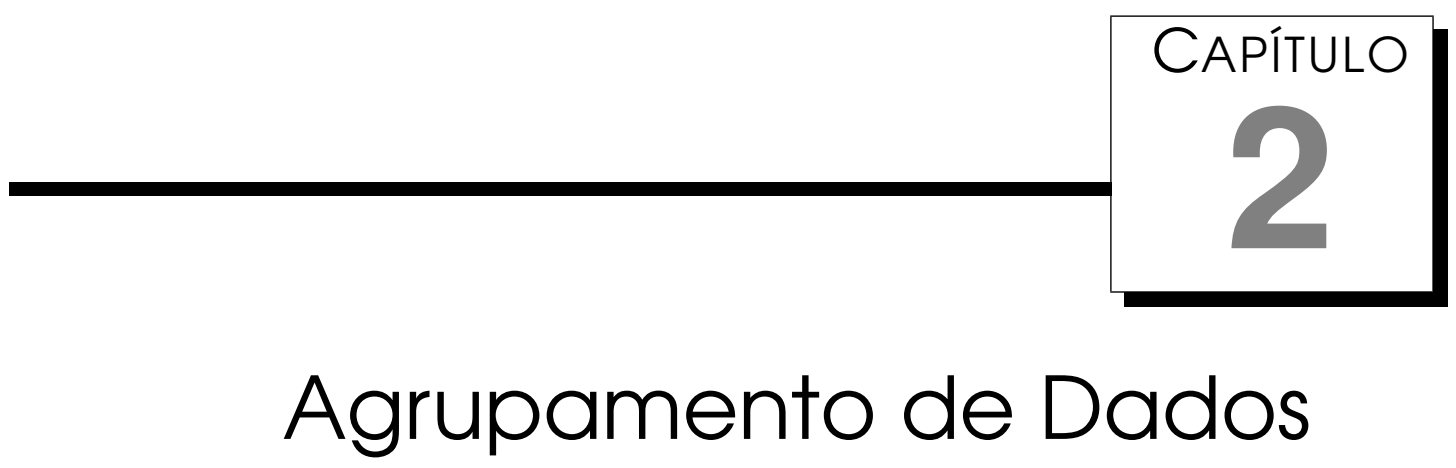

\subsection{Considerações Iniciais}

Neste capítulo, são apresentados os principais conceitos necessários para a compreensão das técnicas de agrupamento de dados (AD) não-supervisionado e semi-supervisionado utilizados nesta Tese. Também são fornecidos alguns exemplos de aplicação dessas técnicas em dados de biologia molecular, que é o domínio de interesse deste trabalho. Apesar de dados dessa natureza não terem sido considerados nas investigações na área de $\mathrm{AD}$ neste trabalho, é importante apresentar uma visão geral deste tipo de aplicação, pois, além de estar entre os trabalhos futuros, as investigações realizadas na área de Mineração de Textos (MT) empregaram agrupamentos de genes propostos por outros autores (Spellman et al., 1998; Eisen et al., 1998). Na Seção 2.2, é introduzida a forma de $\mathrm{AD}$ puramente não-supervisionada e a Seção 2.3 é dedicada a $\mathrm{AD}$ semi-supervisionado. A Seção 2.4 apresenta alguns dos principais critérios de avaliação de resultados de agrupamento. Na Seção 2.5, são fornecidos alguns exemplos de aplicação em dados de biologia molecular e são apresentados alguns importantes trabalhos aplicando técnicas de agrupamento nesses dados.

\subsection{Agrupamento não-supervisionado}

Agrupamento de dados (Duda et al., 2001) envolve a tarefa de agrupar exemplos de dados com base na similaridade entre eles. Algoritmos de agrupamento são utilizados para descobrir padrões nos dados, formando 
grupos, também chamados de clusters. Os clusters encontrados para um conjunto de dados definem uma partição dos dados. No contexto de Aprendizado de Máquina (AM), técnicas de agrupamento são classificadas como aprendizado não-supervisionado, uma vez que não há conhecimento sobre as classes dos dados, apenas sobre seus atributos de entrada, ao contrário do aprendizado supervisionado, quando os dados são previamente rotulados com classes pré-definidas.

Existem diversas técnicas de agrupamento amplamente utilizadas pela comunidade científica. Elas podem ser divididas de acordo com vários critérios. Uma deles divide em duas abordagens: os algoritmos hierárquicos (Duda et al., 2001) e os algoritmos particionais (Jain et al., 1999), sendo os últimos de maior interesse para este trabalho. A seguir, será apresentada uma breve introdução sobre essas abordagens.

As técnicas hierárquicas (Eisen et al., 1998) são divididas em duas abordagens: a aglomerativa, que começa com $N$ clusters, sendo $N$ o número de exemplos na base de dados, ou seja, cada cluster contém um único exemplo, e agrupa os clusters iniciais sucessivamente; e a divisiva, que começa com um único cluster contendo todos os exemplos e forma novos clusters dividindo clusters sucessivamente (Duda et al., 2001). O resultado é uma estrutura em forma de árvore, como ilustrado na Figura 2.1, com o caso hipotético em que os exemplos representam genes. Essas estruturas facilitam a visualização e entendimento da similaridade dos dados, além de fornecerem informação útil sobre o relacionamento entre clusters (Slonim, 2002).

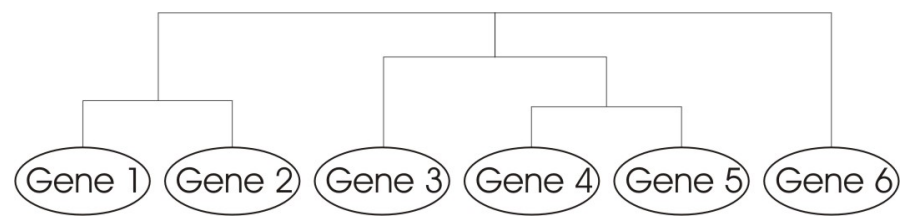

Figura 2.1: Agrupamento hierárquico de genes.

As abordagens hierárquicas definem uma hierarquia de semelhança entre exemplos e grupos de exemplos em vários níveis. Para a obtenção de uma partição é necessária a definição do ponto de corte ideal na hierarquia. Esta é a principal diferença entre as abordagens hierárquicas e as abordagens particionais, que geram no final uma partição dos dados.

Entre os métodos particionais, podem ser citados as Redes Neurais Artificiais (RNAs) auto-organizáveis (self-organizing), que possuem como principais representantes as redes SOM (do inglês Self-Organizing Maps) (Haykin, 1998) e as redes ART (do inglês Adaptive Resonance Theory). As redes SOM fornecem informação valiosa sobre as relações entre clusters. Elas são formadas por mapas de neurônios que possuem os mesmos atributos dos exemplos de entrada. Durante seu treinamento, para cada exemplo, é 
eleito o neurônio mais similar a ele. Esse neurônio e seus neurônios vizinhos terão seus valores ajustados. Ao final, os nós do mapa topologicamente próximos entre si respondem de forma parecida a padrões de entrada semelhantes (Braga et al., 2007). A família de redes ART é capaz de aprender continuamente, sem perder o conhecimento previamente adquirido, ou seja, seu treinamento pode ser ativado a qualquer momento. Para o seu treinamento, deve ser informado um parâmetro de vigilância que controla o nível de semelhança necessário para exemplos pertencentes ao mesmo cluster. A primeiro rede da família ART foi a rede ART 1, que trabalha apenas com dados binários. A partir dela, outras redes surgiram, como o ART 2, que aceita valores contínuos como entrada, a rede ARTMAP, que leva em consideração informações sobre neurotransmissores, a rede Fuzzy ARTMAP, que incorpora lógica fuzzy, além de outras (Braga et al., 2007).

Entre os algoritmos de agrupamento particionais, estão os algoritmos que utilizam o conceito de protótipos de clusters, que são pontos no espaço dimensional dos dados que representam o centro de cada um dos clusters. Os protótipos podem ser representados de duas maneiras: (i) centróides, os protótipos podem assumir qualquer posição no espaço e, (ii) medóides, os protótipos são, necessariamente, exemplos do conjunto de dados.

O algoritmo k-médias (MacQueen, 1967), amplamente utilizado pela comunidade científica, emprega o conceito de centróides. Esse algoritmo necessita que um número $C$ de clusters seja pré-definido. Com isso, são escolhidos $C$ pontos aleatoriamente, que serão os centróides iniciais. $O$ algoritmo particiona os exemplos em $C$ clusters de acordo com sua distância em relação aos centróides. Em seguida, cada centróide é re-calculado como a média dos exemplos associados a ele. O processo é repetido até que os centróides não mudem mais ou até que um determinado número máximo de iterações seja atingido. A métrica de distância normalmente utilizada é a euclidiana quadrática, definida por:

$$
d_{i k}^{2}=\left\|x_{k}-v_{i}\right\|^{2}=\left(x_{k}-v_{i}\right)^{T}\left(x_{k}-v_{i}\right)
$$

onde $x_{k}$ são os exemplos do conjunto de dados e $v_{i}$ são os centróides dos clusters.

A família de algoritmos particionais também inclui algoritmos de $\mathrm{AD}$ fuzzy de dados, onde é permitido que um exemplo seja alocado a vários clusters simultaneamente, com um grau de pertinência associado a cada cluster. $\mathrm{O}$ principal algoritmo dessa categoria é o FCM (do inglês Fuzzy C-Means (Bezdek, 1981)), que funciona de forma similar ao $k$-médias e procura minimizar a seguinte função objetivo: 


$$
F=\sum_{i=1}^{C} \sum_{k=1}^{N} u_{i k}^{m} d_{i k}^{2}
$$

onde $U=\left[u_{i k}\right]$ é a matriz de particionamento que armazena o grau de pertinência dos exemplos $x_{k}$ em relação aos clusters $i$ e $m$ é o grau de fuzzificação de $U$, geralmente igual a 2. A matriz $U$ deve satisfazer a seguinte condição:

$$
\sum_{i=1}^{C} u_{i k}=1
$$

Nesse algoritmo, a matriz $U$ é calculada de acordo com:

$$
u_{i k}=\frac{1}{\sum_{j=1}^{C} \frac{d_{i k}^{2}}{d_{j k}^{2}}}
$$

e os centróides são atualizados de acordo com:

$$
v_{i}=\frac{\sum_{k=1}^{N} u_{i k}^{m} x_{k}}{\sum_{k=1}^{N} u_{i k}^{m}}
$$

Uma variação do algoritmo FCM a ser destacada é o algoritmo Gustafson-Kessel FCM (Gustafson e Kessel, 1978; Krishnapuram e Kim, 1999). Ele é uma extensão do algoritmo FCM que permite que a matriz $u_{i k}$ seja ajustada ao formato dos clusters, ou seja, o algoritmo também estima uma matriz $A_{i}$ utilizada para o cálculo da distância para cada cluster $i$. Dessa forma, o algoritmo minimiza a seguinte função objetivo:

$$
G K=\sum_{i=1}^{C} \sum_{k=1}^{N} u_{i k}^{m}\left\|x_{k}-v_{i}\right\|_{A_{i}}^{2}
$$

Neste caso, a distância entre exemplos e protótipos é calculada da seguinte forma:

$$
\left\|x_{k}-v_{i}\right\|_{A_{i}}^{2}=\left(x_{k}-v_{i}\right)^{T} A_{i}\left(x_{k}-v_{i}\right)
$$

O algoritmo FCM é mais indicado em casos onde os clusters possuem forma esférica, enquanto o Gustafson-Kessel também é capaz de encontrar clusters que possuem forma elipsoidal, porém com maior custo computacional. 


\subsection{Agrupamento semi-supervisionado}

Em agrupamento de dados, há situações em que existe algum conhecimento prévio sobre os dados, mas não suficiente para fornecer rótulos para todos os exemplos, ou o processo de rotular o conjunto inteiro de dados é muito custoso. Nesses casos, o conhecimento disponível pode ser utilizado na forma de dicas para guiar a tarefa de agrupamento com o objetivo de melhorar os resultados. Diversos algoritmos de agrupamento com essa finalidade foram propostos, mostrando que é possível obter melhores resultados empregando conhecimento prévio (Basu et al., 2002; Sanches, 2003; Zeng et al., 2003; Wagstaff et al., 2001; Klein et al., 2002; Demiriz et al., 1999; Bouchachia e Pedrycz, 2006a; Pedrycz et al., 2004; Xing et al., 2003). Esses algoritmos são conhecidos como algoritmos semi-supervisionados.

O objetivo de algoritmos de agrupamento semi-supervisionado é a utilização de conhecimento prévio já disponível sobre os dados no processo de agrupamento (Bruce, 2001). Acredita-se que esse conhecimento possa oferecer "pistas" para a definição dos grupos (Zeng et al., 2003). Em termos de implementação, algoritmos semi-supervisionados podem empregar o conhecimento prévio na forma de exemplos de dados rotulados, presentes entre os dados não rotulados, ou na forma de restrições, de acordo com as quais dois exemplos de dados são ou não considerados como de uma mesma classe ou cluster. Na sequência, serão apresentados algoritmos que seguem essa abordagem de aprendizado.

Em Xing et al. (2003), é apresentado um algoritmo que, dados pares de exemplos com alguma relação (similar, não-similar), otimiza a métrica de distância para os dados. Para isso, é definida uma função objetivo da forma:

$$
X I=\sum_{\left(x_{k}, x_{l}\right) \in P}\left\|x_{k}-x_{l}\right\|_{A}
$$

onde $A$ é a matriz utilizada para o cálculo da distância e $P$ é o conjunto de pares de exemplos considerados não-similares. A função $X I$ é maximizada com respeito à matriz $A$. Assim, o algoritmo busca a matriz $A$ que maximiza a distância entre os exemplos não considerados similares pelas dicas fornecidas.

Pedrycz e Waletzky (1997) propuseram uma modificação do algoritmo FCM (Bezdek, 1981) para incluir dados rotulados. A modificação proposta adiciona, à função objetivo, um termo adicional que mede a relação entre as classes (rótulos disponiveis) e os clusters sendo definidos (Bouchachia e Pedrycz, 2006a).

O algoritmo SEEDED- $k$-médias (Basu et al., 2002) calcula os centróides iniciais do algoritmo $k$-médias como a média dos dados rotulados para 


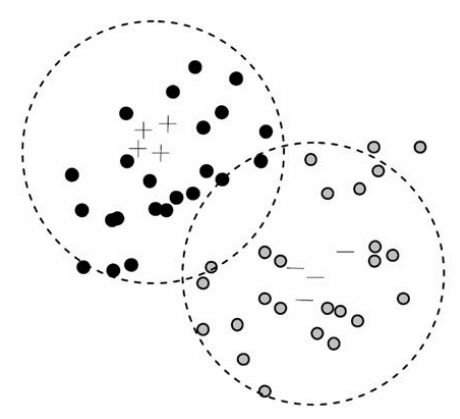

Figura 2.2: Ilustração da abordagem SEEDED-k-médias, onde os símbolos “+” e “-” representam exemplos rotulados de cada uma das duas classes.

cada classe. Posteriormente o algoritmo $k$-médias tradicional é executado normalmente a partir desses centróides iniciais. Uma ilustração desse algoritmo pode ser vista na Figura 2.2 e a sequência de passos é apresentada no algoritmo 1.

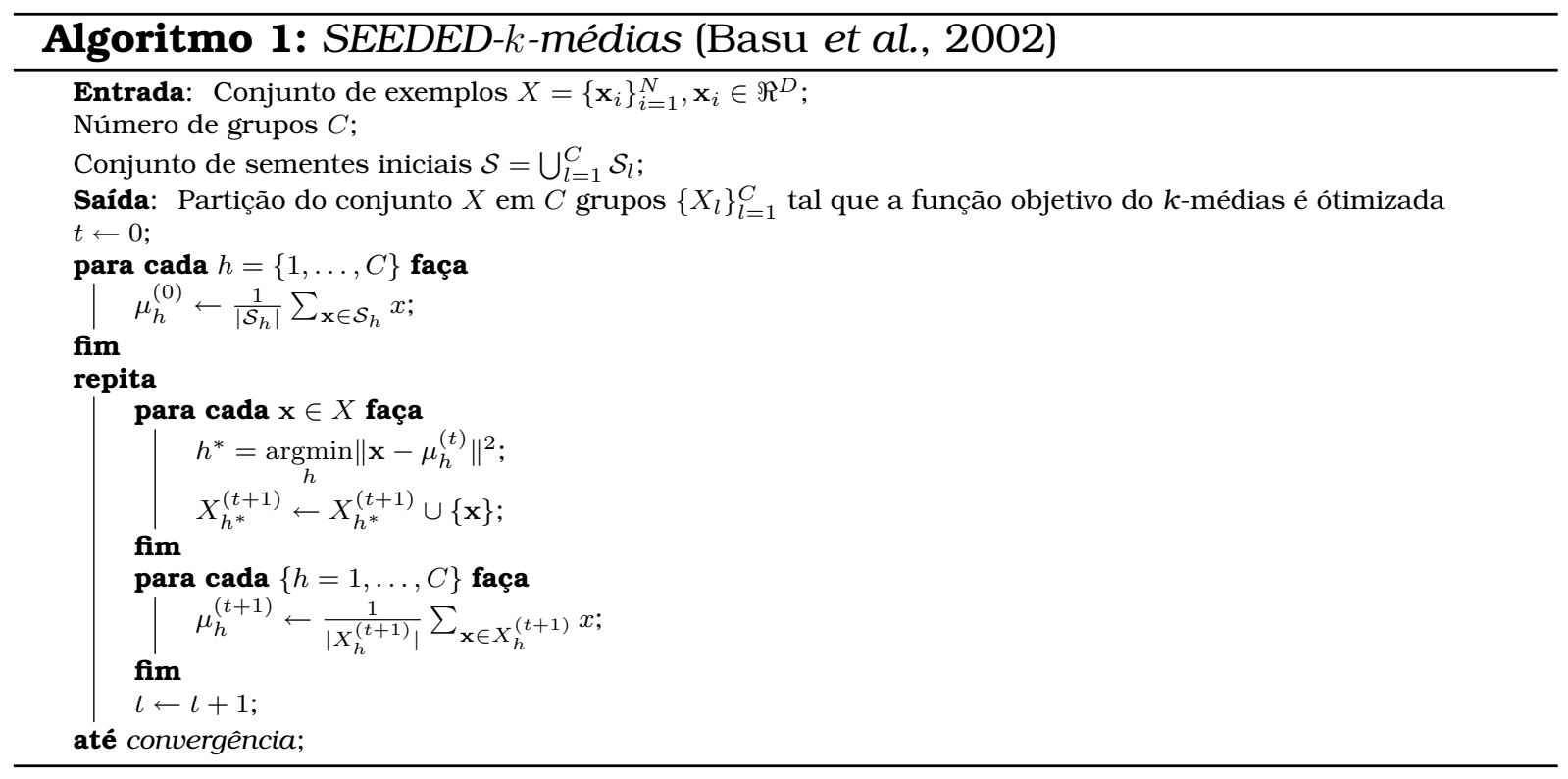

O algoritmo $k$-means $_{k i}$ proposto por Sanches (2003) é semelhante ao SEEDED- $k$-médias. Porém, na etapa em que os exemplos são atribuídos aos clusters, um determinado limiar de distância entre o exemplo e o centróide deve ser respeitado.

Os autores do SEEDED- $k$-médias também propuseram uma variação desse algoritmo, chamada de CONSTRAINED- $k$-médias (Basu et al., 2002), que possui a restrição de não permitir que exemplos rotulados sejam atribuídos a clusters associados a rótulos diferentes ao longo da execução do algoritmo $k$-médias. O CONSTRAINED- $k$-médias está descrito no Algoritmo 2.

Zeng et al. (2003) utilizou a abordagem SEEDED- $k$-médias para o treinamento de classificadores de textos. Ao final do agrupamento, os dados não-rotulados recebem o rótulo dos exemplos rotulados pertencentes ao mesmo cluster. São eleitos os exemplos mais confiáveis, ou seja, 


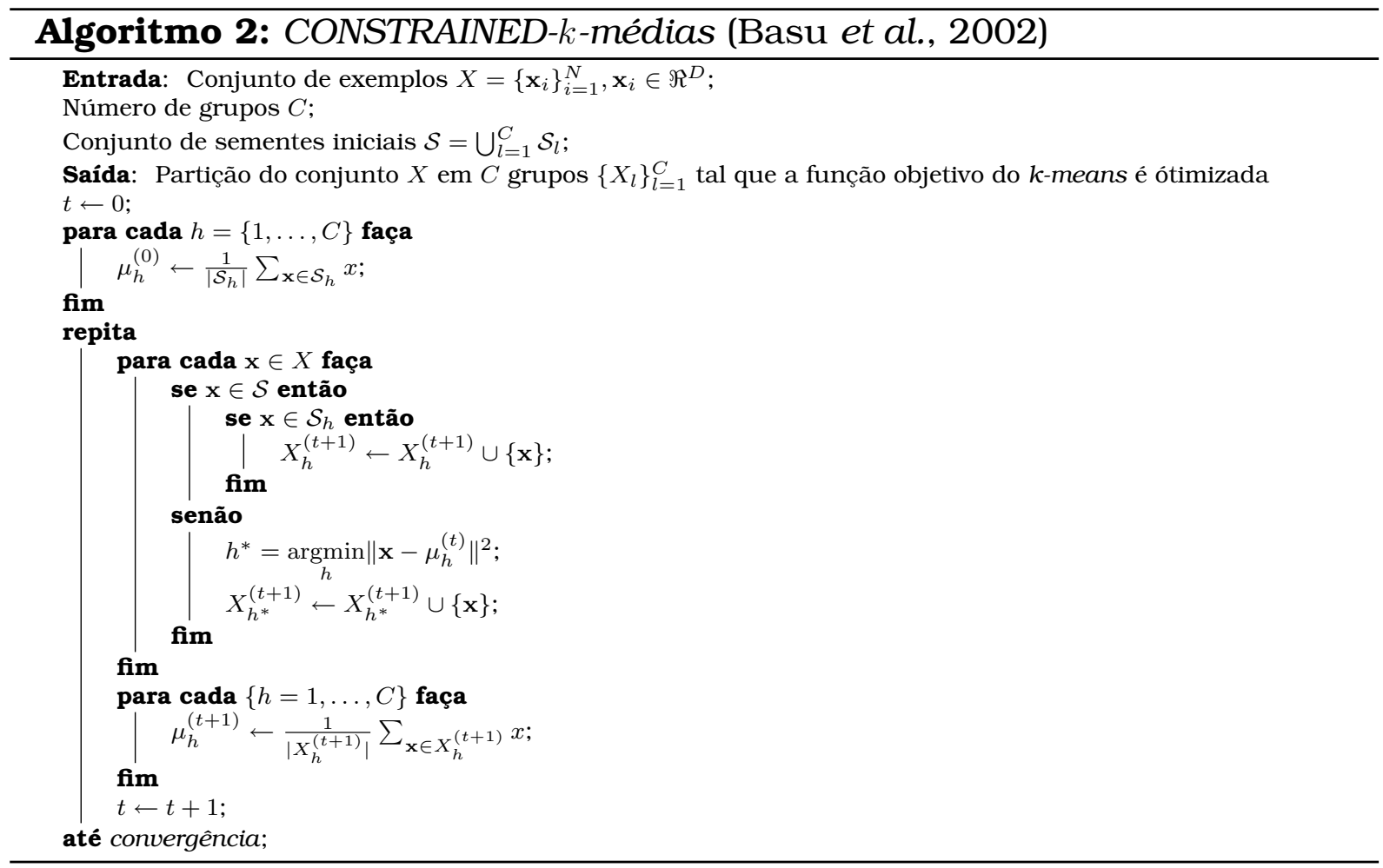

topologicamente próximos aos centróides, para formar um novo conjunto de exemplos rotulados. Esse conjunto é, então, utilizado para o treinamento de classificadores.

O algoritmo COP- $k$-médias (Wagstaff et al., 2001), uma variação do algoritmo de $k$-médias, utiliza o conjunto de dados rotulados para extrair restrições do tipo must-link (especifica quando exemplos devem pertencer ao mesmo cluster) e cannot-link (especifica quando exemplos não devem pertencer ao mesmo cluster). O algoritmo atribui os exemplos aos clusters da mesma maneira que o $k$-médias, porém verificando se as restrições estão sendo violadas.

Klein et al. (2002) propôs a indução de uma interpretação espacial das restrições extraídas dos dados rotulados e, consequentemente, "propagar" as restrições. Por exemplo, se uma restrição must-link está associada a dois exemplos, pode-se assumir que exemplos próximos a eles também devem pertencer ao mesmo cluster.

Na Figura 2.3, são mostrados dois exemplos de agrupamento utilizando restrições do tipo must-link (linhas pontilhadas). No primeiro (Figura 2.3 (b)), apenas as restrições impostas são respeitadas, no segundo (Figura 2.3 (c)), as restrições são generalizadas do âmbito do conjunto de exemplos para o âmbito do espaço de atributos, ou seja, não somente exemplos ligados por restrições must-link devem pertencer ao mesmo cluster, mas também exemplos topologicamente próximos a eles.

Demiriz et al. (1999) aplicaram algoritmos genéticos para otimizar a função 


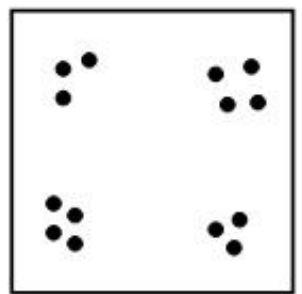

(a)

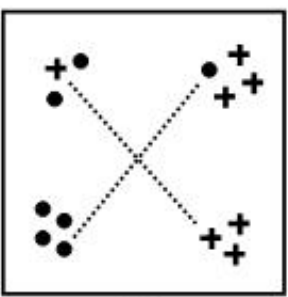

(b)

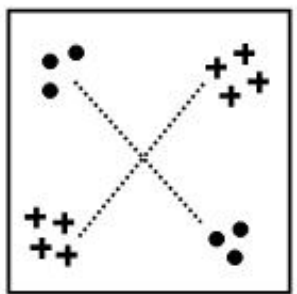

(c)

Figura 2.3: Agrupamentos utilizando restrições e generalizações espaciais das restrições (Figura adaptada de (Klein et al., 2002)).

objetivo na forma representada pela Equação (2.9), que guia o agrupamento dos exemplos do conjunto de dados:

$$
D E M=\eta * D i s p e r s a o \_d o s \_g r u p o s+\zeta * I m p u r e z a \_d o s \_g r u p o s
$$

onde o primeiro termo leva em consideração os dados rotulados e não-rotulados e o segundo se baseia nos dados rotulados. A função objetivo empregada é composta por dois termos que medem a dispersão entre os clusters e a impureza de cada cluster. A dispersão entre os clusters corresponde à parte não-supervisionada da função, enquanto a pureza dos clusters é medida com base nos rótulos disponíveis. A minimização de $D E M$ é realizada para os centróides dos clusters.

O algoritmo sNet-SOM (Mavroudi et al., 2002; Papadimitriou et al., 2001) modifica o algoritmo de treinamento da rede SOM introduzida na Seção 2.2. Nesse novo algoritmo, o aprendizado não-supervisionado atua em regiões "simples" enquanto utiliza aprendizado supervisionado para resolver as regiões "difíceis". A rede SOM é treinada normalmente. Ao final do treinamento, são detectadas as regiões ambíguas, que são regiões onde diferentes classes se sobrepõem ou se situam muito próximas entre si, ou seja, exemplos de diferentes classes são colocados muito próximos entre si nessas regiões. Em seguida, um algoritmo de aprendizado supervisionado é treinado para realizar a tarefa de classificação apenas para essas regiões.

Em Bouchachia e Pedrycz (2003), uma versão modificada do algoritmo FCM (Bezdek, 1981) foi proposta para acomodar o conhecimento prévio sobre os dados no processo de agrupamento. Ela busca otimizar uma função objetivo que contém um segundo termo, que relaciona clusters com classes:

$$
J=\sum_{i=1}^{C} \sum_{k=1}^{N} u_{i k}^{m} d_{i k}^{2}+\alpha \sum_{i=1}^{C} \sum_{k=1}^{N}\left(u_{i k}-\tilde{u}_{i k}\right)^{m} d_{i k}^{2}
$$

onde $U=\left[u_{i k}\right]$ é a matriz de particionamento, como explicado na Seção 2.2. A matriz $\tilde{U}$ representa os rótulos disponíveis de forma que cada classe possa ser particionada em mais de um cluster. Ela é obtida a partir da matriz $F=\left[f_{h k}\right]$, 
em que $f_{h k}$ é o grau de pertinência do exemplo $k$ em relação à classe $h$ e do conjunto $\pi_{h}$ de clusters pertencentes à classe $h$. O grau de pertinência é determinado utilizando o número de exemplos de cada classe em cada cluster de acordo com os rótulos disponíveis.

A função $J$ é minimizada quanto à matriz $U$ e aos centróides, utilizando o método do gradiente descendente. Para isso, a função objetivo é derivada quanto a $U, V$ e $\tilde{U}$, resultando nas Equações 2.11, 2.12 e 2.13, respectivamente. Esse procedimento está explicado no Algoritmo 3.

$$
\begin{gathered}
u_{s t}=\frac{\alpha \tilde{u}_{s t}}{(1+\alpha)}+\frac{1-\frac{\alpha}{(1+\alpha)} \sum_{i=1}^{C} \tilde{u}_{i t}}{\sum_{i=1}^{C} \frac{\left\|x_{t}-v_{s}\right\|^{2}}{\left\|x_{t}-v_{i}\right\|^{2}}} \\
v_{s}=\frac{\sum_{k=1}^{N}\left(u_{s k}^{2}+\alpha\left(u_{s k}-\tilde{u}_{s k}\right)^{2}\right) x_{k}}{\sum_{k=1}^{N}\left(u_{s k}^{2}+\alpha\left(u_{s k}-\tilde{u}_{s k}\right)^{2}\right)} \\
\tilde{u}_{s t}^{(i t)}=\tilde{u}_{s t}^{(i t-1)}+2 \beta \sum_{i=1}^{p}\left(f_{i t}-\sum_{j \in \pi_{i}} \tilde{u}_{j t}^{(i t-1)}\right) * \begin{cases}1 & \text { se } s \in \pi_{i} \\
0 & \text { caso contrário }\end{cases}
\end{gathered}
$$

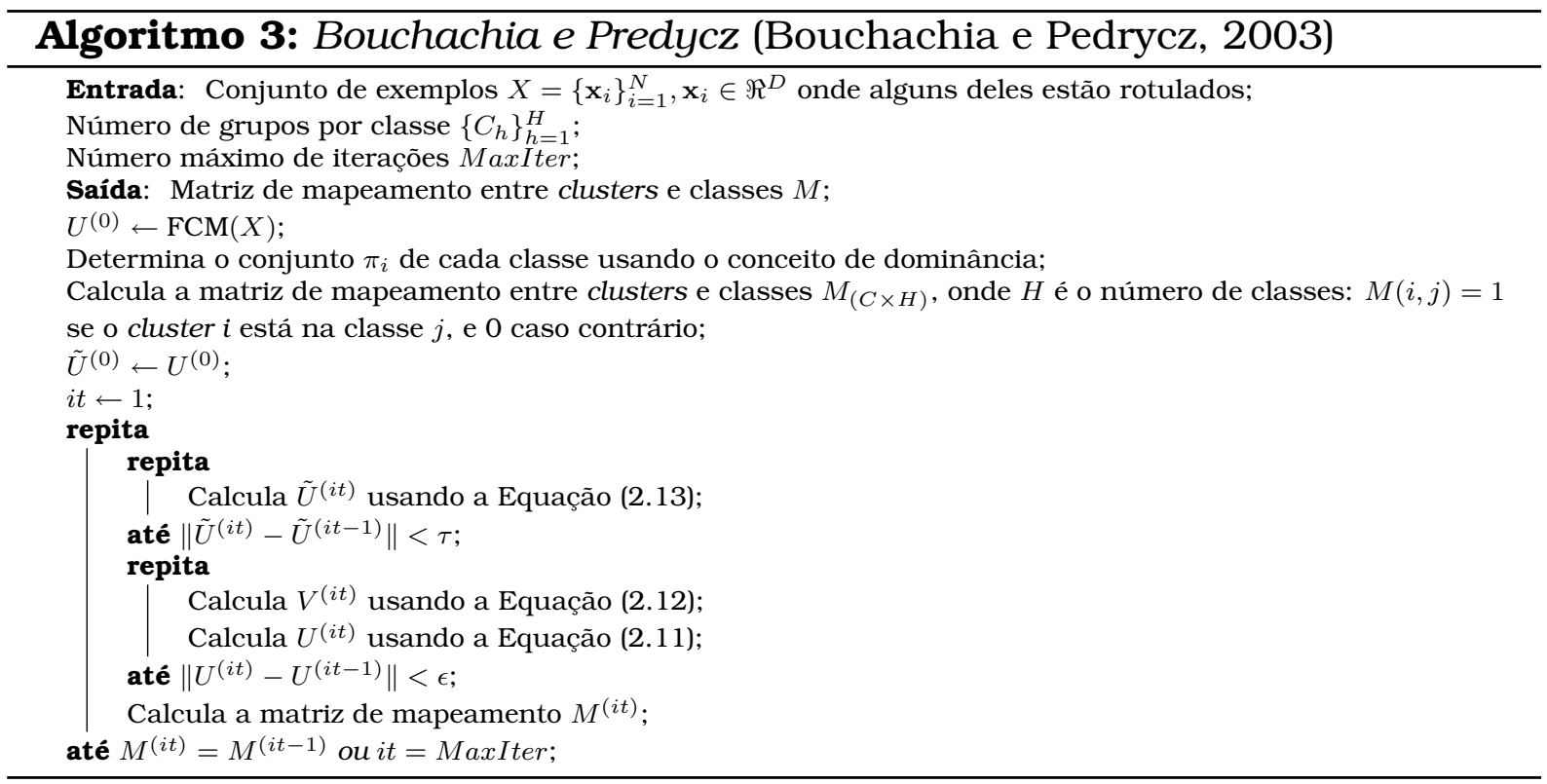

Outro algoritmo de agrupamento semi-supervisionado particularmente interessante é proposto em Pedrycz et al. (2004). Nesse algoritmo, o conhecimento prévio é fornecido na forma de níveis de proximidade entre exemplos de dados. O algoritmo funciona em dois níveis, um externo e um interno. O nível externo utiliza o algoritmo FCM para produzir o primeiro particionamento $U$. O nível interno acomoda dicas de proximidade por meio da otimização da seguinte função objetivo: 


$$
V=\sum_{k_{1}=1}^{N} \sum_{k_{2}=1}^{N}\left(\hat{p}_{k_{1} k_{2}}-p_{k_{1} k_{2}}\right)^{2} B_{k_{1} k_{2}} d_{k_{1} k_{2}}
$$

onde $B_{k_{1}, k_{2}}$ especifica se o grau de proximidade entre os exemplos $k_{1}$ e $k_{2}$ é conhecido, e $p_{k_{1}, k_{2}}$ é o grau de proximidade. A notação $\hat{p}_{k_{1}, k_{2}}$ descreve o grau de proximidade entre $k_{1}$ e $k_{2}$ induzido a partir da matriz de particionamento $U$, na forma:

$$
\hat{p}_{k_{1} k_{2}}=\sum_{i=1}^{C} \min \left(u_{i k_{1}}, u_{i k_{2}}\right)
$$

Existem também algoritmos baseados em grafos, que representam todos os exemplos (rotulados e não-rotulados) como nós de um grafo. As arestas são ponderadas de acordo com a similaridade entre os exemplos. Regras baseadas em heurísticas são utilizadas para propagar os rótulos disponíveis para os exemplos vizinhos (Bouchachia e Pedrycz, 2006a; Zhu et al., 2005; Blum et al., 2004).

\subsection{Medidas de validação}

Diversos índices de validação têm sido criados para avaliar a qualidade de uma partição resultante da aplicação de um algoritmo de agrupamento a uma base de dados. Entre os principais índices encontrados na literatura científica, podem ser citados:

- Davies-Bouldin (Davies e Bouldin, 1979): definida pela equação:

$$
D B=\frac{1}{C} \sum_{i=1}^{C} \max _{l \neq i}\left\{\frac{\sigma_{i}+\sigma_{l}}{\left\|v_{i}-v_{l}\right\|}\right\}
$$

onde $\sigma_{i}$ é a distância média entre os exemplos do cluster $i$ e o protótipo $v_{i}$. O melhor agrupamento é dado pelo menor valor do índice DB.

- Xie-Beni (Xie e Beni, 1991): calculado de acordo com:

$$
X B=\frac{\sum_{i=1}^{C} \sum_{k=1}^{N} u_{i k}^{2}\left\|v_{i}-x_{k}\right\|^{2}}{N\left(\min _{i \neq j}\left\|v_{i}-v_{j}\right\|^{2}\right)}
$$

onde quanto menor o valor de XB, melhor é o agrupamento resultante.

- VRC (Calinski e J., 1974): calculado de acordo com:

$$
V R C=\frac{B(C) /(C-1)}{W(C) /(N-C)}
$$


onde $B(C)$ e $W(C)$ são, respectivamente, as somas dos quadrados das distâncias dos exemplos ao centróide da base de dados e aos centróides dos respectivos clusters. Este índice não está definido para $C=1 \mathrm{e} o$ melhor agrupamento é aquele que minimiza o valor $V R C$.

- Silhueta (Rousseeuw, 1987): definida por:

$$
S I L H=\frac{1}{N} \sum_{j=1}^{N} \frac{c_{j}-a_{j}}{\max \left(a_{j}, c_{j}\right)}
$$

onde $a_{j}$ é a distância média do objeto $j$ a todos os outros pertencentes ao mesmo cluster, $c_{j}$ representa o mínimo $m_{i j}$ para $j=\{1, \ldots, C\}, j \neq i$, onde $m_{i j}$ é a distância média do objeto $j$ a todos os objetos pertencentes ao cluster $i$.

- Reconstrução da base de dados (Pedrycz e Oliveira, 2008): avalia a diferença entre a base de dados original, $X$, e a base recriada, $\tilde{X}$, a partir da matriz de pertinência $U=\left[u_{i j}\right]$ e dos protótipos $v_{i}$, de acordo com:

$$
\tilde{X}=\frac{\sum_{i=1}^{C} u_{i}^{2} v_{i}}{\sum_{i=1}^{C} u_{i}^{2}}
$$

Existem diversos outros índices de validação de agrupamentos, uma revisão abrangente sobre o assunto pode ser encontrada em Faceli et al. (2005).

\subsection{Aplicação em dados de biologia molecular}

Agrupamento de dados pode ser aplicado tanto para organizar e melhorar a visualização de um conjunto de dados, quanto para rotular novos exemplos de dados (Slonim, 2002). Há uma grande quantidade de trabalhos aplicando algoritmos de agrupamento a conjuntos de dados de expressão gênica. Um importante exemplo de aplicação para esses dados é a definição de novas subclasses de doenças. Pacientes sofrendo de uma mesma doença podem apresentar padrões de recuperação diferentes. Isso pode ocorrer porque doenças aparentemente similares são, na verdade, completamente diferentes no nível molecular. Essas subclasses podem ser detectadas por meio de agrupamento de dados de expressão gênica, coletados sob essas diversas circunstâncias de recuperação, como foi feito por Alizadeh et al. (2000) em relação a um tipo de tumor.

Outro exemplo é a utilização de agrupamentos de dados de expressão gênica para a obtenção de pistas sobre funções desconhecidas de genes. Essa 
abordagem foi investigada por Eisen et al. (1998), onde foi implementado um sistema para agrupar genes hierarquicamente. Esse sistema foi aplicado aos genes da levedura Saccharomyces cerevisiae. Os autores concluíram que os grupos resultantes contêm genes com funções similares. Em casos como esse, a partição resultante pode ser utilizada posteriormente para a descoberta de funções de genes desconhecidos. Spellman et al. (1998) aplicaram o algoritmo de Eisen et al. (1998) a um conjunto de dados diferente, também de expressão dos genes da levedura Saccaromyces cerevisiae. Os autores constataram que os genes agrupados atuam nas mesmas etapas do ciclo de vida da célula desse organismo.

Atualmente, encontra-se disponível uma vasta quantidade de conhecimento biológico valioso que pode ser explorado por algoritmos de agrupamento semi-supervisionado. Um exemplo de uma exploração interessante é o trabalho realizado por Mavroudi et al. (2002), no qual foi aplicado o algoritmo sNet-SOM, apresentado na Seção 2.3, a dados de expressão dos genes da levedura Saccharomyces cerevisiae disponíveis publicamente. Os exemplos foram rotulados de acordo com a base de dados CYGD (Comprehensive Yeast Genome Database) presente no MIPS (Munich Information center for Protein Sequences) resultando em 19 classes funcionais referentes, por exemplo, aos ciclos de vida da célula. Os autores obtiveram uma performance de classificação promissora e um pequeno número de nós no mapa auto-organizável. Também foi observado que a curva de ganho com adição de dados rotulados se estabiliza, sugerindo que o algoritmo apresenta bom desempenho com limitada quantidade de dados rotulados, sem melhora aparente quando novos dados são introduzidos. O mesmo algoritmo também foi aplicado para detecção de risco de isquemia do miocárdio (Papadimitriou et al., 2001) com base em dados de exames com eletrocardiograma.

O problema das subclasses de doenças introduzido na Seção 2.2 foi o alvo do trabalho de Bair e Tibshirani (2004). A justificativa para aplicar supervisão parcial a esse problema é utilizar informação clínica disponível sobre os pacientes sem perder a característica exploratória dos algoritmos de agrupamento. Em outras palavras, o objetivo foi utilizar dados de expressão gênica rotulados com as informações clínicas dos pacientes, porém, sem fixá-las como as classes do problema. Bair e Tibshirani (2004) utilizaram a informação clínica disponível dos pacientes com câncer para identificar o conjunto de genes relacionado com a variação clínica de interesse. Para cada gene, foi calculada sua correlação com os dados sobre a recuperação dos pacientes. Apenas genes com correlação resultante acima de um certo valor foram considerados. Um algoritmo de agrupamento é então aplicado a esses genes para descoberta das subclasses do câncer. O agrupamento resultante 
pode ser utilizado para diagnosticar futuros pacientes. Os autores desse trabalho defendem que abordagens puramente supervisionadas, por tornarem fixas as classes, desconsideram a possibilidade de que existam novas subclasses. Em contrapartida, técnicas que utilizam apenas agrupamento correm o risco de identificar grupos que não estão relacionados com o prognóstico do paciente.

\subsection{Considerações Finais}

Neste capítulo, foram apresentados alguns conceitos e exemplos de algoritmos de agrupamento, incluindo agrupamento semi-supervisionado, que associam dados rotulados e não rotulados. Esta abordagem de agrupamento é interessante por fazer uso de conhecimento prévio sobre os dados sem perder benefícios do agrupamento puro: análise exploratória dos dados e descoberta de estruturas implícitas. Foram apresentadas algumas técnicas e abordagens publicadas na literatura científica.

A obtenção de bons resultados com a aplicação de agrupamento semi-supervisionado é muito dependente da especificação do problema. O conhecimento prévio disponível e a maneira como ele será utilizado para auxiliar o processo de agrupamento são pontos cruciais para o desempenho do algoritmo. A disponibilidade de dados rotulados é muito útil, pois esse tipo de dado pode, além de ser aplicado diretamente por algumas técnicas semi-supervisionadas, ser convertido para outras formas de dados, como métricas de similaridade entre exemplos de um conjunto de dados. 


\section{- 3 \\ Mineração de textos biomédicos}

\subsection{Considerações iniciais}

Durante a última década, houve um grande aumento da disponibilização de dados provenientes de experimentos de biologia molecular. Em paralelo, houve o crescimento do número de publicações discutindo esses resultados. Com isso, tem havido um grande interesse por parte da comunidade científica em ferramentas capazes de varrer essa literatura em busca de padrões de informação relevantes, para adicionar valor aos resultados de seus experimentos.

A extração automática de informações de textos é possível por meio da utilização de técnicas de Mineração de Dados (MD) específicas para textos, chamadas técnicas de Mineração de Textos (MT) (Hearst, 1999; Rajman e Besancon, 1997). MD, uma das etapas do processo de Descoberta de Conhecimento em Bases de Dados (KDD - Knowledge Discovery in Databases), tem por objetivo a descoberta de conhecimentos novos e úteis em um conjunto de dados (Fayyad, 1996; Fayyad et al., 1996). Porém, as técnicas tradicionais de MD se baseiam na estrutura de dados com campos pré-definidos. Por trabalhar com textos, formas não estruturadas de dados, MT exige algoritmos mais complexos e sofisticados. Em compensação, não há limite para os tipos de informação que podem ser armazenados em forma de textos e a MT pode descobrir padrões que dificilmente seriam identificados em outras fontes de dados.

Na próxima seção, são apresentados conceitos e técnicas básicas sobre MT. A Seção 3.3 contém a descrição de alguns importantes trabalhos, 
que exemplificam a aplicação de técnicas de MT em biologia molecular. $\mathrm{Na}$ Seção 3.4, são apresentadas algumas ferramentas disponiveis para a comunidade científica que podem ser de grande utilidade no desenvolvimento de trabalhos com MT.

\subsection{Mineração de textos}

Um processo de MT é normalmente constituído de 4 etapas (Matsubara et al., 2003):

1. coleta de documentos;

2. pré-processamento;

3. extração de informação;

4. avaliação e interpretação dos resultados.

Na primeira etapa, deve ser selecionado um conjunto de textos que atendam a uma determinada finalidade. O pré-processamento converte os textos coletados para formas estruturadas de dados, às quais as técnicas de extração de conhecimento podem ser aplicadas. Técnicas de extração de conhecimento são, em sua maioria, projetadas tendo em vista uma aplicação específica.

A MT pode aplicar métodos de duas áreas específicas: Recuperação de informação (RI) e Processamento de Língua Natural (PLN). RI abrange as etapas de coleta e pré-processamento. É uma área que inclui técnicas de seleção de textos que vão desde simples análises estatísticas de presença de palavras à classificação inteligente de textos. Abordagens mais complexas de RI necessitam que seja realizado um pré-processamento aos textos para que possam aplicar suas medidas de seleção. PLN está relacionada com todos os três primeiros estágios de MT. Uma de suas principais características é a modelagem de textos considerando a função de cada palavra na frase em que aparece.

Nas próximas seções serão apresentadas algumas técnicas e conceitos dessas áreas.

\subsubsection{Recuperação de informação}

A RI tem como objetivo identificar, em um grande conjunto de textos, aqueles que são relevantes para as necessidades do usuário (Shatkay e Feldman, 2003). As técnicas de RI podem ser classificadas, basicamente de duas maneiras: 
- De acordo com a forma de consulta: baseada em documento (document-based) ou baseada em consulta (query-based) (Yandell e Majoros, 2002);

- De acordo com a forma de análise: estatística ou semântica (Greengrass, 2000).

RI baseada em consulta basicamente faz uma busca por documentos que atendam a um conjunto de condições fornecido pelo usuário. RI baseada em documento baseia-se na comparação entre documentos. Por exemplo, o usuário pode desejar obter documentos semelhantes a um dado documento. RI estatística é mais comum e baseia-se na análise estatística da presença de palavras nos textos. Já a RI semântica envolve uma análise sintática e semântica dos textos, em que o papel da palavra em uma frase importa, não somente sua presença.

A seguir, serão apresentadas algumas técnicas de RI que seguem as abordagens estatística e semântica.

\section{Abordagens Estatisticas}

As técnicas que seguem a abordagem estatística normalmente quebram textos em palavras isoladas ou palavras compostas, identificadas pela frequência de co-ocorrência ou pela presença em dicionários, ontologias, etc. O pré-processamento normalmente aplicado associa um stem, ou raiz, a essas palavras, ou seja, extrai a raiz de cada palavra para eliminar suas variações (Porter, 1980; Matsubara et al., 2003). Por exemplo, as palavras "expressar", "expressão" e "expresso" são todas consideradas pelo stem "express".

Geralmente, as frequências de ocorrência desses stems nos textos são anotadas em forma de tabelas atributo-valor. Essas tabelas também são conhecidas como bag-of-words, e representam cada texto como um vetor de palavras, ou seja, os atributos são as palavras que podem aparecer nos textos. O valor de cada atributo está relacionado com a quantidade de ocorrências da palavra associada a ele.

Algumas formas de corte dos stems menos importantes também são muito utilizadas. A mais básica delas é o emprego de stop-lists: listas de palavras comuns para a língua em que estão escritos os textos e mesmo palavras comuns para o domínio de conhecimento. Outro critério bastante utilizado é o corte de palavras extremamente raras ou frequentes. A Lei de Zipf (Zipf, 1949) declara que a frequência de ocorrência de algum evento está relacionada a uma função de ordenação. Uma das maneiras de aplicar esta lei a uma coleção de textos é a construção de um histograma baseado em quantas vezes cada palavra aparece na coleção, como pode ser visto na Figura 3.1. Luhn (1958) se 


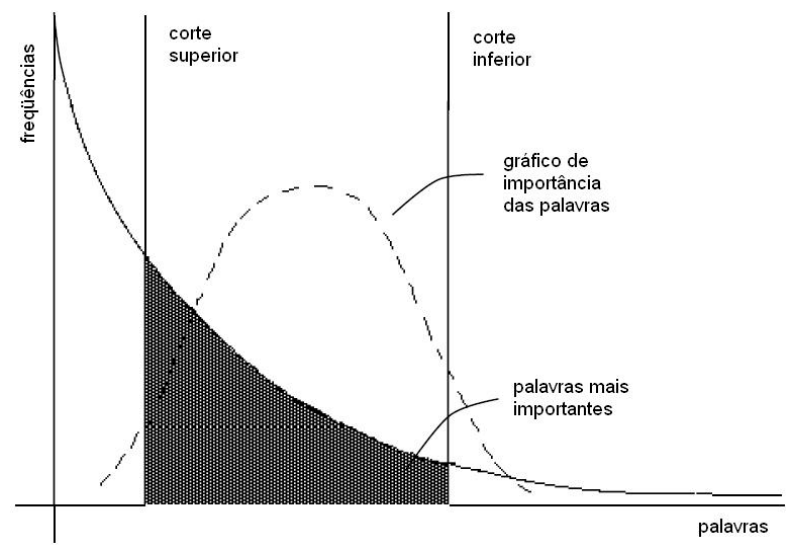

Figura 3.1: Lei de Zipf e Curvas de Luhn.

baseou nessa lei para estabelecer dois cortes no histograma de forma a excluir termos não relevantes, que são os termos acima do corte superior e abaixo do corte inferior, também ilustrado na Figura 3.1.

Assim, os textos possuem uma representação estruturada que pode ser submetida a diversas técnicas de RI estatísticas. A seguir, serão explicadas brevemente algumas delas.

A técnica booleana de RI é a forma mais simples e é baseada em consultas. Baseia-se na combinação booleana de termos (AND, OR e NOT). É a abordagem utilizada pela popular ferramenta de busca Google ${ }^{1}$. Um grande problema dessa abordagem é que uma consulta muito geral resulta em muitos resultados e, consequentemente, muitos resultados irrelevantes. À medida que a consulta se torna mais específica, diminui a quantidade de resultados produzidos. Alguns refinamentos possiveis para aprimorar a eficácia dessa abordagem são:

- Especificação do componente do texto (resumo, introdução, etc) onde uma determinada palavra deve ocorrer;

- Especificação da posição dentro do componente (primeiro parágrafo, etc);

- Utilização de um operador de proximidade entre palavras, por exemplo, se o usuário deseja que duas palavras ocorram na mesma frase;

- Ordenação dos resultados de acordo com sua relevância em relação à consulta.

A técnica que utiliza o Espaço de Vetores (Yandell e Majoros, 2002; Greengrass, 2000; Shatkay e Feldman, 2003) é baseada em documento. Para que ela seja aplicada, é necessário que os textos sejam representados em uma tabela atributo-valor. Cada linha dessa tabela constitui um vetor no espaço $\Re^{n}$ onde $n$ é o número de termos selecionados para descrever os textos.

${ }^{1}$ http://www.google.com.br 


\begin{tabular}{|c|c|c|}
\hline Termo & Texto $\mathbf{A}$ & Texto $\mathbf{B}$ \\
\hline cirurgia & 2 & 1 \\
\hline medicamento & 1 & 2 \\
\hline
\end{tabular}

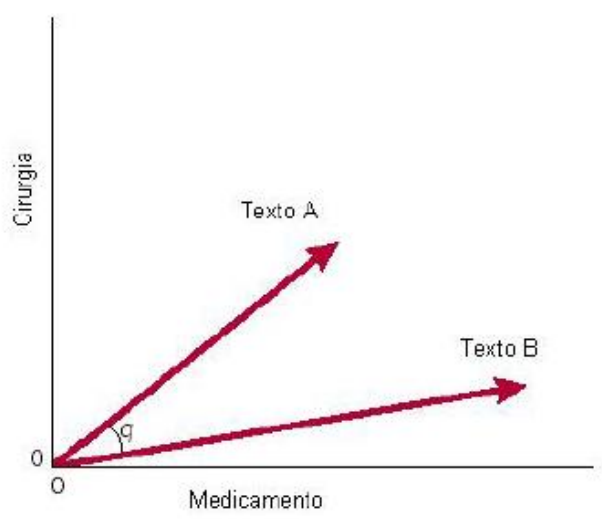

Figura 3.2: Comparação de dois textos no espaço de vetores.

Assim, a semelhança entre os textos pode ser medida utilizando o ângulo formado por seus respectivos vetores no espaço $\Re^{n}$. Uma forma muito comum de calcular essa semelhança é a partir do produto interno entre os vetores (cosseno do ângulo entre eles). Na Figura 3.2, é ilustrada a comparação entre dois textos no espaço de vetores, onde os atributos são as palavras "cirurgia" e "medicamento".

Um problema dessa técnica é que nenhuma informação relativa às relações entre as palavras é considerada, pois todas são representadas por eixos ortogonais no espaço $\Re^{n}$ da mesma maneira. Isso representa uma deficiência, uma vez que, por exemplo, existem os sinônimos e, em contrapartida, existem as palavras cujo significado depende do contexto (Shatkay e Feldman, 2003).

A técnica baseada em Indexação de Semântica Latente (ISL) (do inglês Latent Semantic Indexing (LSI)) (Deerwester et al., 1990; Greengrass, 2000; Shatkay e Feldman, 2003) evoluiu a partir da técnica baseada em espaço de vetores para utilizar a informação sobre as relações estatísticas termo-termo no cálculo da semelhança entre textos. Ela é baseada na frequência de co-ocorrência de palavras. Uma tabela atributo-valor é uma matriz $M_{t \times d}$, sendo $d$ o número de textos e $t$ o número de palavras que representam esses textos. Sendo uma matriz, operadores algébricos podem ser aplicados a essa tabela. Desses operadores, Singular Value Decomposition (SVD) pode ser utilizado para extrair os "componentes significativos" da matriz, que são os $k$ maiores valores singulares, onde $k$ é menor do que $t$. Cada texto pode ser representado por uma combinação linear desses $k$ valores singulares. Cada um desses $k$ valores pode ser visto como um representante de uma classe de palavras, ou seja, uma semântica escondida (Shatkay e Feldman, 2003), 
ou ainda, um conceito. A decomposição SVD, responsável por extrair esses $k$ valores, é uma adaptação da decomposição de matrizes em auto-valores e auto-vetores para matrizes não-quadradas. Resumidamente, a matriz $M$ é decomposta em três outras matrizes, $M=T_{0} S_{0} D_{0}^{\prime}$, onde:

- $T_{0}$ : termos $\times$ conceitos;

- $S_{0}$ : matriz diagonal contendo os pesos dos conceitos;

- $D_{0}$ : textos $\times$ conceitos.

Se essas três matrizes forem truncadas pelo $k$-ésimo conceito mais relevante, obtém-se $T S D^{\prime}=M_{k} \approx M$. Essa matriz $M_{k}$ é a representação dos textos no espaço $k$-dimensional e pode ser utilizada como a tabela atributo-valor da mesma maneira. Esse é um exemplo de abordagem mista, ou seja, é estatística, porém adiciona um significado semântico.

Técnicas de classificação de textos também podem ser utilizadas para selecionar textos. Há duas principais maneiras de realizar a classificação de textos. A primeira, chamada de Engenharia do Conhecimento (Hayes, 1992), define manualmente um conjunto de regras para classificar os textos utilizando o conhecimento de um especialista. A segunda maneira utiliza técnicas de Aprendizado de Máquina (AM) (Mitchell, 1997) para induzir uma hipótese de classificação a partir de um conjunto de textos rotulados. Essa é uma maneira de aprendizado supervisionado, ou seja, necessita de exemplos de treinamento rotulados, pois os algoritmos buscam extrair padrões de cada classe previamente definida a fim de, posteriormente, classificar novos exemplos desconhecidos. Exemplos de algoritmos de classificação são C4.5 (Quinlan, 1988), C4.5rules (Quinlan, 1988), Redes Neurais Artificiais (RNAs) (Haykin, 1998) e Support Vector Machines (SVMs) (Haykin, 1998; Lorena e Carvalho, 2003). Técnicas de classificação de textos são baseadas em documentos, por natureza. Por exemplo, textos podem ser procurados por semelhança a um texto cujo rótulo é conhecido. Também pode ser feita uma busca por textos de uma determinada classe, se as classes forem conhecidas pelo usuário.

Técnicas de agrupamento de textos podem ser utilizadas para seleção de textos. Para isso, um conjunto inicial de textos é submetido a uma dessas técnicas para que sejam definidos grupos de textos semelhantes entre si. Essa alternativa é uma forma não-supervisionada de aprendizado, pois requer, apenas, um conjunto de exemplos com suas características (atributos), não necessitando dos rótulos. A partir desses exemplos, o algoritmo definirá grupos contendo exemplos semelhantes entre si. Após estarem definidos os grupos de textos, essas técnicas podem ser utilizadas da mesma maneira que as técnicas de classificação para selecionar textos. 


\section{Abordagens Semânticas}

Abordagens semânticas se referem a métodos que se baseiam no conhecimento sintático e semântico das palavras contidas nos textos. As abordagens estatísticas para coleta de textos podem ser aprimoradas com a aplicação de alguns critérios semânticos. Essa medida pode possibilitar a construção mais inteligente de conjuntos de atributos ou mesmo uma melhor interpretação das palavras contidas em uma consulta e, consequentemente, resposta com melhores resultados.

Uma forma comum de aplicação de abordagem semântica é a identificação de substantivos compostos. Nas abordagens estatísticas, cada palavra é considerada isoladamente. No máximo, palavras que aparecem consecutivamente, diversas vezes no texto, podem ser agrupadas em um único atributo. Essa simples verificação dá margem a erros como o caso de um substantivo e um verbo serem agrupados, por exemplo, "gene induces", devido à ocorrência de diversas frases do tipo " $X$ gene induces $Y$ gene expression". Análises semânticas levam em consideração as classes gramaticais das palavras, evitando esse tipo de erro.

Outra forma de aplicar abordagens semânticas é o tratamento de palavras ambíguas. Quando uma palavra que contém mais de um significado ocorre no texto, a análise de sua vizinhança pode ajudar a determinar qual dos significados está sendo empregado. Para isso, é necessário que sejam empregadas medidas estatísticas relacionando co-ocorrências de palavras aos seus significados.

\subsubsection{Processamento de língua natural (PLN)}

A área de pesquisa Processamento de Língua Natural (PLN) é uma importante ferramenta utilizada em métodos de MT. Técnicas de PLN podem ser aplicadas para aprimorar os resultados em quase todas as etapas da MT. Quando aplicadas a documentos escritos, abordagens de PLN buscam modelar os textos considerando as funções gramaticais e sintáticas de palavras, estrutura das frases e até mesmo parágrafos e textos inteiros.

Três operações comuns em modelagens de textos com PLN são: tokenização, part-of-speech tagging (PoS tagging) e Parsing. A tokenização, primeira das etapas da aplicação de PLN, consiste em quebrar os textos em unidades, chamadas tokens. Os tokens podem variar quanto à granularidade, ou seja, os textos podem ser quebrados em capítulos, seções, parágrafos, frases, palavras ou até sílabas, dependendo da aplicação. A forma mais comum é quebrar o texto em frases e palavras. Uma dificuldade desse processo é determinar quando um ponto final sinaliza o fim de uma frase, uma 
vez que esse sinal possui outras funções, como abreviações, por exemplo.

PoS tagging é a tarefa de rotular cada palavra de acordo com sua classe morfológica em uma frase, ou seja, decidir se uma palavra é substantivo, verbo, adjetivo, etc. Essa não é uma tarefa simples, uma vez que a mesma palavra pode assumir funções diferentes em frases diferentes. Existem duas principais abordagens utilizadas em técnicas de POS tagging, uma baseada em regras e outra em estatística.

A abordagem baseada em regras utiliza informação de contexto para rotular palavras desconhecidas ou ambíguas. Um exemplo de regra é: "Se a palavra estiver precedida por um artigo e seguida por um substantivo, então a palavra é um adjetivo" (Shatkay e Feldman, 2003). Muitas vezes, informação morfológica (estrutura da palavra) é utilizada para solucionar ambiguidades. Por exemplo, se uma palavra termina com o sufixo -ous (na língua inglesa) ela será classificada como adjetivo (ex: delicious).

Existem diversas técnicas para a realização do PoS tagging. As mais comuns são baseadas nos HMMs (do inglês Hidden Markov Models) (Yandell e Majoros, 2002; Manning e Schutze, 1999). Os HMMs são modelos estatísticos empregados para estimar a probabilidade de uma sequência de tags de PoS. Um HMM é um autômato finito em que a mudança de estados produz um token. A cada estado é atribuída uma probabilidade, chamada probabilidade de emissão. A cada possível transição entre estados é atribuída uma probabilidade de transição. Essas probabilidades são determinadas por meio de exemplos de treinamento, ou seja, sentenças previamente analisadas manualmente. Um exemplo de modelagem com HMM para frases pode ser visto na Figura 3.3.

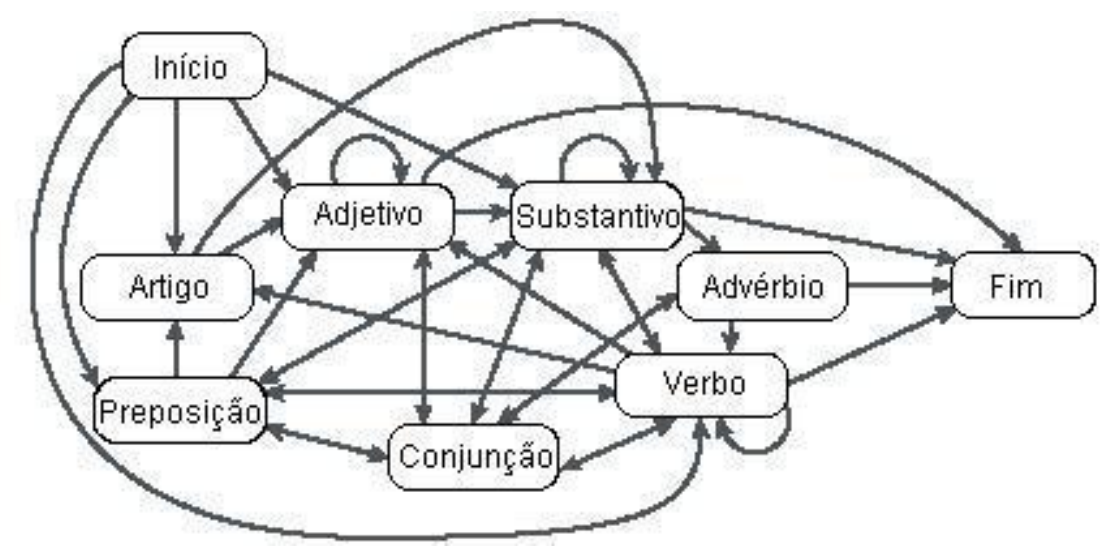

Figura 3.3: Hidden Markov Model para frases (Yandell e Majoros, 2002).

O parsing é o processo de determinação da estrutura sintática completa de uma frase. Essa estrutura é, geralmente, em forma de árvore, onde as folhas são palavras isoladas e os nós internos correspondem a estruturas sintáticas, como sintagma nominal, sintagma verbal, etc. Como ainda 
não existe uma técnica eficiente e precisa para realização de parsing, uma alternativa bastante utilizada é a chamada shallow parsing. Esse processo quebra textos em algumas sequências de palavras de forma que palavras relacionadas sintaticamente fiquem agrupadas. Essas sequências recebem rótulos gramaticais pré-definidos. O shallow parsing tem a vantagem de ser mais robusto e, mesmo sendo menos completo do que o parsing, é muito útil para etapas de pré-processamento que resultam em tabelas de atributo-valor.

Uma vez extraídas dos textos essas estruturas de frases com palavras rotuladas, pode-se inferir alguns fatos como, por exemplo, relacionamentos entre entidades do texto. Para isso, expressões regulares são frequentemente utilizadas. Expressões regulares são uma notação para representar templates que definem moldes para sequências de símbolos. Esses moldes são encaixados às frases estruturadas a fim de extrair fatos e armazená-los de maneira estruturada. Um exemplo desse procedimento pode ser visto na Figura 3.4 .

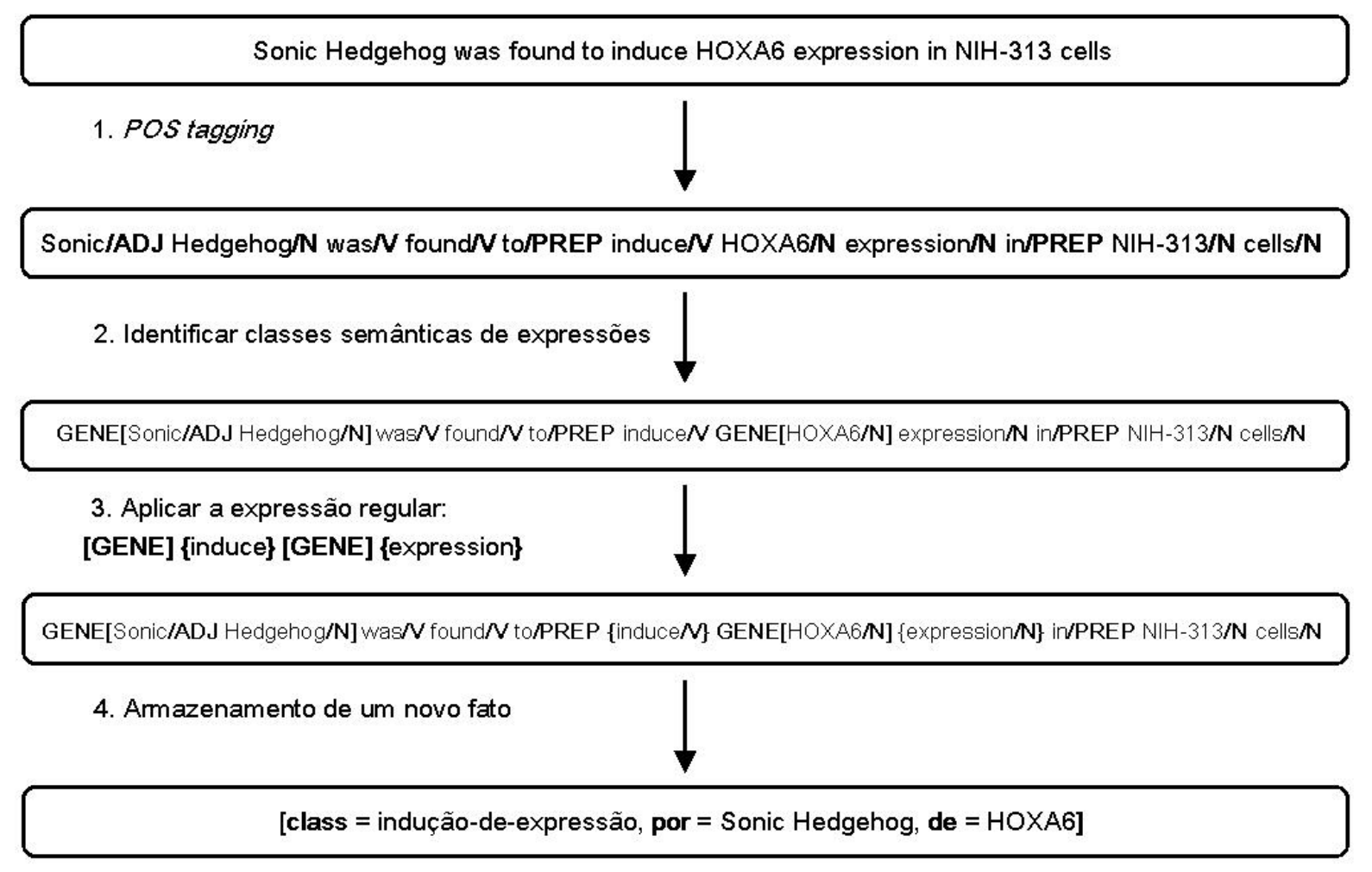

Figura 3.4: Extração de informação. Adaptado de Yandell e Majoros (2002).

Um grande desafio da área de PLN é a capacidade de identificar entidades que são referenciadas indiretamente nas frases, utilizando pronomes, por exemplo. Considere a frase analisada na Figura 3.4. Uma pequena alteração provocada pela troca da expressão "Sonic Hedgehog" por "That gene" (considerando que ela já fora citada anteriormente) dificulta consideravelmente o procedimento. Esse problema é conhecido como 
resolução de Anáfora (Shatkay e Feldman, 2003; Manning e Schutze, 1999). Algumas regras são utilizadas para a identificação do conceito mais provável de estar sendo referenciado. Por exemplo, quando se trata de um pronome, entidades que apareceram em frases anteriores no mesmo parágrafo são possiveis candidatas.

\subsubsection{Avaliação e interpretação dos resultados}

Quando se aplica qualquer forma de análise de textos, é delicado encontrar uma forma confiável de avaliar os resultados. Não é possível prever todos os textos que deveriam ser encontrados, no caso de RI, e tampouco saber qual o desempenho ideal na extração de conhecimento. Assim, uma solução é comparar o desempenho obtido com o de outras técnicas de mesmo objetivo.

Três medidas comuns para avaliar o desempenho de sistemas de AM são: recall, precisão e exatidão (accuracy) (Shatkay e Feldman, 2003). Considere que existe um conjunto de $N$ itens, sejam palavras, frases ou textos, e é definido que a técnica em avaliação deve rotular os $N$ itens como positivos ou negativos. Seja de acordo com relevância a um conjunto de textos, em caso de palavras, ou pertinência a uma classe, no caso de textos. Quatro situações são possíveis:

- Verdadeiros positivos: $A$ itens rotulados corretamente como positivos;

- Falsos positivos: $B$ itens rotulados incorretamente como positivos;

- Verdadeiros negativos: $C$ itens rotulados corretamente como negativos;

- Falsos negativos: $D$ itens rotulados incorretamente como negativos.

Sendo $N=A+B+C+D$ as medidas de avaliação são calculadas da seguinte maneira:

- Precisão: $P=\frac{A}{A+B}$

- Recall: $R=\frac{A}{A+D}$

- Exatidão: $E=\frac{A+C}{N}$

Em caso de problemas de classificação multi-classes, a análise deverá ser realizada uma vez para cada classe.

É importante salientar que a participação de um especialista do domínio na avaliação de novos métodos é muito importante, principalmente quando deseja-se analisar novas hipóteses resultantes da aplicação de tais métodos. 


\subsection{Mineração de textos em Bioinformática}

Quase toda informação referente a genes, proteínas e suas funções em processos biológicos está reportada em algum lugar na vasta literatura biomédica publicada. Durante os últimos anos, houve o surgimento de um grande interesse em utilizar a literatura biomédica (Shatkay et al., 2000; Blaschke et al., 2001; Fukuda et al., 1998; Friedman et al., 2001; Rindflesch et al., 2000; Jenssen et al., 2001; Masys et al., 2001; Raychaudhuri et al., 2003, 2002).

Um dos maiores desafios para o sucesso dessas aplicações, além da própria definição de uma abordagem que retorne as informações desejadas, é a falta de padronização de nomes de entidades biológicas. Diversos nomes são dados para o mesmo gene, até mesmo no mesmo artigo. Mesmo a referência a conceitos gerais da área sofre de diversos níveis de ambigüidade.

As aplicações de maior destaque objetivam analisar relacionamentos entre genes. Mais especificamente, descobrir os relacionamentos em si, que indiquem compartilhamento de funções ou cooperação em processos biológicos; explicar o significado de relacionamentos detectados por técnicas baseadas em outros tipos de dados, como expressão gênica; e mesmo ajudar a avaliar a taxa de acerto do conjunto de relacionamentos descobertos por outras técnicas. Alguns exemplos de trabalhos realizados com esses objetivos serão apresentados a seguir.

\subsection{Agrupamento de genes e descoberta do significado dos clusters}

Alguns dos resultados mais importantes, obtidos por experimentos com dados biológicos, são provenientes da aplicação de algoritmos de agrupamento a dados de expressão gênica. Porém, descobrir o significado por trás dos clusters formados apresenta um novo desafio para esses trabalhos. Com isso, houve o surgimento de diversas abordagens aplicando técnicas de mineração de textos para buscar esse significado na literatura biomédica publicada.

O sistema GEISHA (do inglês Gene Expression Information System for Human Analysis) (Blaschke et al., 2001; Oliveros et al., 2000; Tamames et al., 2002) tem como objetivo explicar o significado biológico de clusters de genes. Esse sistema se baseia na frequência com que certos termos ocorrem nos textos analisados. Inicialmente, são coletados textos contendo determinadas palavras-chave e o nome de pelo menos um dos genes do cluster sendo analisado. Os termos significativos são escolhidos por meio de métodos estatísticos. A importância de um termo para o significado de um cluster é calculada de acordo com a frequência com que esse termo aparece nos 
textos relacionados a esse cluster, comparada à sua frequência nos textos relacionados aos outros clusters. A saída desse sistema contém os termos considerados importantes e as sentenças contendo grande concentração de termos importantes.

No trabalho desenvolvido por Shatkay et al. (2000), foi escolhido um documento para representar cada gene (kernel document). Foi aplicada uma busca por similaridade, resultando em um conjunto de documentos semelhantes para cada kernel. Em seguida, foram eliminados os documentos considerados semelhantes a apenas um documento kernel, conservando apenas os documentos relevantes a dois ou mais documentos kernel. Cada documento kernel foi comparado aos documentos associados a ele por meio de uma medida de similaridade baseada no cosseno do ângulo entre os vetores que representam os textos. Posteriormente, foram determinadas relações entre genes. No final, é produzido um resumo com as partes dos textos que justificam os resultados. Um dos objetivos dessa estratégia é a tentativa de enfrentar o problema da nomenclatura dos genes por meio da identificação de textos que descrevem um determinado gene, independente do nome dado a ele. A principal limitação desse método é que seus resultados dependem da escolha do documento inicial (kernel) (Tamames et al., 2002).

No trabalho desenvolvido por Masys et al. (2001), com o objetivo de explicar o significado biológico de clusters de genes, existe uma maior preocupação com a semântica dos termos extraídos dos textos. Nesse trabalho, foi construída uma base de identificadores de genes. A partir desses identificadores, é feita uma busca por documentos relacionados a um cluster de genes. Os documentos encontrados são varridos em busca por palavras-chave contidas na ontologia MeSH (do inglês Medical Subject Headings). A partir das palavras-chave encontradas, são extraídas as palavras-chave "pai" na hierarquia do MeSH até chegar na raiz, gerando um conjunto de árvores de palavras-chave. Em seguida, são calculadas as frequências com que as palavras-chave ocorrem nesses conjuntos de árvores, o que auxilia a inferência sobre o significado biológico do cluster.

Em Raychaudhuri et al. (2003), os autores defendem que abordagens baseadas em dados de expressão gênica podem ser aprimoradas se incorporarem conhecimento prévio sobre os genes na análise. Eles desenvolveram uma abordagem que utiliza a literatura científica, não apenas para explicar o significado dos clusters, mas também para ajudar a formá-los. Nessa abordagem, um algoritmo de agrupamento hierárquico é aplicado aos dados de expressão gênica. Depois, uma técnica de MT é utilizada para definir as margens do agrupamento hierárquico. Essa técnica, denominada NDPG (do inglês Neighbor Divergence Per Gene) (Raychaudhuri e Altman, 2003), tem o 
objetivo específico de avaliar a coerência de um cluster de genes. Para isso devem ser fornecidos textos relacionados aos genes dos clusters. Esses textos são comparados no espaço de vetores e, para cada texto, são selecionados os textos mais semelhantes. A coerência de um cluster de genes é calculada com base no nível de semelhança entre os textos sobre os genes do cluster. O método foi aplicado com os clusters de genes propostos por Eisen et al. (1998).

Os autores do artigo Homayouni et al. (2005) também propuseram uma abordagem baseada na mineração da literatura biomédica para agrupamento de genes. Eles implementaram o SGO (do inglês Semantic Gene Organizer). Para esse sistema, devem ser fornecidos um conjunto de genes e textos sobre eles. Textos sobre o mesmo gene são concatenados, resultando em um texto por gene. Esses textos são transformados em vetores de palavras, de acordo com a abordagem bag-of-words. Por fim, a tabela resultante, de textos - gene $\times$ palavras, é submetida à aplicação da técnica LSI (descrita na Seção 3.2.1). Assim, os genes (linhas da tabela LSI) podem ser comparados, dois a dois, no espaço de vetores. Utilizando essa medida de similaridade para os genes, um algoritmo de agrupamento hierárquico é aplicado sobre eles. O sistema foi aplicado a genes classificados manualmente e os clusters produzidos apresentaram grande similaridade com as classes.

\subsubsection{Descoberta de relacionamentos entre genes}

Em paralelo ao estudo de clusters de genes, há uma grande quantidade de pesquisas que se concentram em descobrir relacionamento entre pares de genes. A seguir, são apresentadas algumas das principais abordagens encontradas na literatura.

No trabalho realizado por Jenssen et al. (2001), foi construída uma rede de ligações entre genes. Nessa rede, um gene é ligado a outro quando eles são co-mencionados em títulos e resumos de artigos. O sistema foi testado com genes bem conhecidos e um dos principais motivos para a ocorrência de ligações incorretas foi a falta de padronização da nomenclatura dos genes. Trabalhos semelhantes a esse procuraram identificar a natureza das co-ocorrências identificando-as no contexto de determinados verbos que indicam interações como "reprimir", "induzir", etc. (Yandell e Majoros, 2002).

O sistema GENIES (do inglês GENomics Information Extraction System (Friedman et al., 2001)) tem como objetivo extrair e estruturar informações sobre interações e eventos entre proteínas, genes e medicamentos. As estruturas resultantes da aplicação do sistema contêm os elementos "tipo", "valor" e, quando necessário, outros elementos considerados importantes. Essas estruturas podem representar objetos e suas propriedades ou ações que envolvem esses objetos de forma aninhada, ou seja, os argumentos requeridos 
por algumas estruturas podem ser outros objetos ou outras ações. Por exemplo, o objeto $I l-2$ é representado pela estrutura [proteína, I1-2], a ação descrita pela frase $R a f-1$ activates Mek-1 é representada por [ação, ativar, [proteina, Raf-1],[Mek-1]. A definição dessas estruturas é ditada por regras gramaticais formuladas manualmente pelos autores do trabalho por meio da observação de padrões semânticos e sintáticos em amostras de textos.

O Sistema EDGAR (do inglês Extraction of Drugs, Genes and Relations) (Rindflesch et al., 2000) extrai de textos informações sobre medicamentos e genes relacionados com câncer a partir de resumos de artigos biomédicos. Sua principal abordagem consiste em identificar nomes de genes, células e medicamentos; e relações entre eles que indiquem modificações no comportamento de expressão de determinados genes, de acordo com a sensibilidade a certos medicamentos em determinados tipos de células. Por exemplo, da frase "Compared with parental or mock-tranfected HAG-1 cells, $v$-src-tranfected HAG/src3-1 cells showed a 3.5-fold resistance to cis-diamminedichloroplatinum (CDDP)" é extraída a seguinte interpretação semântica estruturada é_resistente(v-src,HAG/src3-1,CDDP). Para a identificação das entidades (genes, células e medicamentos) o sistema utiliza um Part-of-Speech tagger estatístico. Para a extração de interações delas é considerado que, em resumos de artigos, elas são descritas em uma única frase.

Ultimamente, relacionamentos entre genes e outras moléculas, descobertos com utilização de abordagens como as descritas anteriormente, ou mesmo com métodos experimentais, estão sendo submetidas a bases de interações. São exemplos desse tipo de base de dados: a BIND (do inglês Biological Interaction Network Database) (Bader et al., 2003), INTERACT (Eilbeck et al., 1999) e DIP (Xenarios et al., 2000).

A base de dados BIND, em particular, possui três tipos de associações entre moléculas: interações entre duas moléculas, complexos moleculares e pathways. Um registro dessa base representa uma interação de dois ou mais objetos que ocorre em algum organismo. O objeto pode ser uma proteína, sequência de DNA (ex: gene), RNA, etc. Um complexo molecular é uma coleção de duas ou mais moléculas que se associam para formar uma unidade funcional. Um pathway é uma coleção de duas ou mais interações que ocorrem em uma determinada sequência.

A análise de uma coleção de fatos extraídos de vários textos pode resultar na formulação de novas hipóteses. Por exemplo, do documento 1 é extraída a relação "A implica B"; do documento 2, "B implica C". Como resultado, surge a hipótese "A implica C", que deve ser estudada. Blaschke et al. (1999) utilizou uma coleção de interações extraídas automaticamente para construir um grafo 
de interações de proteínas.

\subsection{Recursos para mineração de textos}

O interesse por parte da comunidade científica em extrair automaticamente conhecimento útil de textos atinge todas as áreas de pesquisa, não apenas biologia molecular. Isso resultou na produção e disponibilidade de recursos que auxiliam trabalhos envolvendo MT, incluindo softwares, bibliotecas, código pronto para reuso, etc. A seguir, serão apresentados brevemente alguns desses recursos.

\subsection{Biblioteca Libbow}

É uma biblioteca escrita na linguagem $\mathrm{C}$ que auxilia no desenvolvimento de programas que aplicam MT estatística (McCallum, 1996). Entre os recursos oferecidos, podem ser mencionados métodos para:

- Tokenizar textos, como detecção de palavras compostas;

- Construção de tabelas de atributo-valor com base nas informações sobre frequências das palavras nos textos.

Não são incluídas facilidades para aplicação de técnicas de PLN, como análise da estrutura de frases (POS-tagging). Junto com a biblioteca, são disponibilizados alguns softwares prontos para serem utilizados. Entre as facilidades oferecidas por estes softwares, estão coleta, classificação e agrupamento de textos.

\subsubsection{PreTexT}

A ferramenta PreTexT (Matsubara et al., 2003) fornece suporte para o pré-processamento de textos. Ela aplica a técnica bag-of-words e permite a utilização de diversas stoplists. Essa ferramenta também fornece suporte à aplicação da Lei de Zipf e dos Cortes de Luhn. Os valores para os cortes de Luhn podem ser determinados manualmente ou por meio de um valor que limita a inclusão das palavras de acordo com sua distância da mediana no gráfico de frequências. Também pode ser fornecida uma taxonomia contendo a informação de quais conjuntos de atributos podem ser transformados em um único atributo, seja por generalização ou por igualdade de significado.

O cálculo do valor de cada atributo pode ser realizado de três maneiras distintas:

- Valor booleano: o valor será verdadeiro se a palavra está contida no texto, ou falso caso contrário; 
- Frequência da palavra: utiliza a informação sobre a frequência com que a palavra aparece no texto;

- Palavras ponderadas: leva em consideração o fato de que palavras que aparecem na maioria dos textos não acrescentam informação útil para classificação dos textos. As palavras são ponderadas de forma que, quanto maior for o número de textos em que a palavra aparece, menor será seu peso.

Ao final do pré-processamento, o PreTexT produz a tabela atributo-valor, que representa os textos, e diversos relatórios como lista de stems e palavras derivadas em ordem de frequência e alfabética, entre outros.

\subsubsection{General Text Parser}

Essa ferramenta também permite a criação de tabelas de atributo-valor a partir dos textos, fornecendo diversos critérios de ponderação das palavras (Giles et al., 2003). Algumas características interessantes são:

- Permite o processamento de textos no formato PDF, seguindo filtros fornecidos pelo usuário;

- Converte textos ou consultas fornecidas pelo usuário para vetores, compatíveis com a tabela que representa os textos, e realiza comparações no espaço de vetores;

- Fornece o recurso de decompor a tabela atributo-valor de acordo com a abordagem LSI.

\subsubsection{OpenNLP}

OpenNLP (http://opennlp.sourceforge.net/index.html) é um centro de projetos onde podem ser acopladas implementações de funcionalidades de PLN. Para o desenvolvimento desses projetos, é fornecida uma biblioteca na linguagem Java com diversos recursos relacionados com tokenização, pos-tagging, parser, cálculo de frequência de termos, etc. Também são disponibilizadas ferramentas prontas para realização de algumas dessas tarefas.

\subsubsection{Mallet}

Mallet (McCallum, 2002) é uma biblioteca na linguagem Java que fornece facilidades para a realização de pos-tagging, detecção de sintagmas nominais, classificação e agrupamento de textos, entre outros. Ela também contém 
alguns programas que podem ser utilizados por meio de linha de comando. Algumas das opções fornecidas por estes programas possibilitam:

- Tokenizar os textos;

- Criar tabelas de atributo-valor;

- Especificar pipelines de procedimentos a serem aplicados aos textos em algum momento do processamento.

\subsubsection{Natural Language Toolkit}

O NLTK (http://nltk.sourceforge.net/) contém uma biblioteca na linguagem Python, com facilidades para realização de tokenização, parser e construção de tabelas atributo-valor.

\subsubsection{JavaNLP}

JavaNLP (http://www-nlp.stanford.edu/javanlp/) é um projeto que visa a constante construção de um repositório de utilidades de PLN, em linguagem Java, para disponibilização entre seus membros. Entre os membros desse grupo estão os autores do livro Foundations of Statistical Natural Language Processing (Manning e Schutze, 1999). Esse repositório contém implementações de pos-taggers, parsers, etc., que podem ser utilizados pelos membros do grupo. São disponibilizados livremente algumas ferramentas implementadas com os recursos do repositório, como o Stanford Parser e Stanford POS Tagger.

\subsection{Considerações finais}

Neste capítulo, foram apresentados alguns conceitos básicos e técnicas de MT e PLN. Procurou-se fornecer um retrato do atual estado da aplicação dessas técnicas a dados de biologia molecular e quais os tipos de informação atualmente possíveis de serem extraídos. Foi também apresentada uma revisão de algumas das mais interessantes ferramentas disponiveis para auxílio de trabalhos com MT e algumas das funcionalidades fornecidas por elas.

Minerar textos, principalmente quando sobre assuntos biomédicos, é um processo extremamente delicado. Diversos pontos são determinantes na obtenção de bons resultados. A coleta de textos, o pré-processamento e a extração de informação são etapas não-triviais e dependentes da aplicação. Por esse motivo, a quantidade de informações que a literatura biomédica pode oferecer ainda está longe de ser completamente explorada. Ainda há muito 
espaço para aplicação de novas abordagens e técnicas inteligentes de MT e PLN, que implementem novos mecanismos de extração de informação, visando descobrir conhecimento cada vez mais completo e útil na vasta literatura biomédica. 


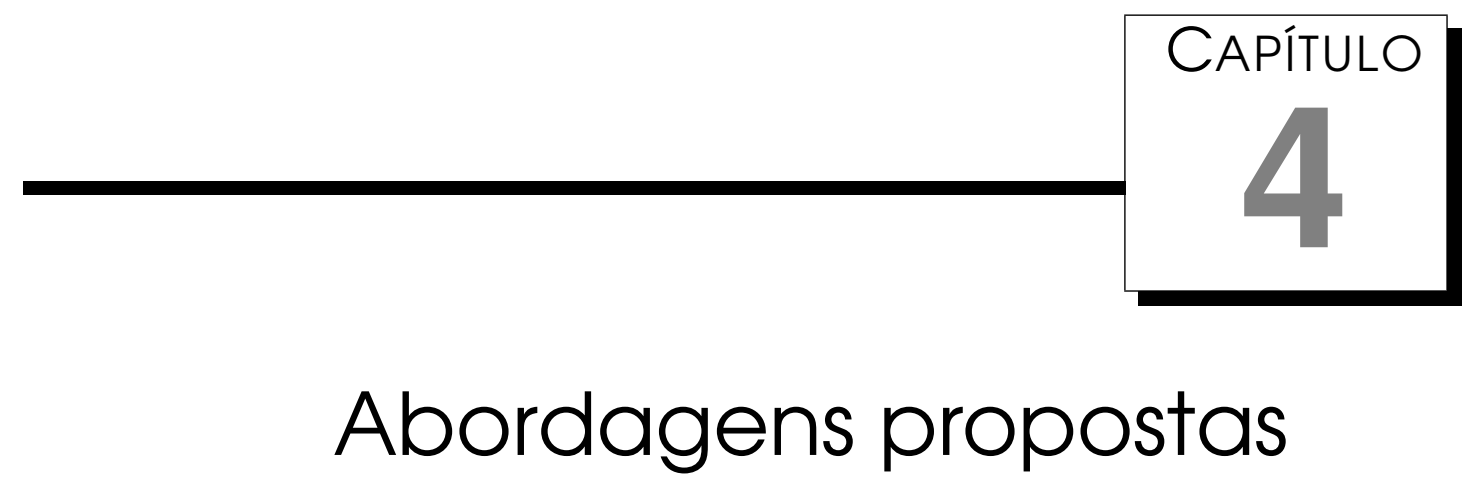

\subsection{Considerações iniciais}

As investigações realizadas neste trabalho, na área de agrupamento de dados, se concentraram na utilização de algoritmos de Otimização Baseada em População (OBP) em conjunto com funções-objetivo formuladas para buscar o agrupamento mais adequado para cada base de dados. As contribuições realizadas nesta área estão organizadas nas próximas seções. Na Seção 4.2, é apresentada uma análise de algumas das principais funções de validação de agrupamentos utilizadas aqui como critério de aptidão para algoritmos de OBP. A Seção 4.3 contém as investigações relacionadas com a proposta de uma técnica de agrupamento fuzzy semi-supervisionado que consiste na ponderação de diferentes objetivos permitindo a utilização de conhecimento prévio sobre os dados disponíveis em duas formas: dados rotulados e proximidade entre exemplos. Com base nessa mesma técnica, também foi proposta a utilização de uma métrica de distância adaptativa, ou seja, que se ajusta aos dados. Apresenta-se também uma abordagem proposta para a otimização do número de clusters para uma determinada base de dados, utilizando os conceitos aplicados para desenvolver a técnica de agrupamento semi-supervisionado. Também foram realizadas algumas investigações e propostas no sentido de aprimorar a utilização e funcionamento de algoritmos de OBP, em especial o PSO (Particle Swarm Optimization) (Kennedy e Eberhart, 2001; Shi e Eberhart, 1998), apresentadas na Seção 4.4. A Seção 4.5 descreve a investigação realizada em relação à análise de clusters em dados biomédicos. 


\subsection{Agrupamento de dados não-supervisionado}

A utilização de algoritmos baseados em população como método de otimização abre todo um leque de possibilidades para o emprego de diferentes índices de validação de agrupamentos. Além disso, a vantagem de algoritmos baseados em população em relação a métodos matemáticos de minimização de funções-objetivo é a capacidade de evitar mínimos locais, uma vez que avaliam, a cada iteração, diversas posições no espaço de soluções. Existem trabalhos na literatura reportando a utilização de algoritmos evolutivos em conjunto com alguma função-objetivo para AD (Hruschka et al., 2009). A maioria desses trabalhos considera que cada exemplo de dado pertence a somente um cluster. Os trabalhos em $\mathrm{AD}$ fuzzy evolutivo geralmente empregam Algoritmos Genéticos (AGs) e a função-objetivo do algoritmo Fuzzy c-means como critério de aptidão, diferindo entre si quanto à forma de representar os clusters no cromossomo (Van Le, 1995; Klawonn e Keller, 1997; Egan et al., 1998). Neste trabalho, foi realizada uma análise com algumas das principais funções de validação de agrupamentos. Essas funções foram utilizadas como critério de aptidão pelo algoritmo de OBP para evoluir uma população de protótipos de clusters. A opção por representar as soluções candidatas por meio de protótipos se deve ao fato de ser uma abordagem de menor custo computacional, em comparação com a opção de representar as matrizes de pertinência.

O algoritmo de otimização utilizado foi o PSO (do inglês Particle Swarm Optimization) (Kennedy e Eberhart, 2001; Shi e Eberhart, 1998), que possui algumas vantagens em relação aos AGs, como o fato de, ao invés de empregar operadores genéticos, cada partícula evolui com base em sua própria experiência e na experiência da população. Um resumo sobre o funcionamento do PSO pode ser encontrado no Apêndice B.

As investigações realizadas aqui consideraram duas formas de representar os protótipos dos clusters:

- Centróides: os protótipos podem assumir qualquer posição no espaço de busca.

- Medóides: os protótipos são, necessariamente, objetos da base de dados. A natureza combinatória dessa representação leva a um menor custo computacional, quando comparado com a busca em todo o espaço de protótipos.

Como métrica de distância, foi utilizada uma forma de distância euclidiana ponderada adaptativa, em que é permitida a flexibilidade de ponderação dos atributos e esses pesos são estimados pelo algoritmo de otimização, 
simultaneamente a estimativa dos protótipos. Dessa forma, a estrutura das partículas do PSO (indivíduos da população) foi definida de duas formas diferentes, ilustradas na Figura 4.1.

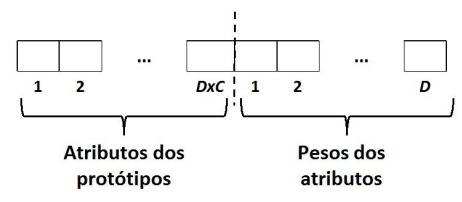

(a) Representação dos protótipos baseada em centróides.

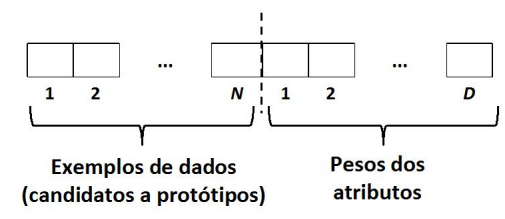

(b) Representação dos protótipos baseada em medóides.

Figura 4.1: Estruturas utilizadas como partícula do PSO, onde $N$ é o número de objetos na base de dados, $C$ é o número de clusters e $D$ é o número de atributos da base de dados.

Como visto na Figura 4.1, cada partícula é representada por dois vetores. A porção esquerda da partícula se refere à representação do protótipo. São dois esquemas de representação, dependendo se se trata de representação baseada em centróides ou medóides. Centróides são representados por $N \times C$ números reais especificando os valores dos atributos dos protótipos. Medóides são representados por $N$ números reais no intervalo de $[0,1]$, de onde os $C$ maiores valores são selecionados como protótipos. Considerando o exemplo hipotético em que a base de dados contém 5 itens de dados e devem ser encontrados dois protótipos, uma partícula com os valores [ $\left.\begin{array}{llllll}0.15 & 0.0 & 0.57 & 0.24 & 0.11\end{array}\right]$ representa uma estrutura em que os protótipos são o terceiro e o quarto elementos da base de dados. O segundo componente da partícula codifica os pesos para os atributos e são otimizados simultaneamente aos protótipos.

Foram considerados, para critério de aptidão, os índices de validação apresentados na Seção 2.4. Os índices Davies-Bouldin, VRC e Silhueta foram originalmente desenvolvidos para avaliar agrupamentos hard ${ }^{1}$. Em uma busca na literatura científica por referências a adaptações destes índices para o contexto fuzzy de $\mathrm{AD}$, foi encontrado o trabalho proposto por Campello e Hruschka (2006) onde é apresentada uma versão do índice Silhueta para $\mathrm{AD}$ fuzzy. Sobre os índices VRC e Davies-Bouldin não foram encontradas referências a generalizações para o contexto fuzzy de $\mathrm{AD}$, então eles foram adaptados neste trabalho, da seguinte forma:

- Davies-Bouldin fuzzy (FDB): $\sigma_{i}=\frac{\sum_{k=1}^{N} u_{i k}\left\|x_{k}-v_{i}\right\|}{N}$.

- VRC fuzzy: $B(K)=\sum_{i=1}^{C} \sum_{k=1}^{N} u_{i k} d_{i k}$ e $W(K)=\sum_{i=1}^{C}\left(\left\|v_{i}-\bar{x}\right\|^{2} \sum_{k=1}^{N} u_{i k}\right)$, onde $\bar{x}$ é a média de todos os objetos da base de dados.

A versão do índice Silhueta proposta por Campello e Hruschka (2006) é

\footnotetext{
${ }^{1}$ Forma de agrupamento onde cada exemplo de dado pode pertencer a apenas um cluster.
} 
calculada da seguinte forma:

$$
F S=\frac{\sum_{j=1}^{N}\left(p_{r j}-p_{q j}\right) s_{j}}{\sum_{j=1}^{N}\left(p_{r j}-p_{q j}\right)}
$$

onde $p_{r j}$ e $p_{q j}$ são, respectivamente, o primeiro e o segundo maiores valores de pertinência do $j$-ésimo objeto e $s_{j}=\frac{c_{j}-a_{j}}{\max \left(a_{j}, c_{j}\right)}$ onde $a_{j}$ é a distância média do objeto $j$ a todos os outros pertencentes ao mesmo cluster, $c_{j}$ representa o mínimo $m_{i j}$ para $j=\{1, \ldots, C\}, j \neq i$ onde $m_{i j}$ é a distância média do objeto $j$, a todos os objetos pertencentes ao cluster $i$. Dessa forma, a matriz de pertinência deve ser binarizada para o cálculo de $c_{j}$ e $a_{j}$. Neste trabalho, foi desenvolvida uma versão modificada do índice Silhueta onde o cálculo de $c_{j} \mathrm{e}$ $a_{j}$ faz uso da informação fuzzy contida na matriz de pertinência, da seguinte forma: $a_{j}=\sum_{i=1}^{C} u_{i j} m_{i j}$ e $m_{i j}=\frac{\sum_{k=1}^{N} u_{i k} d_{j k}}{\left(\sum_{k=1}^{N} u_{i k}\right)-u_{i j}}$.

Os resultados experimentais desta análise são apresentados na Seção 5.2 do Capítulo 5.

\subsection{Agrupamento de dados semi-supervisionado}

Nesta Tese, foi investigada a utilização, em processos de agrupamento, de conhecimento prévio em duas formas, simultaneamente: presença de exemplos de dados rotulados e informação de nível de proximidade de pares de exemplos. Também foi investigada a utilização de métrica de distância adaptativa, estimada pelo próprio algoritmo. Dessa forma, duas abordagens de $\mathrm{AD}$ semi-supervisionado foram propostas. A primeira é capaz de acomodar o conhecimento prévio disponível nas duas formas mencionadas ao agrupamento dos dados. A segunda abordagem é uma evolução da primeira, em que não é necessário que seja fornecido o número de clusters, o qual é estimado pelo próprio algoritmo. As Seções 4.3.1 e 4.3.2 contêm detalhes sobre essas abordagens.

\subsubsection{SSL+P: Unindo rótulos e proximidade de pares de exemplos}

O principal objetivo deste algoritmo de agrupamento, denominado Semi-Supervised Label + Proximity (SSL+P), é o particionamento dos dados em clusters coerentes com o conhecimento prévio fornecido. Esse conhecimento prévio é disponibilizado em duas formas: rótulos e níveis de proximidade de pares de exemplos. Os rótulos disponíveis informam o algoritmo sobre as classes em que os dados estão organizados. É natural pensar que uma classe pode ser particionada em vários clusters, pois, em algumas situações reais, os rótulos podem não refletir a estrutura espacial dos dados. Dessa forma, 
é necessário que seja informado ao algoritmo o número de clusters que cada classe contém.

A técnica consiste na minimização de uma função multi-objetivo composta por 3 termos, de acordo com a Equação (4.2).

$$
Q=N S+\alpha \sum_{h=1}^{H} \sum_{k=1}^{N}\left(\gamma_{h k}-f_{h k}\right)^{2} b_{k} d_{h k}^{2}+\beta \sum_{k_{1}=1}^{N} \sum_{k_{2}=1}^{N}\left(\hat{p}_{k_{1} k_{2}}-p_{k_{1} k_{2}}\right)^{2} B_{k_{1} k_{2}} d_{k_{1} k_{2}}
$$

O primeiro termo da função $Q, N S$ é a parte não-supervisionada do algoritmo, ou seja, é o termo que não envolve nenhum conhecimento prévio. Duas alternativas foram consideradas para o cálculo desse termo: de acordo com a função-objetivo do algoritmo FCM (Bezdek, 1981) (Equação (2.2)) e de acordo com o índice de validação Silhueta (Rousseeuw, 1987), adaptado para o contexto de AD fuzzy descrito na Seção 4.2.

O segundo termo da Equação (4.2) destina-se a acomodar os rótulos disponíveis, onde $b_{k}$ é um vetor binário que indica se o exemplo $k$ está rotulado ou não e os rótulos estão organizados na matriz $F=\left[f_{h k}\right]$. Os rótulos podem ser binários, 1 ou 0 , indicando se o exemplo $k$ pertence ou não à classe $h$, ou fuzzy, assumindo valores reais no intervalo $[0,1]$, indicando o grau de pertinência do exemplo $k$ em relação à classe $h$. O valor de $\gamma_{h k}$ é definido por $\sum_{i \in \pi_{h}} u_{i k}$ onde $\pi_{h}$ é o conjunto de clusters pertencentes à classe $h$ e é determinado com base no número de exemplos de cada classe em cada cluster de acordo com os rótulos disponíveis. A notação $d_{h k}$ é igual à soma das distâncias do exemplo $k$ aos centróides dos clusters pertencentes à classe $h$.

O terceiro termo da Equação (4.2) tem a função de acomodar os valores conhecidos de proximidade entre exemplos, onde $B_{k_{1} k_{2}}$ é uma matriz binária que especifica se o grau de proximidade entre os exemplos $k_{1}$ e $k_{2}$ é conhecido e o valor está armazenado na matriz $P=\left[p_{k_{1} k_{2}}\right]$. A notação $\hat{p}_{k_{1} k_{2}}$ descreve o grau de proximidade entre $k_{1}$ e $k_{2}$, calculados a partir da matriz de particionamento $u_{i k}$, de acordo com a Equação (2.15) e $d_{k_{1} k_{2}}$ é a distância euclidiana entre os exemplos $k_{1}$ e $k_{2}$. Devido ao fato de a função de aptidão ser composta por uma ponderação de múltiplos objetivos, a Equação 4.2 utiliza os parâmetros $\alpha$ e $\beta$ para controlar o equilíbrio entre os dois tipos de conhecimento prévio.

Três maneiras são consideradas para o cálculo da distância entre itens de dados e protótipos dos clusters, $d_{i k}^{2}$, necessária para o cálculo do primeiro e segundo termos da Equação (4.2). A primeira maneira utiliza a tradicional distância euclidiana, supondo que os clusters sejam esféricos. A segunda maneira usa a distância euclidiana ponderada, na qual são atribuídos pesos aos atributos, automaticamente, durante o processo de otimização, permitindo que o formato dos clusters seja melhor ajustado ao 
conhecimento prévio disponivel. A terceira maneira utiliza uma métrica de distância totalmente adaptativa, em que não somente são atribuídos pesos aos atributos, mas também valores de correlação entre os atributos. Considerando essas três maneiras, a distância é calculada de acordo com a Equação (2.7). A matriz $A_{i}$ é uma matriz identidade no caso de métrica euclidiana, uma matriz diagonal, no caso de métrica euclidiana ponderada, e uma matriz completamente preenchida, no caso de métrica totalmente adaptativa. Para ser utilizada para cálculo de distância cada matriz $A_{i}$ deve ser simétrica e definida positiva.

Para minimizar a função-objetivo definida pela Equação 4.2, utiliza-se o algoritmo de OBP PSO (Kennedy e Eberhart, 2001). A estrutura das soluções candidatas é definida de três maneiras diferentes, ilustradas na Figura 4.2. No caso de distância euclidiana, a partícula é composta de $D \times C$ números reais, os valores dos atributos dos protótipos. Quando utilizada uma métrica adaptativa, a partícula é formada por duas porções, a primeira, referente aos protótipos e, a segunda, referente à métrica de distância. No caso de métrica euclidiana ponderada, a partícula codifica apenas a diagonal principal das matrizes $A_{i}$. No caso de métrica totalmente adaptativa, a partícula contém os valores do triângulo superior das matrizes $A_{i}$.

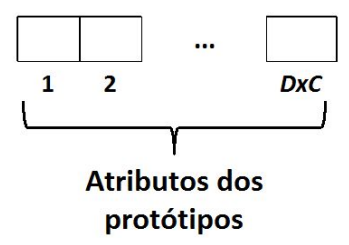

(a) Métrica de distância euclidiana.

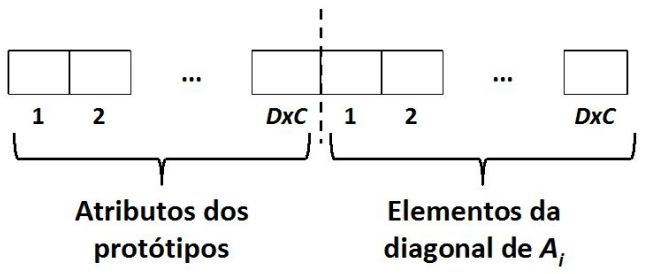

(b) Métrica de distância euclidiana ponderada.

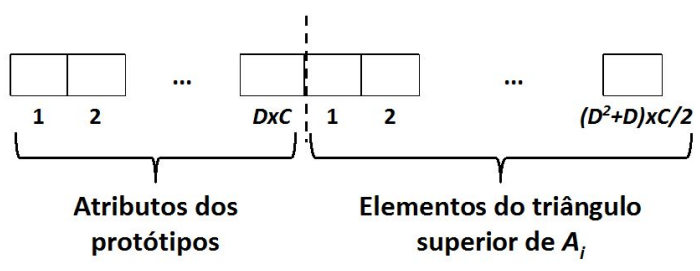

(c) Métrica de distância totalmente adaptativa.

Figura 4.2: Conteúdo da partícula.

Como mencionado, uma matriz deve ser definida positiva para ser utilizada no cálculo da distância, em outras palavras todos os seus auto-valores $\Lambda=\left[\lambda_{l}\right]$ devem ser maiores do que zero. Outra restrição imposta às matrizes de distância candidatas é a limitação do tamanho dos clusters, para evitar que eles cresçam descontroladamente para minimizar a função. O tamanho de cada cluster é proporcional ao determinante da matriz de distância. Dessa forma, foi fixada uma restrição para que o determinante das matrizes seja 
sempre igual a 1, como definido por Bouchachia e Pedrycz (2006b). Assim, as soluções candidatas representadas nas partículas passam por um tratamento antes de serem utilizadas para o cálculo das distâncias. Esse tratamento consiste em projetar os valores codificados nas partículas no espaço de soluções factíveis. Em outras palavras, é estimada a matriz mais próxima à matriz codificada pela partícula, que respeite as restrições. Este procedimento é realizado da seguinte maneira:

1. A matriz codificada na partícula é decomposta em auto-valores $\Lambda$ e auto-vetores $\Theta$.

2. É estimado o conjunto de auto-valores $\Lambda^{\prime}$ mais próximo de $\Lambda$ cujos valores sejam positivos e seu produtório seja igual a $1^{2}$. Baseando-se no trabalho de Xing et al. (2003), isto é realizado por meio de duas projeções:

$$
\begin{aligned}
& \Lambda^{\prime}:=\arg \min _{\Lambda^{\prime}}\left\{\left\|\Lambda^{\prime}-\Lambda\right\|_{F}: \lambda_{l}^{\prime}>0, l=1 \ldots D\right\} \\
& \Lambda^{\prime}:=\arg \min _{\Lambda^{\prime}}\left\{\left\|\Lambda^{\prime}-\Lambda\right\|_{F}: \prod_{l=0}^{D} \lambda_{l}^{\prime}=1\right\}
\end{aligned}
$$

onde $\|\cdot\|_{F}$ é a norma de Frobenius definida por $\|W\|_{F}=\sqrt{\sum_{r} w_{r}^{2}}$.

3. A matriz é reconstruída pelos auto-valores $\Lambda^{\prime}$ e auto-vetores $\Theta$.

Dessa forma, a matriz de pertinência candidata $u_{i k}$ representada em cada partícula é computada em função da distância entre os exemplos e protótipos candidatos, utilizando as matrizes de distância projetadas no espaço de soluções factíveis, de acordo com a Equação (2.4). Resultados experimentais desta técnica são apresentados na Seção 5.3.

\subsubsection{SSL+P*: Otimização do número de clusters}

Nesta seção, é apresentada uma abordagem de AD semi-supervisionado que não necessita que seja informado o número de clusters. Essa abordagem, SSL+P* (Semi-Supervised Label + Proximity incrementado), baseia-se na técnica apresentada na Seção 4.3.1, ou seja, ela minimiza a função-objetivo definida pela Equação (4.2), por meio da utilização do algoritmo PSO, porém em duas etapas. A primeira etapa destina-se à determinação do número ideal de clusters para cada classe. Nessa etapa, os protótipos são itens da base de dados, ou seja, medóides, e é utilizada a métrica de distância euclidiana. Dessa forma, a partícula é estruturada como ilustrado na Figura 4.3.

A primeira porção da partícula, formada pelos primeiros $H$ elementos, são números inteiros e indicam quantos clusters devem ser associados a cada classe. A segunda parte representa os exemplos da base de dados

\footnotetext{
${ }^{2} \mathrm{O}$ determinante de uma matriz é igual ao produto de seus autovalores.
} 


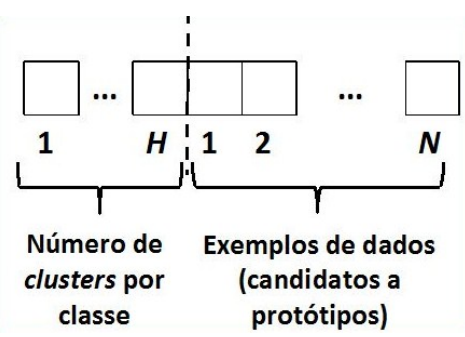

Figura 4.3: O conteúdo da partícula (solução candidata do algoritmo PSO). $H$ representa o número de classes e $N$ o número de elementos na base de dados

da mesma maneira como explicado na Seção 4.2 (Figura 4.1), diferindo apenas no fato de que o número de medóides selecionados é igual à soma dos elementos da primeira porção da partícula. Com base no número de clusters para cada classe e medóides resultantes desta etapa do algoritmo, é criada uma população inicial de centróides da seguinte maneira: utilizando uma distribuição gaussiana multivariada, são gerados $P$ pontos para cada medóide, onde $P$ é o tamanho da população a ser evoluída pelo PSO. Dessa forma, uma população inicial de centróides é criada com pontos próximos aos medóides resultantes da primeira etapa do algoritmo.

A segunda etapa do algoritmo utiliza a técnica apresentada na Seção 4.3 e tem como finalidade refinar o agrupamento. São fornecidos, para essa etapa, o número de clusters para cada classe resultantes da primeira etapa e a população inicial de centróides gerada, como explicado anteriormente.

Para essa técnica, apenas o índice Silhueta (Equação (2.19)) é considerado para o cálculo do primeiro termo da função-objetivo. Isso se deve ao fato de que a função-objetivo do algoritmo FCM (Equação (2.2)) baseia-se na minimização das distâncias entre os objetos e protótipos e, se utilizada para estimar o número de clusters, irá valorizar soluções com muitos clusters, pois quanto menores forem os clusters, menor será o valor dessas distâncias. Os resultados experimentais obtidos com essa técnica estão apresentados na Seção 5.3 .

\subsection{Otimização baseada em população}

Nesta seção, são apresentadas algumas investigações e propostas para aprimorar a utilização de algoritmos de OBP, como o PSO, com o propósito específico de agrupar dados. Duas contribuições foram propostas nesse sentido:

1. Inicialização de uma população inicial de protótipos de clusters. Quatro abordagens foram desenvolvidas para a geração de uma população inicial de protótipos, com o objetivo de acelerar a convergência e alcançar melhores valores de aptidão. 
2. Proposta de duas versões modificadas do algoritmo PSO, onde alguns de seus parâmetros são atualizados durante a convergência, com o objetivo de alcançar melhores valores de aptidão e diminuir o desvio-padrão entre diversas execuções do algoritmo.

As Seções 4.4.1 e 4.4.2 contêm maiores detalhes sobre essas contribuições.

\subsubsection{Produção da população inicial de soluções}

Foram desenvolvidas quatro abordagens de inicialização de uma população inicial de candidatos a protótipos de clusters. Essas abordagens levam em consideração a disposição dos dados, em contrapartida à abordagem tradicional, em que são selecionados aleatoriamente pontos no espaço de busca. O intuito é acelerar o processo de convergência e aumentar a probabilidade de alcance do ótimo global no espaço de soluções. Essas abordagens são explicadas a seguir:

1. Medóides: como população inicial de protótipos, são selecionados, aleatoriamente, $S$ conjuntos de $C$ exemplos de dados, onde $S$ é o tamanho da população e $C$ é o número de clusters.

2. Centróides-1: São definidos aleatoriamente diferentes partições da base de dados representadas por $S$ vetores de números inteiros $\mathbf{p}^{i}$, de tamanho $N$, com $i=\{1, \ldots, S\}$, onde $S$ é o tamanho da população e $N$ o número de exemplos da base de dados. $p_{k}^{i}$ representa o cluster ao qual pertence o exemplo $k$. A partir destas partições, são geradas matrizes de pertinência binárias que são, então, utilizadas para calcular os protótipos, de acordo com a Equação (2.5), que irão compor a população inicial de partículas.

3. Centróides-2: Para cada uma das $S$ partículas iniciais, são definidos $C$ clusters na base de dados da seguinte maneira: primeiramente é calculada a matriz de distância euclidiana entre exemplos $N \times N$, então são selecionados aleatoriamente $C$ exemplos de dados e, para cada um deles, é selecionada uma amostra de tamanho $\lfloor N / C\rfloor$ de exemplos da base de dados, sendo que a probabilidade de cada exemplo ser selecionado é proporcional à distância ao exemplo em questão. Definidos esses grupos de exemplos, é calculada a matriz de pertinência binária e os protótipos da população inicial, de acordo com a Equação (2.5).

4. Centróides-3: Baseada no algoritmo "Medóides". A partir de cada conjunto de medóides, é calculada a matriz de particionamento de acordo com a Equação (2.4). Em seguida, são calculados os centróides dos clusters resultantes, de acordo com a Equação (2.5). 
Os resultados experimentais destas formas de inicialização de população, em comparação com a abordagem tradicional aleatória, estão apresentados na Seção 5.4 .

\subsubsection{Modificações do PSO}

Algumas investigações foram realizadas no sentido de se obter melhores resultados modificando o mecanismo do algoritmo PSO (vide Apêndice B para o funcionamento do PSO tradicional). Foram, então, propostas duas versões modificadas desse algoritmo, denominadas Dynamic-PSO (DPSO), 1 e 2 (Medeiros e Carvalho, 2010). Essa denominação justifica-se pelo fato de que, nessas versões, os parâmetros $c_{1}$ e $c_{2}$ são atualizados durante a execução do algoritmo.

No algoritmo DPSO-1, se a melhor aptidão da população permanecer constante durante $\chi$ gerações, $c_{1}$ e $c_{2}$ são diminuídos em $s \times 10 \%$ do valor original, onde $s-1$ é igual ao número de vezes que $c_{1}$ e $c_{2}$ já foram atualizados, ou seja, $c_{1}$ e $c_{2}$ são atualizados de acordo com:

$$
\begin{aligned}
& c_{1}=c_{1}^{o}(1-0.1 s) \\
& c_{2}=c_{2}^{o}(1-0.1 s)
\end{aligned}
$$

onde $c_{1}^{o}$ e $c_{2}^{o}$ são os valores iniciais de $c_{1}$ e $c_{2}$. É também especificado um valor mínimo para $c_{1}$ e $c_{2}$, definidos por $c_{1}^{o}(1-0.1 \rho)$ e $c_{2}^{o}(1-0.1 \rho)$, respectivamente, sendo $\rho$ uma constante inteira positiva.

O algoritmo DPSO-2 é semelhante ao DPSO-1. A única diferença é que, além da regra para diminuição dos parâmetros $c_{1}$ e $c_{2}$, também existe uma regra para o aumento desses valores. Se a melhor aptidão da população melhorar ao longo de $t$ gerações, os parâmetros $c_{1}$ e $c_{2}$ são incrementados em $s \times 10 \%$ do valor original, ou seja, são atualizados de acordo com a Equação 4.4 .

$$
\begin{aligned}
& c_{1}=c_{1}^{o}(1+0.1 s) \\
& c_{2}=c_{2}^{o}(1+0.1 s)
\end{aligned}
$$

No algoritmo DPSO-2 também existe valor máximo para $c_{1} \mathrm{e} c_{2}$, definidos como $c_{1}^{o}(1+0.1 \rho)$ e $c_{2}^{o}(1+0.1 \rho)$, respectivamente.

Os resultados experimentais dos algoritmos DPSO-1 e DPSO-2, em comparação com versões tradicionais do PSO, são apresentados na Seção 5.4. 


\subsection{Análise automática de clusters de dados biomédicos}

Um desafio enfrentado por trabalhos que realizam mineração de textos sobre genes é a falta de padronização na nomenclatura dos genes, ou seja, nomes diferentes são designados ao mesmo gene, mesmo em um único texto. Isso dificulta muito a identificação de textos sobre estes genes. Uma alternativa para não depender dos nomes dos genes é coletar manualmente textos confiáveis e coletar automaticamente textos semelhantes. Isso pode ser feito por meio de algoritmos de AM supervisionados, treinados com os textos-modelo para classificar textos candidatos à coleta.

Uma vez que um conjunto de dados é particionado em clusters, é interessante avaliar se os clusters resultantes fazem sentido dentro do domínio a que pertencem seus dados. Tratando-se de dados biológicos, existe muita informação disponível, em forma de artigos científicos disponibilizados eletronicamente. Neste trabalho, foi desenvolvida uma abordagem baseada em MT e aprendizado de regras e árvores de decisão para identificar o significado de cada cluster de um agrupamento de dados biológicos (Medeiros e Carvalho, 2004, 2005). Ela consiste na descoberta de informações em artigos científicos que ajudem a explicar o significado de clusters de entidades biológicas, por exemplo, genes ou proteínas. A abordagem funciona da seguinte maneira:

1. Coleta de textos: são coletados resumos (abstracts) de artigos relacionados com as entidades biológicas agrupadas.

2. Pré-processamento dos textos: os resumos são submetidos a uma ferramenta de pré-processamento de textos para serem transformados em tabelas atributo-valor. Os atributos dessas tabelas representam as palavras selecionadas para representar os textos. Os valores dos atributos são calculados de acordo com a freqüência de ocorrência da respectiva palavra.

3. Rotulação dos textos: cada texto é rotulado de acordo com o cluster ao qual pertence a entidade biológica descrita por ele. Esse esquema de rotulação é ilustrado na Figura 4.4 para um exemplo de análise de clusters de genes.

4. Extração de informação: a tabela atributo-valor que descreve o conjunto de textos é submetida a um algoritmo de AM supervisionado simbólico, como os algoritmos C4.5 e C4.5rules (Guinlan, 1988).

O conhecimento adquirido fornece informações sobre os textos de cada classe, ou seja, sugere hipóteses sobre as classes aprendidas, que, no 


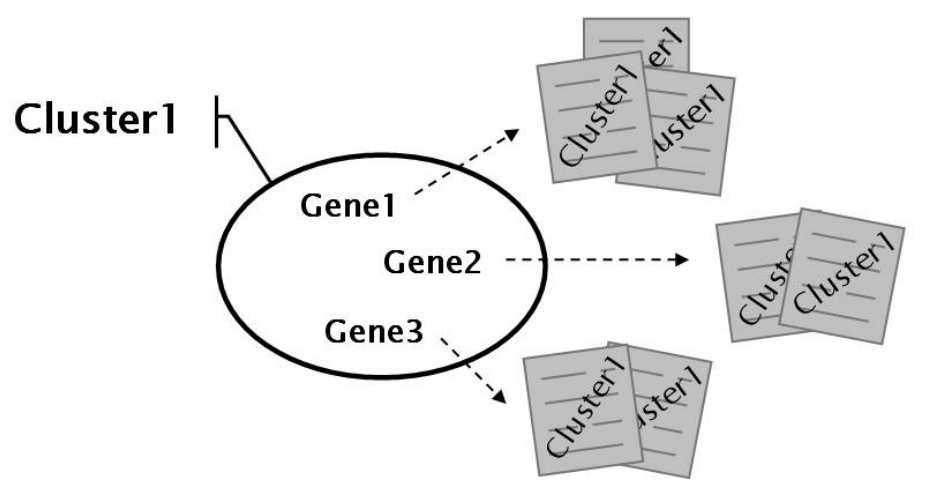

Figura 4.4: Esquema de rotulação dos textos.

caso, são clusters de entidades biológicas. Por exemplo, se for utilizado um algoritmo de aprendizado de regras de decisão, as regras aprendidas classificam os textos com base na frequência das palavras. Como os textos de cada classe representam um cluster de entidades biológicas, o objetivo é encontrar nessas regras o conjunto de palavras que caracteriza o significado de cada cluster. Se for considerada a utilização de um algoritmo de aprendizado de árvores de decisão, as sub-árvores aprendidas podem fornecer informações de como os clusters se relacionam. Experimentos com esta abordagem são apresentados na Seção 5.5.

\subsection{Considerações finais}

Neste capítulo foram detalhadas as contribuições desta Tese. Especificamente, a investigação do uso de diferentes funções de aptidão para um algoritmo de $\mathrm{OBP}$ para $\mathrm{AD}$, a proposta de uma técnica de $\mathrm{AD}$ fuzzy semi-supervisionado multi-objetivo, a extensão dessa técnica para o cenário em que o número de clusters não é conhecido, duas modificações no algoritmo PSO e uma investigação da análise de clusters em dados biomédicos. 


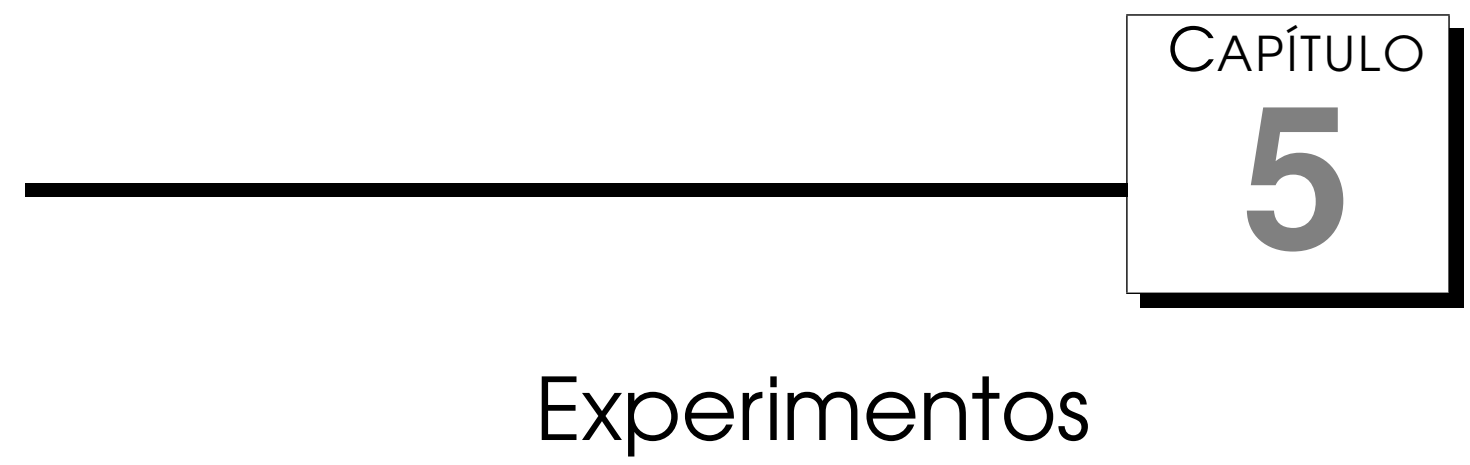

\subsection{Considerações iniciais}

Neste capítulo, são descritos os experimentos realizados para analisar e avaliar as propostas e conceitos apresentados no Capítulo 4. A Seção 5.2 apresenta detalhes sobre o conjunto de experimentos montado para realizar a análise descrita na Seção 4.2, bem como seus resultados comentados. A Seção 5.3 contém os experimentos realizados para avaliar o desempenho das abordagens de AD semi-supervisionado propostas, SSL+P e SSL+P*. Na Seção 5.4 são apresentadas análises experimentais das contribuições realizadas na área de OBP: versões modificadas do algoritmo PSO, DPSO-1 e DPSO-2 e as 4 formas de inicialização de população de soluções. Por fim, as análises experimentais com a abordagem de MT para análise de clusters de dados de biologia molecular estão contidas na Seção 5.5.

\subsection{Agrupamento de dados não-supervisionado}

Nesta seção, são apresentados os resultados experimentais da análise descrita na Seção 4.2. Resumidamente, foi investigada a utilização do algoritmo de otimização PSO para, dada uma base de dados e o número de clusters desejado, encontrar o melhor conjunto de protótipos de acordo com um dado critério de aptidão. Foi analisada a utilização de alguns dos principais índices de validação de agrupamentos como critério de aptidão. Também foram consideradas duas formas de representar protótipos: baseando-se em medóides e baseando-se em centróides. A seguir, 
serão apresentadas as bases de dados, a metodologia para realização dos experimentos e os resultados obtidos.

\subsubsection{Bases de dados}

Quanto as bases de dados, foram utilizadas três bases de classificação do repositório UCI (Newman et al., 1998), Diabetes, Glass e Wine, e duas bases de dados sintéticas. As bases sintéticas foram produzidas de forma a se conhecer o número ideal de clusters. Elas foram criadas com distribuição gaussiana multivariada, com clusters esféricos a partir das configurações na Tabela 5.1. Ambas as bases sintéticas estão ilustradas na Figura 5.1.

Tabela 5.1: Configurações para criação das bases de dados sintéticas.

\begin{tabular}{l||c|c}
\hline \hline Base & Sintética-1 & Sintética-2 \\
\hline \hline No. de Clusters & 3 & 6 \\
\hline No. de Atributos & 3 & 2 \\
\hline No. de Exemplos por cluster & 50 & 50 \\
\hline \multirow{4}{*}{ Protótipos } & & $(2.0,6.0)$ \\
& $(8.54,7.53,4.91)$ & $(3.5,2.0)$ \\
& $(2.86,8.97,1.14)$ & $(5.0,5.0)$ \\
& $(4.37,4.76,8.37)$ & $(5.0,8.0)$ \\
& & $(6.5,2.0)$ \\
& & $(8.0,6.0)$ \\
\hline \hline
\end{tabular}

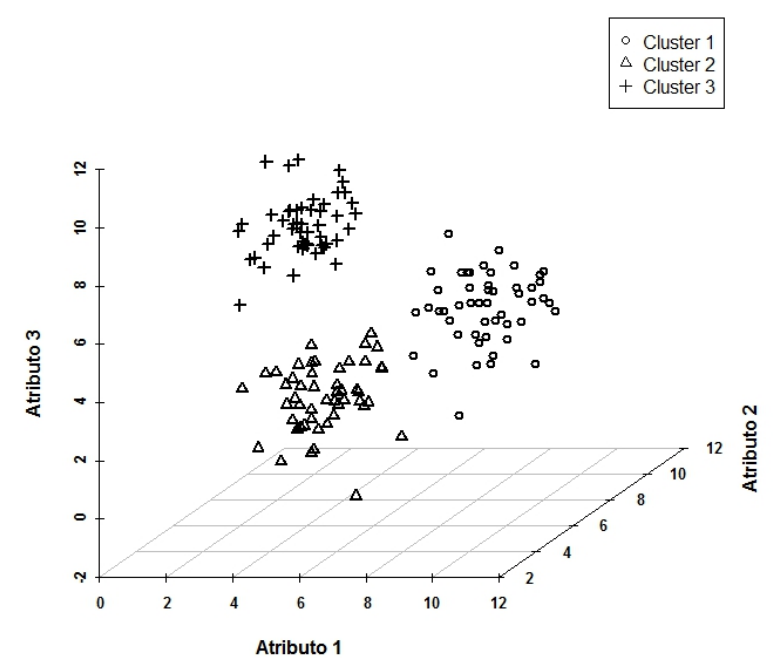

(a) Base de dados Sintética-1.

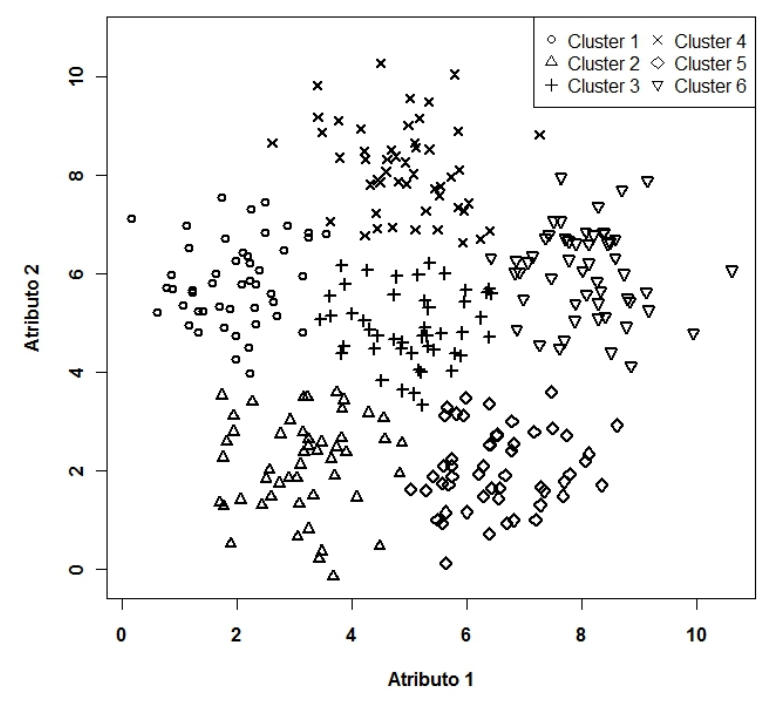

(b) Base de dados Sintética-2.

Figura 5.1: Gráficos das bases de dados Sintética-1 e Sintética-2.

A Tabela 5.2 resume as principais características de cada uma das bases 
utilizadas.

Tabela 5.2: Principais características das bases de dados utilizadas.

\begin{tabular}{l||c|c|c|c|c}
\hline \hline Base & Diabetes & Glass & Wine & Sintética-1 & Sintética-2 \\
\hline \hline No. de classes & 2 & 7 & 3 & 3 & 6 \\
\hline No. de atributos & 8 & 9 & 13 & 3 & 2 \\
\hline No. de exemplos & 768 & 214 & 178 & 150 & 300 \\
\hline \hline
\end{tabular}

\subsubsection{Metodologia}

Para todas as bases de dados utilizadas, foi considerado o número de clusters variando no intervalo [3,16], com o intuito de observar a tendência geral da performance do agrupamento com diversas estruturas de particionamento.

Como algoritmo de OBP, foi utilizada a versão do PSO introduzida por Shi e Eberhart (1998), onde o parâmetro de inércia $w$ é definido como uma função de tempo decrescente, de acordo com a Equação (5.1):

$$
w=w_{\max }-\frac{i \operatorname{ter} *\left(w_{\max }-w_{\min }\right)}{i \operatorname{ter}_{\max }}
$$

Os demais parâmetros do PSO foram definidos da seguinte forma: $c_{1}=c_{2}=$ 2 , $w_{\max }=0.9, w_{\min }=0.2$, iter $\max =200$, como sugerido por Shi e Eberhart (1998), e tamanho da população igual a 100. A população de partículas inicial foi gerada com a técnica Centróides-3, proposta neste trabalho de Doutorado, descrita na Seção 4.4.1. Foi também aplicada uma restrição para a condição de parada do PSO, que exige que a melhor aptidão da última geração da população seja, necessariamente, melhor do que a melhor aptidão da população inicial.

Para a análise dos resultados, foi utilizado um critério denominado Erro de Proximidade, que consiste na diferença da matriz de proximidade calculada com base na estrutura de classes original e da matriz de proximidade obtida utilizando o agrupamento resultante. No caso das bases obtidas do repositório UCI, a estrutura de classes original é representada como uma matriz binária $F^{o}=\left[f_{h k}^{o}\right], H \times N$, onde $f_{h k}^{o}=1$ se o exemplo $k$ pertence à classe $h$ e $f_{h k}^{o}=0$ caso contrário. No caso das bases sintéticas, $F^{o}$ é uma matriz de pertinência fuzzy, onde $f_{h k}^{o}$ é o grau de pertinência do exemplo $k$ à classe $h$. A matriz de proximidade consiste de uma matriz $P=\left[p_{k_{1} k_{2}}\right], N \times N$ onde $p_{k_{1} k_{2}}$ representa o grau de proximidade entre os pares de exemplos $k_{1}$ e $k_{2}$ e é calculada de acordo com a Equação (2.15). Como consequência, o Erro de Proximidade é obtido de acordo com a seguinte equação: 


$$
\text { Erro de Proximidade }=\sum_{N}^{k_{1}} \sum_{N}^{k_{2}}\left|p_{k_{1} k_{2}}^{o}-p_{k_{1} k_{2}}^{r}\right|
$$

onde $p_{k_{1} k_{2}}^{o}$ é a matriz de proximidade calculada a partir de $F^{o}$ e $p_{k_{1} k_{2}}^{r}$ é a matriz de proximidade calculada a partir da matriz de pertinência resultante.

$\mathrm{O}$ algoritmo FCM foi aplicado às bases de dados e os resultados foram utilizados como referência no processo de comparação.

\subsubsection{Resultados}

A seguir serão apresentados os resultados dos experimentos utilizando PSO com as 5 diferentes funções de aptidão e as 2 formas de representação de protótipos.

A Figura 5.2 exibe os resultados medidos de acordo com o Erro de Proximidade para a base Sintética-1. Tanto o algoritmo FCM, bem como o PSO (independente do critério de aptidão) forneceram melhores resultados para 3 clusters, que é o valor original para esta base. As duas formas de representar os protótipos não influenciaram significativamente quanto ao Erro de Proximidade. O melhor resultado foi alcançado pelo PSO com critério de aptidão Reconstrução e 3 clusters.

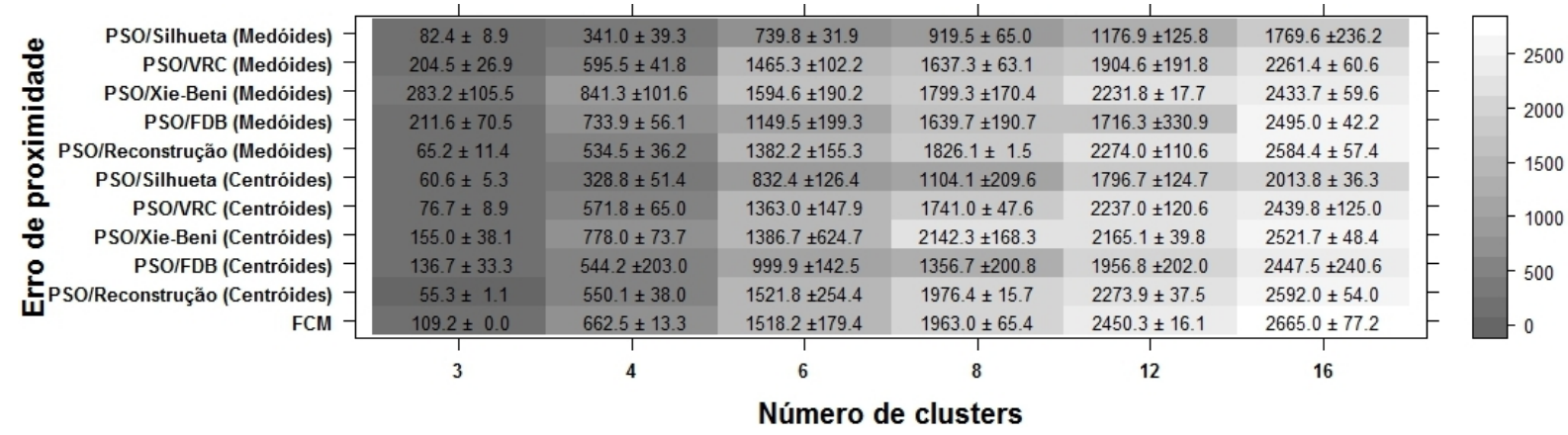

Figura 5.2: Gráfico do Erro de Proximidade para as bases Sintética-1 em função do número de clusters para os critérios de aptidão: Silhueta, VRC, Xie-Beni, FDB e Reconstrução com representação de protótipos baseada em centróides e medóides.

A Figura 5.3 exibe os resultados medidos de acordo com o Erro de Proximidade para a base Sintética-2. Os valores ilustrados nessa figura sugerem que o algoritmo FCM e o PSO com aptidão por Reconstrução e Silhueta forneceram melhores resultados quando 6 clusters são utilizados, que é o número de clusters original desta base. As demais técnicas tendem a oferecer melhores resultados com números de clusters mais altos. Para esta base de dados, o melhor resultado foi o agrupamento com 6 clusters produzido pelo FCM.

A Figura 5.4 exibe os resultados medidos de acordo com o Erro de Proximidade para a base Diabetes, do repositório UCI. Com esta base de 


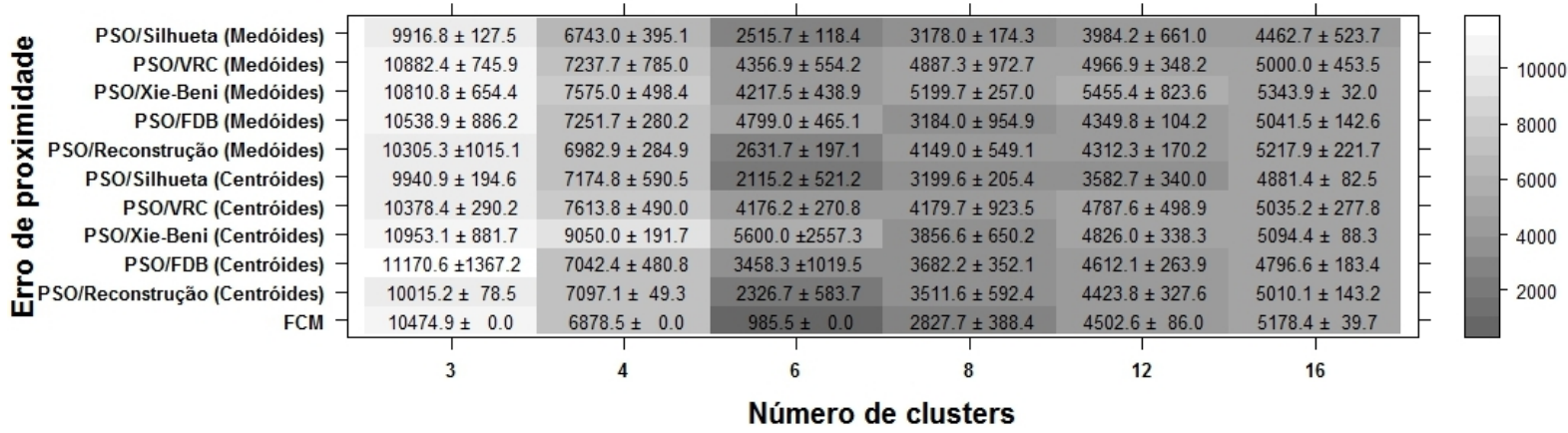

Figura 5.3: Gráfico do Erro de Proximidade para a base Sintética-2 em função do número de clusters para os critérios de aptidão: Silhueta, VRC, Xie-Beni, FDB e Reconstrução, com representação de protótipos baseada em centróides e medóides.

dados, todos os critérios de aptidão se comportaram de maneira semelhante e produzindo os melhores resultados para valores de número de cluster igual a 3 e quatro. As duas formas de representação de protótipos também forneceram resultados semelhantes, sendo que os centróides apresentaram uma leve tendência de fornecer melhores resultados. O menor valor de Erro de Proximidade foi produzido pelo PSO com aptidão FDB e representação por medóides. Porém, se forem consideradas todas as situações, nota-se a tendência de os melhores resultados serem fornecidos pelo PSO com aptidão Silhueta.

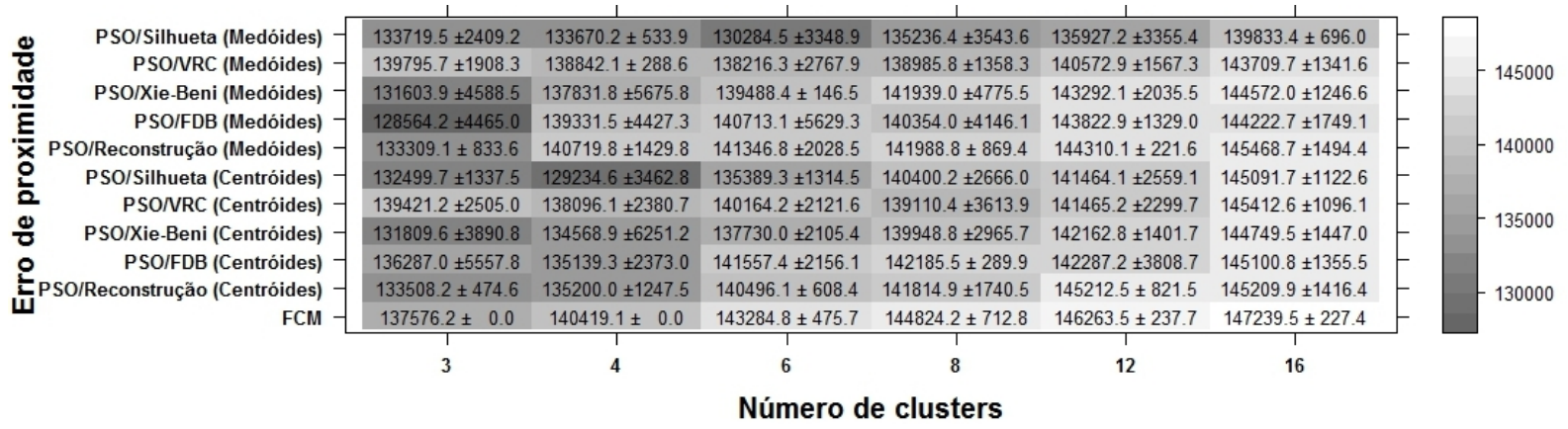

Figura 5.4: Gráfico do Erro de Proximidade para a base Diabetes em função do número de clusters para os critérios de aptidão: Silhueta, VRC, Xie-Beni, FDB e Reconstrução, com representação de protótipos baseada em centróides e medóides.

A Figura 5.5 exibe os resultados medidos de acordo com o Erro de Proximidade para a base Glass. Com esta base, os menores valores de Erro de Proximidade são fornecidos para valores de número de cluster iguais a 3, 4 e 6. As formas de representação de protótipos se comportaram de maneira semelhante, sendo que os medóides forneceram melhores resultados em alguns casos. O gráfico também aponta uma tendência de o critério de aptidão Silhueta alcançar menores valores de Erro de Proximidade na maioria das situações.

A Figura 5.6 exibe os resultados medidos de acordo com o Erro de Proximidade para a base Wine. Para esta base, os melhores resultados 


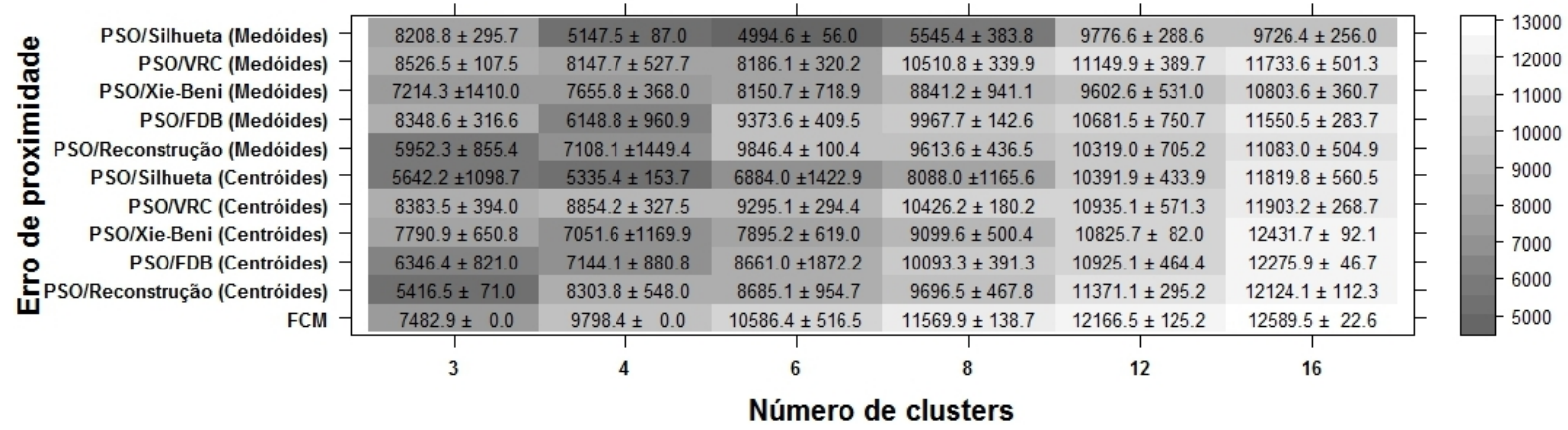

Figura 5.5: Gráfico do Erro de Proximidade para a base Glass em função do número de clusters para os critérios de aptidão: Silhueta, VRC, Xie-Beni, FDB e Reconstrução, com representação de protótipos baseada em centróides e medóides.

são alcançados para 3 clusters. Nesse gráfico, é evidente a melhora nos resultados com a utilização da representação de protótipos baseada em centróides. Quanto aos critérios de aptidão, nota-se que a Silhueta com ambas as representações e o índice de Reconstrução com centróides resultaram nos menores valores do Erro de Proximidade, tendo esta última fornecido o menor valor, para 3 clusters.

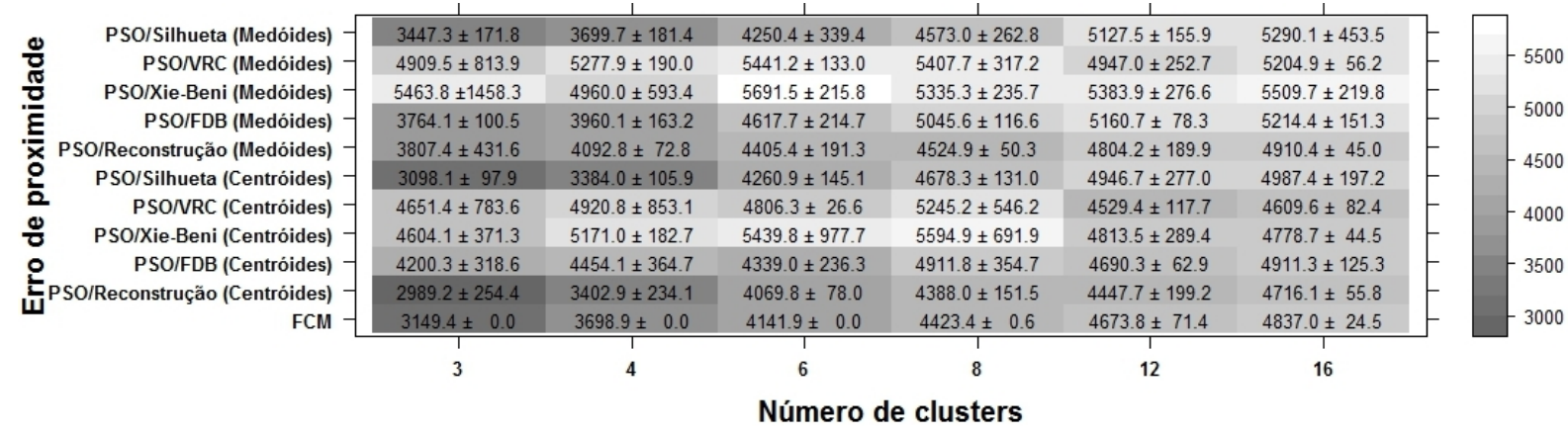

Figura 5.6: Gráfico do Erro de Proximidade para a base Wine em função do número de clusters para os critérios de aptidão: Silhueta, VRC, Xie-Beni, FDB e Reconstrução com representação de protótipos baseada em centróides e medóides.

Considerando todos os resultados apresentados, é possivel notar uma tendência de os melhores resultados serem produzidos pelo PSO, principalmente quando o critério de aptidão utilizado é a função Silhueta. Em geral, a representação de protótipos por centróides alcança melhores resultados, o que é o natural, pois esta representação permite acesso a todo o espaço dimensional, não apenas aos pontos onde estão os exemplos de dados, como com a representação baseada em medóides. Porém, em alguns casos, a representação por medóides alcança menores Erros de Proximidade, o que dá indícios de que o PSO não foi capaz de cobrir todo o espaço dimensional. Este fato motivou o desenvolvimento das duas versões modificadas do algoritmo PSO, DPSO-1 e DPSO-2, apresentadas na Seção 4.4.2.

Para facilitar a visualização dos resultados, a Tabela 5.3 contém o número de vitórias, empates e derrotas das técnicas listadas na primeira coluna, em 
comparação com as técnicas listadas na primeira linha. As técnicas são comparadas nas 30 situações: 5 bases de dados $\times 6$ números de clusters. Por exemplo, o valor "17/0/13" na terceira linha da segunda coluna significa que o PSO com função de aptidão DB e representação de protótipos baseada em medóides obteve melhores resultados do que o FCM em 17 situações e piores em 13 situações, não empatando em nenhuma.

Tabela 5.3: Tabela de vitórias/empates/derrotas das variações listadas na primeira coluna, em relação àquelas listadas na primeira linha.

\begin{tabular}{|c|c|c|c|c|c|c|c|c|c|c|c|}
\hline & FCM & PSO/DB (M) & $\mathrm{PSO} / \mathrm{DB}(\mathrm{C})$ & PSO/Rec (M) & $\mathrm{PSO} / \operatorname{Rec}(\mathrm{C})$ & PSO/VRC (M) & PSO/VRC (C) & PSO/Silh (M) & PSO/Silh (C) & PSO/XB (M) & $\mathrm{PSO} / \mathrm{XB}(\mathrm{C})$ \\
\hline FCM & ב- & 13/0/17 & $12 / 0 / 18$ & $111 / 0 / 19$ & $5 / 0 / 25$ & $14 / 0 / 16$ & $10 / 0 / 20$ & $9 / 0 / 21$ & $7 / 0 / 23$ & $15 / 0 / 15$ & $14 / 0 / 16$ \\
\hline $\mathrm{PSO} / \mathrm{DB}(\mathrm{M})$ & $17 / 0 / 13$ & - & $14 / 0 / 16$ & $16 / 0 / 14$ & $13 / 0 / 17$ & $15 / 0 / 15$ & $17 / 0 / 13$ & $2 / 0 / 28$ & $6 / 0 / 24$ & $20 / 0 / 10$ & $20 / 0 / 10$ \\
\hline $\mathrm{PSO} / \mathrm{DB}(\mathrm{C})$ & $18 / 0 / 12$ & $16 / 0 / 14$ & - & $12 / 0 / 18$ & $13 / 0 / 17$ & $21 / 0 / 9$ & $21 / 0 / 9$ & $3 / 0 / 27$ & $4 / 0 / 26$ & $20 / 0 / 10$ & $18 / 0 / 12$ \\
\hline $\mathrm{PSO} / \operatorname{Rec}(\mathrm{M})$ & $19 / 0 / 11$ & $14 / 0 / 16$ & $18 / 0 / 12$ & - & $12 / 0 / 18$ & $20 / 0 / 10$ & $17 / 0 / 13$ & $6 / 0 / 24$ & $6 / 0 / 24$ & $17 / 0 / 13$ & $16 / 0 / 14$ \\
\hline $\mathrm{PSO} / \operatorname{Rec}(\mathrm{C})$ & $25 / 0 / 5$ & $17 / 0 / 13$ & $17 / 0 / 13$ & $18 / 0 / 12$ & - & $17 / 0 / 13$ & $20 / 0 / 10$ & $10 / 0 / 20$ & $8 / 0 / 22$ & $18 / 0 / 12$ & $17 / 0 / 13$ \\
\hline PSO/VRC (M) & $16 / 0 / 14$ & $15 / 0 / 15$ & $9 / 0 / 21$ & $10 / 0 / 20$ & $13 / 0 / 17$ & - & $12 / 0 / 18$ & $2 / 0 / 28$ & $4 / 0 / 26$ & $18 / 0 / 12$ & $13 / 0 / 17$ \\
\hline $\mathrm{PSO} / \mathrm{VRC}(\mathrm{C})$ & $20 / 0 / 10$ & $13 / 0 / 17$ & $9 / 0 / 21$ & $13 / 0 / 17$ & $10 / 0 / 20$ & $18 / 0 / 12$ & - & $3 / 0 / 27$ & $3 / 0 / 27$ & $17 / 0 / 13$ & $18 / 0 / 12$ \\
\hline $\mathrm{PSO} / \mathrm{s}$ & $21 / 0 / 9$ & $3 / 0 / 2$ & $27 / 0 / 3$ & $24 / 0 / 6$ & $20 / 0 / 10$ & $28 / 0 / 2$ & $27 / 0 / 3$ & - & $19 / 0 / 11$ & $27 / 0 / 3$ & $26 / 0 / 4$ \\
\hline $\mathrm{PSO} / \mathrm{Silh}(\mathrm{C})$ & $23 / 0 / 7$ & $24 / 0 / 6$ & $26 / 0 / 4$ & $24 / 0 / 6$ & $22 / 0 / 8$ & $26 / 0 / 4$ & $27 / 0 / 3$ & $11 / 0 / 19$ & - & $26 / 0 / 4$ & $25 / 0 / 5$ \\
\hline $\mathrm{PSO} / \mathrm{XB}(\mathrm{M})$ & $15 / 0 / 15$ & $10 / 0 / 20$ & $10 / 0 / 20$ & $13 / 0 / 17$ & $12 / 0 / 18$ & $12 / 0 / 18$ & $13 / 0 / 17$ & $3 / 0 / 27$ & $4 / 0 / 26$ & - & $13 / 0 / 17$ \\
\hline $\mathrm{PSO} / \mathrm{XB}(\mathrm{C})$ & $16 / 0 / 14$ & $10 / 0 / 20$ & $12 / 0 / 18$ & $14 / 0 / 16$ & $13 / 0 / 17$ & $17 / 0 / 13$ & $12 / 0 / 18$ & $4 / 0 / 26$ & $5 / 0 / 25$ & $17 / 0 / 13$ & - \\
\hline
\end{tabular}

Testes estatísticos foram aplicados aos resultados seguindo a abordagem proposta em Demšar (2006). Mais especificamente, o teste de Friedman é aplicado para testar a hipótese nula de que os algoritmos em avaliação possuem desempenho semelhante. Se esta hipótese for rejeitada, o teste post-hoc de Nemenyi é empregado para comparar os algoritmos par-a-par. Foram considerados dois valores para grau de confiança, 90\% e 95\%, ou seja, $\alpha=10 \%$ e $\alpha=5 \%$, respectivamente. Os resultados são exibidos na Tabela 5.4 onde cada célula representa se houve diferença estatisticamente significante entre os dois algoritmos, por exemplo, o símbolo “*” na segunda linha da nona coluna, indica que o PSO com aptidão por Silhueta e representação de protótipo baseada em medóides obteve melhores resultados do que o algoritmo FCM com significância estatística de 95\%.

Tabela 5.4: Resultados dos testes estatísticos de Friedman e Nemenyi (“+” significa diferença estatística 90\% e “*” 95\%).

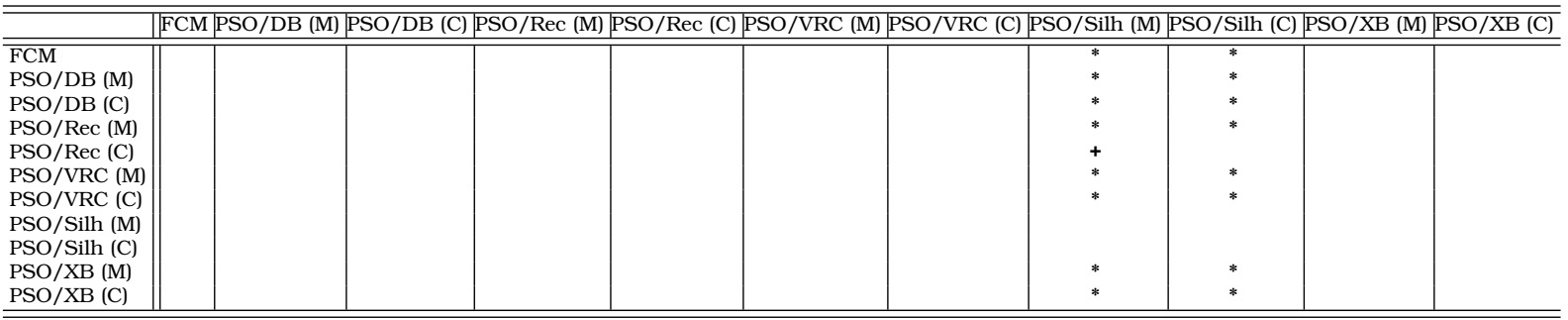




\subsection{Agrupamento de dados semi-supervisionado}

Nesta seção, são apresentados os resultados experimentais das abordagens de $\mathrm{AD}$ semi-supervisionado propostas, SSL+P e SSL+P*, descritas na Seção 4.3. Resumidamente, as abordagens propostas são técnicas de $\mathrm{AD}$ fuzzy que têm por objetivo utilizar conhecimento prévio sobre os dados em duas formas diferentes: rótulos e graus de proximidade entre exemplos. A técnica SSL+P necessita que seja informado o número de clusters contidos em cada classe. Já a técnica SSL+P* foi proposta para resolver esta limitação. A seguir, serão apresentadas as bases de dados, a metodologia para realização dos experimentos e os resultados gerados.

\subsubsection{Bases de dados}

Para avaliar a performance dos algoritmos de $\mathrm{AD}$ semi-supervisionado propostos, 5 bases de dados foram utilizadas, sendo 3 sintéticas e 2 obtidas do repositório UCI (Newman et al., 1998): Íris e Wine. Dentre as bases sintéticas, uma trata-se da base Sintética-1, utilizada nos experimentos reportados na Seção 5.2. As demais bases sintéticas foram criadas da seguinte forma:

1. Sintética-3: esta base foi criada com o objetivo de reproduzir duas características específicas, conter clusters de formatos diversos e apresentar classes contendo mais de um cluster. Para isso, a base foi gerada com distribuição Gaussiana multivariada com 3 clusters, cada um com 100 exemplos, com os valores de centróide e covariância exibidos a seguir:

$$
\begin{gathered}
v_{1}=\left[\begin{array}{ll}
4 & 5
\end{array}\right], \\
v_{2}=\left[\begin{array}{ll}
2 & -2
\end{array}\right], \\
G_{1}=\left[\begin{array}{ll}
2.00 & 0.44 \\
0.44 & 2.00
\end{array}\right], G_{2}=\left[\begin{array}{ll}
2.00 & 1.77 \\
1.77 & 2.00
\end{array}\right], G_{3}=\left[\begin{array}{cc}
10.00 & -0.33 \\
-0.33 & 1.00
\end{array}\right]
\end{gathered}
$$

Essa base contém duas classes, sendo a primeira delas formada pelos dois primeiros clusters e a segunda contendo apenas o terceiro cluster. A essa base está associada uma matriz $F=\left[f_{h k}\right]$, contendo a estrutura original de classes da base de dados, criada da seguinte forma: primeiro é gerada a matriz $U=\left[u_{i k}\right]$ de acordo com a Equação (2.4). Para o cálculo das distâncias entre centróides e exemplos de dados, são utilizadas as matrizes $A_{i}$ calculadas com base nas matrizes de covariância $G_{i}$ de acordo com Bouchachia e Pedrycz (2006a):

$$
A_{i}=\rho_{i}\left(\operatorname{det}\left(G_{i}\right)\right)^{1 / D} G_{i}^{-1}
$$


onde $\rho_{i}$ é o parâmetro que restringe o volume dos clusters. Sendo assim, $f_{h k}=\sum_{i \in \pi_{h}} u_{i k}$ onde $\pi_{h}$ é o conjunto de clusters pertencentes à classe h. A matriz $F$ é utilizada para produção das DCPs, ou seja, rótulos e proximidade de pares de exemplos e, também, como critério externo de avaliação dos algoritmos de agrupamento. O procedimento de produção de dicas é explicado na Seção 5.3.2.

2. Sintética-4: Essa base foi inicialmente gerada no espaço de 4 dimensões, com distribuição gaussiana multivariada, contendo 3 clusters com 50 exemplos cada. Os valores para os centróides e covariância utilizados foram:

$$
\begin{aligned}
v_{1}=\left[\begin{array}{llll}
0.20 & 0.80 & 0.50 & 0.40
\end{array}\right], G_{1}=\left[\begin{array}{llll}
0.010 & 0.000 & 0.000 & 0.000 \\
0.000 & 0.025 & 0.000 & 0.000 \\
0.000 & 0.000 & 0.001 & 0.000 \\
0.000 & 0.000 & 0.000 & 0.002
\end{array}\right] \\
v_{2}=\left[\begin{array}{llll}
0.20 & 0.40 & 0.70 & 0.60
\end{array}\right], G_{2}=\left[\begin{array}{llll}
0.021 & 0.000 & 0.000 & 0.000 \\
0.000 & 0.017 & 0.000 & 0.000 \\
0.000 & 0.000 & 0.006 & 0.000 \\
0.000 & 0.000 & 0.000 & 0.007
\end{array}\right] \\
v_{3}=\left[\begin{array}{llllll}
0.60 & 0.30 & 0.20 & 0.20
\end{array}\right], G_{3}=\left[\begin{array}{llll}
0.031 & 0.000 & 0.000 & 0.000 \\
0.000 & 0.018 & 0.000 & 0.000 \\
0.000 & 0.000 & 0.009 & 0.000 \\
0.000 & 0.000 & 0.000 & 0.013
\end{array}\right]
\end{aligned}
$$

A base contém 3 classes, cada uma formada por um cluster. A matriz $F=\left[f_{h k}\right]$ foi gerada da mesma maneira como explicado para a base Sintética-3. Depois de gerada a matriz $F$, com os dados no espaço dimensional original, o segundo e terceiro atributos foram excluídos, resultando em uma nova base. Essa nova base de dados permite avaliar a capacidade do algoritmo de $\mathrm{AD}$ semi-supervisionado de compensar a falta de um ou mais atributos. Ela proporciona uma situação hipotética em que as DCPs são obtidas de uma fonte que possui informações sobre a base, mas essas informações ainda não foram incorporadas nos dados.

As bases Sintética-3 e Sintética-4 estão ilustradas na Figura 5.7. Na Tabela 5.5, pode ser visto um resumo das princpais características de cada uma das bases utilizadas.

Apenas as bases sintéticas foram utilizadas para avaliar as técnicas que necessitam que o número de clusters por classe seja informado. Para avaliar as técnicas que estimam estes valores, foram utilizadas as bases Íris, Wine, Sintética-3 e Sintética-4. 


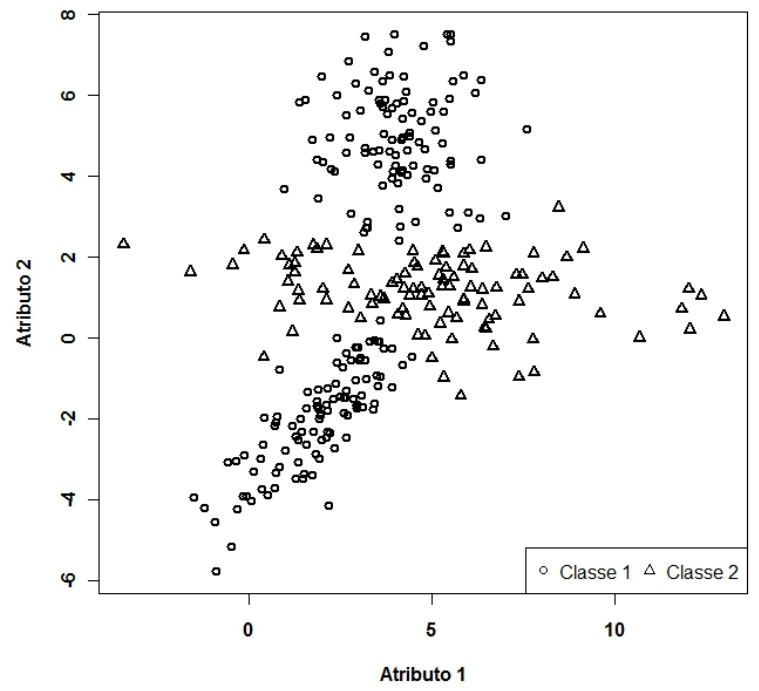

(a) Base sintética 3 .

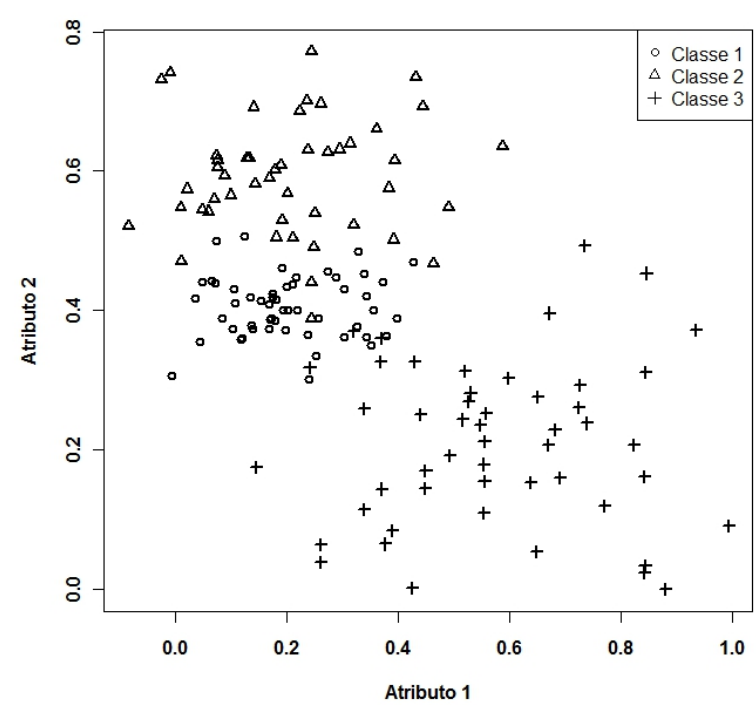

(b) Base sintética 4 .

Figura 5.7: Gráficos das bases de dados Sintética-3 e Sintética-4.

Tabela 5.5: Principais características das bases de dados utilizadas.

\begin{tabular}{l||c|c|c|c|c}
\hline \hline Base & Íris & Wine & Sintética-1 & Sintética-3 & Sintética-4 \\
\hline \hline No. de classes & 3 & 7 & 3 & 2 & 3 \\
\hline No. de clusters por classe & - & - & $(1,1,1)$ & $(2,1)$ & $(1,1,1)$ \\
\hline No. de atributos & 4 & 13 & 3 & 2 & 2 \\
\hline No. de exemplos & 150 & 178 & 150 & 300 & 150 \\
\hline \hline
\end{tabular}

\subsubsection{Metodologia}

As abordagens propostas para $\mathrm{AD}$ semi-supervisionado foram comparadas com 3 técnicas bastante referenciadas na literatura: o SEEDED- $k$-médias e CONSTRAINED- $k$-médias, propostas por Basu et al. (2002) e descritas na Seção 2.3, e a técnica desenvolvida por Bouchachia e Pedrycz (2003), também apresentada na Seção 2.3.

As DCPs utilizadas nos experimentos foram produzidas de duas formas:

- Proximidade baseada nos rótulos disponíveis: utilizada para permitir uma comparação "justa” entre os algoritmos propostos e os algoritmos encontrados na literatura, já que os últimos utilizam conhecimento prévio apenas na forma de rótulos. São selecionados aleatoriamente $R$ exemplos da base de dados, cujos rótulos, ou seja, valores de pertinência a cada classe armazenados na matriz $F=\left[f_{h k}\right]$, são fornecidos aos algoritmos. Com base nesses rótulos, é calculada a proximidade entre todas as combinações de pares dos $R$ exemplos, de acordo com a Equação 
(2.15). Esses valores de proximidade são fornecidos aos algoritmos propostos. Assim, os algoritmos propostos recebem a mesma informação fornecida aos algoritmos de comparação.

- Aleatória: são selecionados aleatoriamente $R$ exemplos da base de dados e $R$ pares de exemplos. Os rótulos dos $R$ exemplos selecionados e os graus de proximidade dos $R$ pares selecionados, armazenados na matriz $P=\left[p_{k_{1} k_{2}}\right]$, são fornecidos aos algoritmos propostos. Esta forma de produzir as dicas simula a situação em que existe conhecimento prévio adicional, na forma de proximidade de pares de exemplos.

Dois valores para $R$ foram considerados: aproximadamente $0.1 \times N$ e $0.5 \times N$, onde $N$ é o número de exemplos na base de dados. Quanto ao algoritmo de otimização, foi utilizada a mesma versão do PSO descrita na Seção 5.2.2, com as mesmas configurações.

As três técnicas utilizadas para comparação necessitam que seja informado o número de clusters. A técnica proposta por Bouchachia e Pedrycz (2003) permite que cada classe contenha mais de um cluster. Assim, para as bases sintéticas, são utilizados os valores de número de clusters por classe originais; para a base Wine são considerados 2 clusters para a primeira classe e um cluster para cada uma das demais, de acordo com Bouchachia e Pedrycz (2006a); e para a base Íris é considerado um cluster por classe, como é frequentemente utilizado na literatura para esta base. As técnicas SEEDED- $k$-médias e CONSTRAINED- $k$-médias consideram a existência de um cluster para cada classe, tanto pela natureza das técnicas, quanto por essa ser uma convenção utilizada por seus autores para experimentos com $\mathrm{AD}$ com bases do repositório UCI, como pode ser visto em Basu e Mooney (2003). Um resumo dos números de clusters utilizados para cada base de dados pode ser visto na Tabela 5.6.

Tabela 5.6: Números de clusters empregados para cada base de dados.

\begin{tabular}{l||c|c|c|c|c}
\hline \hline Base & Íris & Wine & Sintética-1 & Sintética-3 & Sintética-4 \\
\hline \hline SSL+P & - & - & $(1,1,1)$ & $(2,1)$ & $(1,1,1)$ \\
\hline SSL+P* & estimado & estimado & estimado & estimado & estimado \\
\hline Bouchachia e Pedrycz & $(1,1,1)$ & $(2,1,1)$ & $(1,1,1)$ & $(2,1)$ & $(1,1,1)$ \\
\hline SEEDED- $k$-médias & 3 & 4 & 3 & 2 & 3 \\
\hline CONSTRAINED- $k$-médias & 3 & 4 & 3 & 2 & 3 \\
\hline \hline
\end{tabular}

A avaliação dos resultados é realizada no contexto de classificação de dados. O desempenho de classificação mede o quanto um classificador atribui corretamente os exemplos do conjunto de dados às suas respectivas classes. Nesse caso, a atribuição será correta se o exemplo pertencer a um dos clusters 
da classe correta. Em seguida, para cada exemplo $k$, é determinado o cluster $i$ para o qual o grau de pertinência é maior. A classe será, então, a classe $h$ à qual pertence o cluster $i$ e será comparada com a classe à qual o exemplo $k$ pertence originalmente. Os resultados são quantificados quanto à proporção dos exemplos que foram atribuídos a uma classe incorreta. No caso dos algoritmos SSL+P, SSL+P* e do algoritmo proposto por Bouchachia e Pedrycz (2003), a matriz $\Gamma=\left[\gamma_{h k}\right]$ resultante é binarizada de forma a informar a qual classe cada exemplo foi atribuído. Os rótulos originais são utilizados para calcular o erro de classificação, ou seja, a proporção dos exemplos rotulados incorretamente. Os algoritmos de $\mathrm{AD}$ propostos que estimam o número de clusters também são avaliados quanto ao número de clusters resultante. Para os experimentos com a técnica $\mathrm{SSL}+\mathrm{P}^{*}$, foi definido um número máximo de clusters igual a $\sqrt{N}$, de acordo com Pal e Bezdek (1995).

Quanto aos parâmetros $\alpha$ e $\beta$, foi verificada uma faixa de valores entre 0 e 1.2 para cada um dos parâmetros. Quando $\alpha=0$ e $\beta>0$, apenas dicas sobre o nível de proximidade entre exemplos são consideradas. Em contrapartida, se $\alpha>0$ e $\beta=0$, o algoritmo emprega apenas os rótulos disponíveis. Os algoritmos foram executados 5 vezes para se obter a média dos resultados. Dessa forma, é possível verificar o desempenho dos algoritmos na presença de apenas um dos dois tipos de conhecimento prévio.

\subsubsection{Resultados}

A seguir serão apresentados os resultados dos experimentos comparando a técnica SSL+P e suas variações de métrica de distância e função não-supervisionada $(N S)$ com as técnicas propostas por Basu et al. (2002) e Bouchachia e Pedrycz (2003). Os resultados são apresentados em gráficos de niveis de cor, porém, as tabelas com os valores são exibidas no Apêndice A.

A Figura 5.8 exibe os resultados medidos de acordo com o Erro de classificação para a base Sintética-1. Com esta base, as variações do algoritmo SSL+P e os algoritmos de comparação alcançaram valores de Erro de Classificação próximos de 0 , independente da quantidade de DCPs e da forma com que elas foram produzidas. A técnica SSL+P utilizando a função objetivo do algoritmo FCM e as distâncias adaptativas, diagonal e completa, se mostrou bastante sensível à variação dos parâmetros $\alpha$ e $\beta$, principalmente com uma menor quantidade de DCPs $(0.1 N)$, alcançando os melhores resultados com valores altos para estes parâmetros. O contrário ocorreu com as demais variações do algoritmo, que alcançaram o mesmo resultado, independente do valor de $\alpha$ e $\beta$.

A Figura 5.9 exibe os resultados medidos de acordo com o Erro de Classificação para a base Sintética-3. Para esta base de dados os melhores 


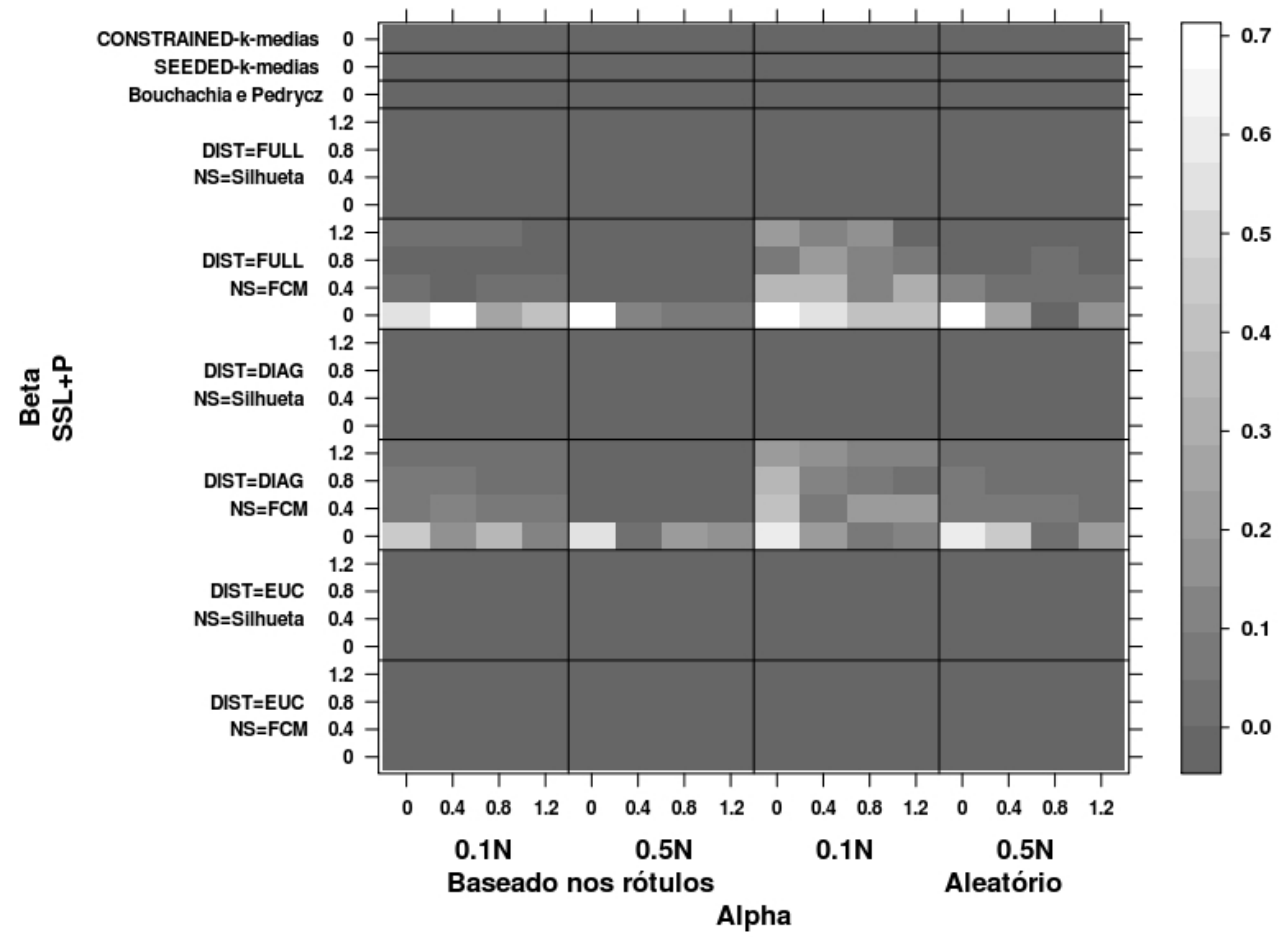

Figura 5.8: Gráfico do Erro de Classificação para a base Sintética-1 com a técnica $\mathrm{SSL}+\mathrm{P}$ em função dos valores de $\alpha$ e $\beta$ para as variações de métrica de distância (euclidiana (EUC), euclidiana ponderada (DIAG) e completamente adaptativa (FULL)), função não-supervisionada $(N S)$, quantidades de dicas $(0.1 N$ e $0.5 N)$ e forma de produção das dicas, em comparação com as técnicas propostas por Basu et al. (2002) e Bouchachia e Pedrycz (2003).

resultados foram alcançados pelo $\mathrm{SSL}+\mathrm{P}$ com as distâncias adaptativas (diagonal e completa), o que é natural, pois esta base é formada por clusters de formatos diversos. Valores altos para o parâmetro $\alpha$ também colaboram para melhores resultados. Aparentemente, a quantidade de DCPs não influenciou nos resultados. Um fato curioso ocorreu com estes resultados: nos experimentos realizados com as DCPs cujos valores de proximidade são baseados nos rótulos, o desempenho do SSL+P é melhor quando $\beta=0$, ou seja, quando os valores de proximidade não são levados em consideração. Isso não acontece quando são empregadas DCPs de proximidade selecionadas aleatoriamente, porém o resultado permanece inalterado.

A Figura 5.10 exibe os resultados medidos de acordo com o Erro de Classificação para a base Sintética-4. Com esta base, todas as técnicas alcançaram um valor de Erro de Classificação próximo a 0.1 , exceto o algoritmo CONSTRAINED- $k$-médias, que atingiu um Erro próximo de 0.05 com quantidade de DCPs igual a $0.5 \mathrm{~N}$ e do algoritmo proposto por Bouchachia e Pedrycz (2003) que resultou nos piores resultados. O desempenho do SSL+P não foi influenciado pela variação de valores de $\alpha$ e $\beta$ e de quantidade de DCPs.

Seguindo a modo de exibição da Tabela 5.3, as Tabelas 5.7 e 5.8 contêm o número de vitórias, empates e derrotas das técnicas listadas na primeira 


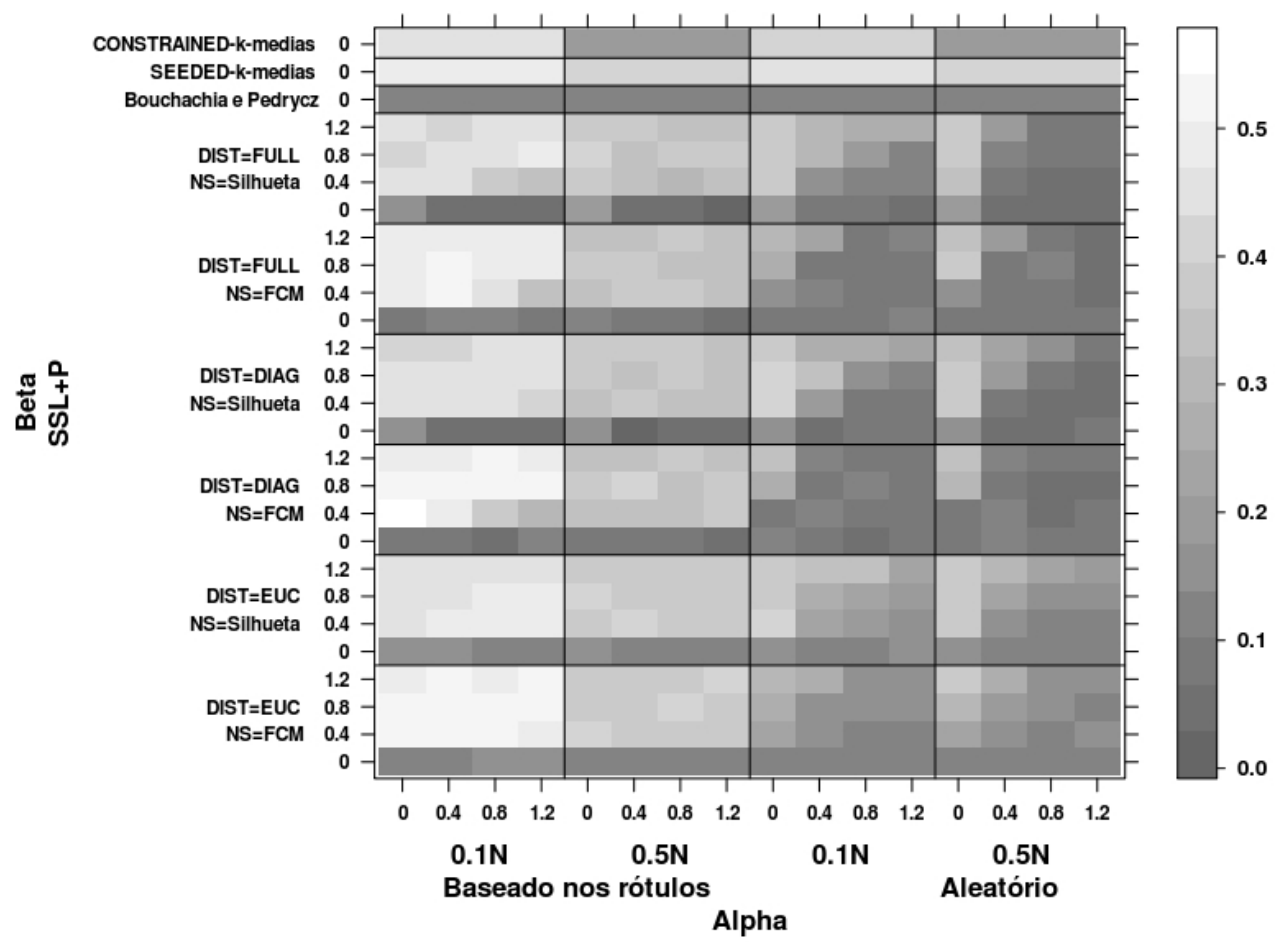

Figura 5.9: Gráfico do Erro de Classificação para a base Sintética-3 com a técnica SSL+P em função dos valores de $\alpha$ e $\beta$ para as variações de métrica de distância (euclidiana (EUC), euclidiana ponderada (DIAG) e completamente adaptativa (FULL)), função não-supervisionada $(N S)$, quantidades de dicas $(0.1 N$ e $0.5 N)$ e forma de produção das dicas, em comparação com as técnicas propostas por Basu et al. (2002) e Bouchachia e Pedrycz (2003).

coluna, em comparação com as técnicas listadas na primeira linha para o emprego de dicas deduzidas e aleatórias, respectivamente. As técnicas são comparadas em 96 situações: 3 bases de dados $\times 16$ variações dos parâmetros $\alpha$ e $\beta \times 2$ quantidades de dicas.

Tabela 5.7: Tabela de vitórias/empates/derrotas das técnicas listadas na primeira coluna, em relação àquelas listadas na primeira linha comparando as técnicas de referência e as variações do SSL+P utilizando de dicas deduzidas.

\begin{tabular}{|c|c|c|c|c|c|c|c|c|c|}
\hline & $\begin{array}{l}\text { NS = FCM } \\
\text { Dist. = Euc. }\end{array}$ & & & & $\begin{aligned} \text { NS } & =\text { Sil } \\
\text { Dist. } & =\text { Di }\end{aligned}$ & $\begin{array}{l}\text { NS = Silh. } \\
\text { Dist. = Full }\end{array}$ & \begin{tabular}{c|c} 
CONST. \\
k-médias
\end{tabular} & $\begin{array}{l}\text { SEEDED } \\
\text { k-médias }\end{array}$ & $\begin{array}{l}\text { Bouchachia } \\
\text { \& Pedrycz }\end{array}$ \\
\hline$\overline{V S}=r$ & & $43 / 18 / 35$ & $45 / 20 / 31$ & $27 / 36 / 33$ & $24 / 34 / 38$ & $29 / 34 / 33$ & $24 / 32 / 40$ & $8 / 13$ & $32 / 32 / 32$ \\
\hline & & & $46 / 1$ & & & & & & \\
\hline & & & - & $30 / 18 / 48$ & & & & & \\
\hline & & & $48 / 18 / 30$ & - & $17 / 36 / 43$ & 27 & & & \\
\hline & & & & & - & $36 / 37 / 2$ & & & \\
\hline & & & & & $23 / 3$ & - & $15 / 33 / 48$ & 50 & \\
\hline & & & & & & & & $64 / 32 / 0$ & \\
\hline & & & & & & & $0 / 32 / 64$ & - & $/ 32 / 32$ \\
\hline Bouchachia \& Pedrycz & $32 / 32 / 32$ & $44 / 12 / 40$ & $38 / 18 / 40$ & $34 / 32 / 30$ & $28 / 32 / 36$ & $28 / 32 / 36$ & $32 / 32 / 32$ & $32 / 32 / 32$ & - \\
\hline
\end{tabular}

Aplicando os testes de Friedman e Nemenyi com significância estatística de 90\% e 95\% obtem-se o resultado mostrado nas Tabelas 5.9 e 5.10, seguindo a forma de exibição da Tabela 5.4.

A seguir, serão apresentados os resultados dos experimentos com a técnica SSL+P*, aplicada às bases de dados Sintética-3, Sintética-4, Íris e Wine. 


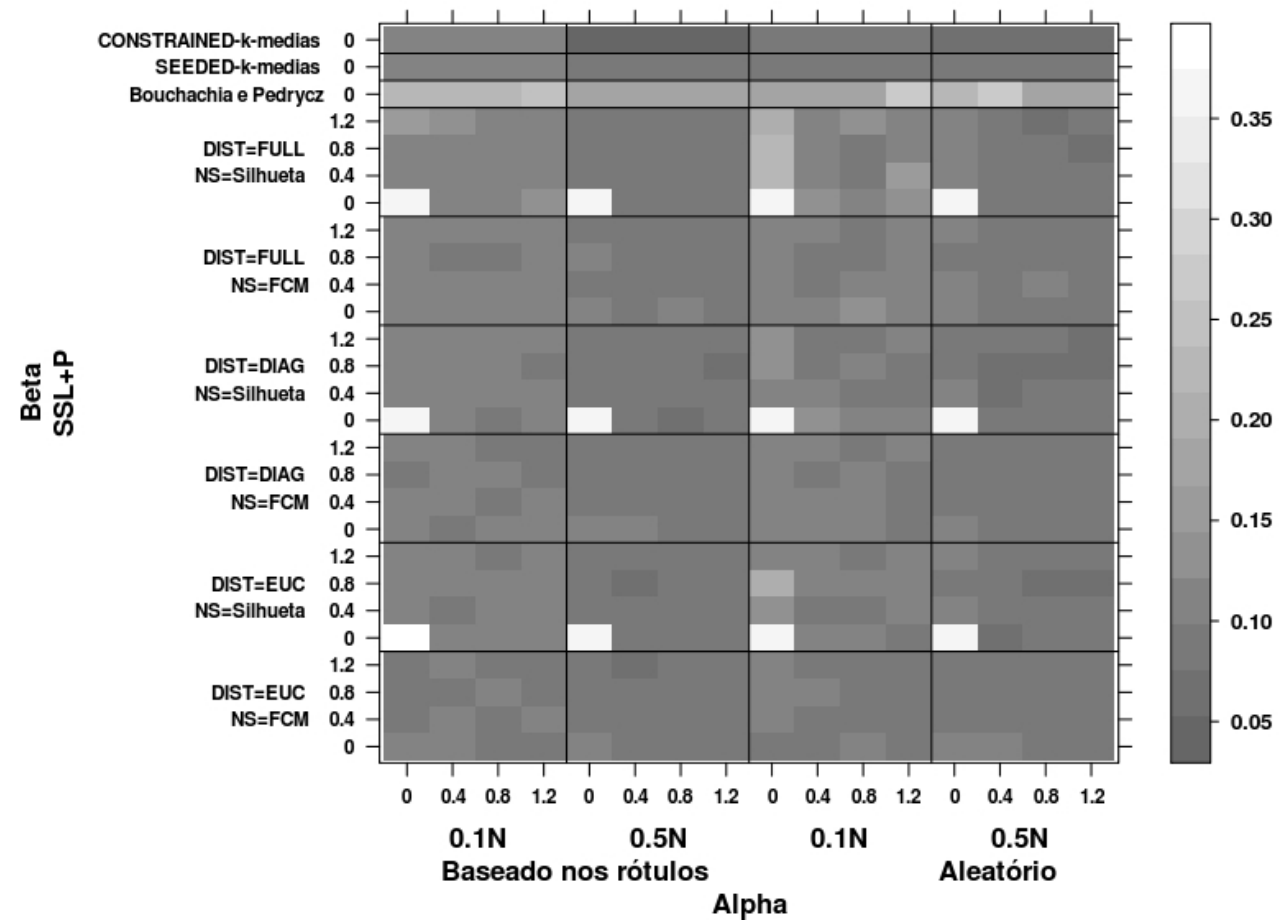

Figura 5.10: Gráfico do Erro de Classificação para a base Sintética-4 com a técnica $\mathrm{SSL}+\mathrm{P}$ em função dos valores de $\alpha$ e $\beta$ para as variações de métrica de distância (euclidiana (EUC), euclidiana ponderada (DIAG) e completamente adaptativa (FULL)), função não-supervisionada $(N S)$, quantidades de dicas $(0.1 N$ e $0.5 N)$ e forma de produção das dicas, em comparação com as técnicas propostas por Basu et al. (2002) e Bouchachia e Pedrycz (2003).

Tabela 5.8: Tabela de vitórias/empates/derrotas das técnicas listadas na primeira coluna, em relação àquelas listadas na primeira linha comparando as técnicas de referência e as variações do SSL+P utilizando de dicas aleatórias.

\begin{tabular}{|c|c|c|c|c|c|c|c|c|c|}
\hline & $\begin{array}{l}\text { NS = FCM } \\
\text { Dist. = Euc. }\end{array}$ & $\begin{array}{l}\text { NS }=\text { FCM } \\
\text { Dist. }=\text { Diag. }\end{array}$ & $\begin{array}{l}\text { NS = FCM } \\
\text { Dist. = Full }\end{array}$ & $\begin{array}{l}\text { NS = Silh. } \\
\text { Dist. = Euc. }\end{array}$ & $\begin{array}{l}\text { NS }=\text { Silh. } \\
\text { Dist. }=\text { Diag. }\end{array}$ & $\begin{array}{l}\text { NS = Silh. } \\
\text { Dist.= Full }\end{array}$ & \begin{tabular}{c|c} 
CONST. \\
k-médias \\
\end{tabular} & \begin{tabular}{|l|} 
SEEDED \\
k-médias
\end{tabular} & $\begin{array}{l}\text { Bouchachia } \\
\text { \& Pedrycz }\end{array}$ \\
\hline NS = FCM, Dist. $=$ Euc. & & $49 / 6 / 41$ & $47 / 13 / 36$ & $44 / 32 / 20$ & $26 / 33 / 37$ & $33 / 34 / 29$ & $28 / 32 / 36$ & $46 / 33 / 17$ & $32 / 32 / 32$ \\
\hline NS $=$ FCM Dist. $=$ Diag. & $41 / 6 / 49$ & - & $50 / 2 / 44$ & $48 / 0 / 48$ & $31 / 1 / 64$ & $41 / 2 / 53$ & $30 / 0 / 66$ & $41 / 1 / 54$ & $60 / 0 / 36$ \\
\hline NS $=$ FCM, Dist. $=$ Full & $36 / 13 / 47$ & $44 / 2 / 50$ & - & $42 / 10 / 44$ & $31 / 9 / 56$ & $41 / 9 / 46$ & $30 / 9 / 57$ & $37 / 10 / 49$ & $56 / 9 / 31$ \\
\hline NS $=$ Silh., Dist. $=$ Euc. & $20 / 32 / 44$ & $48 / 0 / 48$ & $44 / 10 / 42$ & - & $15 / 35 / 46$ & $30 / 33 / 33$ & $26 / 32 / 38$ & $46 / 33 / 17$ & $30 / 33 / 33$ \\
\hline NS $=$ Silh., Dist. $=$ Diag. & $37 / 33 / 26$ & $64 / 1 / 31$ & $56 / 9 / 31$ & $46 / 35 / 15$ & & $43 / 32 / 21$ & $28 / 32 / 36$ & $47 / 33 / 16$ & $44 / 32 / 20$ \\
\hline NS $=$ Silh., Dist. $=$ Full & $29 / 34 / 33$ & $53 / 2 / 41$ & $46 / 9 / 41$ & $33 / 33 / 30$ & $21 / 32 / 43$ & - & $28 / 32 / 36$ & $45 / 32 / 19$ & $41 / 32 / 23$ \\
\hline CONST. k-médias & $36 / 32 / 28$ & $66 / 0 / 30$ & $57 / 9 / 30$ & $38 / 32 / 26$ & $36 / 32 / 28$ & $36 / 32 / 28$ & - & $64 / 32 / 0$ & $32 / 32 / 32$ \\
\hline SEEDED k-médias & $17 / 33 / 46$ & $54 / 1 / 41$ & $49 / 10 / 37$ & $17 / 33 / 46$ & $16 / 33 / 47$ & $19 / 32 / 45$ & $0 / 32 / 64$ & - & $32 / 32 / 32$ \\
\hline Bouchachia \& Pedrycz & $32 / 32 / 32$ & $36 / 0 / 60$ & $31 / 9 / 56$ & $33 / 33 / 30$ & $20 / 32 / 44$ & $23 / 32 / 41$ & $32 / 32 / 32$ & $32 / 32 / 32$ & - \\
\hline
\end{tabular}

Tabela 5.9: Testes estatísticos de Friedman e Nemenyi dos resultados das técnicas de referência e das variações do SSL+P utilizando de dicas deduzidas. ("+" significa diferença estatística 90\% e “*” 95\%).

\begin{tabular}{|c|c|c|c|c|c|c|c|c|c|}
\hline & $\begin{array}{l}\text { NS = FCM } \\
\text { Dist. = Euc. }\end{array}$ & $\begin{array}{c}\text { NS }=\text { FCM } \\
\text { Dist. }=\text { Diag. }\end{array}$ & $\begin{array}{l}\mathrm{NS}=\mathrm{FCM} \\
\text { Dist. = Full }\end{array}$ & $\begin{array}{l}\text { NS = Silh. } \\
\text { Dist. = Euc. }\end{array}$ & $\begin{array}{l}\text { NS }=\text { Silh. } \\
\text { Dist. }=\text { Diag. }\end{array}$ & $\begin{array}{l}\text { NS = Silh. } \\
\text { Dist. = Full }\end{array}$ & $\begin{array}{l}\text { CONST. } \\
\text { k-médias }\end{array}$ & $\begin{array}{l}\text { SEEDED } \\
\mathrm{k} \text {-médias }\end{array}$ & $\begin{array}{l}\text { Bouchachia } \\
\text { \& Pedrycz }\end{array}$ \\
\hline $\begin{array}{l}\text { NS = FCM, Dist. = Euc. } \\
\text { NS = FCM, Dist. = Diag. } \\
\text { NS = FCM, Dist. = Full } \\
\text { NS = Silh., Dist. = Euc. } \\
\text { NS = Silh., Dist. }=\text { Diag. } \\
\text { NS = Silh., Dist. }=\text { Full } \\
\text { CONST. k-médias } \\
\text { SEEDED k-médias } \\
\text { Bouchachia \& Pedrycz }\end{array}$ & $*$ & & & $*$ & $\begin{array}{l}+ \\
*\end{array}$ & $*$ & $\begin{array}{l}* \\
*\end{array}$ & & $*$ \\
\hline
\end{tabular}


Tabela 5.10: Testes estatísticos de Friedman e Nemenyi dos resultados das técnicas de referência e das variações do SSL+P utilizando de dicas aleatórias ("+" significa diferença estatística 90\% e “*” 95\%).

\begin{tabular}{|c|c|c|c|c|c|c|}
\hline & \begin{tabular}{||l|l|} 
NS $=$ FCM & NS $=$ FCM \\
Dist. $=$ Euc. & Dist. = Diag \\
\end{tabular} & \begin{tabular}{l|l} 
NS = FCM & NS = Silh. \\
Dist.= Full & Dist.= Euc \\
\end{tabular} & $\begin{array}{l}\text { NS }=\text { Silh. } \\
\text { Dist. }=\text { Diag }\end{array}$ & \begin{tabular}{l|l} 
NS = Silh. & CONST. \\
Dist.= Full & k-médias \\
\end{tabular} & \begin{tabular}{|l|}
$\begin{array}{l}\text { SEEDED } \\
\text { k-médias }\end{array}$ \\
\end{tabular} & $\begin{array}{l}\text { Bouchachia } \\
\text { \& Pedrycz }\end{array}$ \\
\hline $\begin{array}{l}\text { NS = FCM, Dist.= Euc. } \\
\text { NS = FCM, Dist. = Diag. } \\
\text { NS = FCM, Dist. = Full } \\
\text { NS = Silh., Dist. = Euc. } \\
\text { NS = Silh., Dist. = Diag. } \\
\text { NS = Silh., Dist. }=\text { Full } \\
\text { CONST. k-médias } \\
\text { SEEDED k-médias } \\
\text { Bouchachia \& Pedrycz }\end{array}$ & & & $\begin{array}{l}* \\
+\end{array}$ & + & & \\
\hline
\end{tabular}

A Figura 5.11 exibe os resultados da técnica SSL+P* medidos de acordo com o Erro de Classificação para a base Sintética-4. Estes resultados apresentam uma situação semelhante àquela observada na Figura 5.10. O algoritmo CONSTRAINED- $k$-médias alcançou os melhores resultados com $0.5 N$ de DCPs. Nesses resultados, é possível ver claramente o impacto da utilização de uma maior quantidade de DCPs. Já, a forma de produção das DCPs e as variações de $\alpha$ e $\beta$ não influenciaram muito os resultados. É também interessante observar que o emprego de distância adaptativa tende a diminuir a sensibilidade à variação dos parâmetros $\alpha$ e $\beta$.

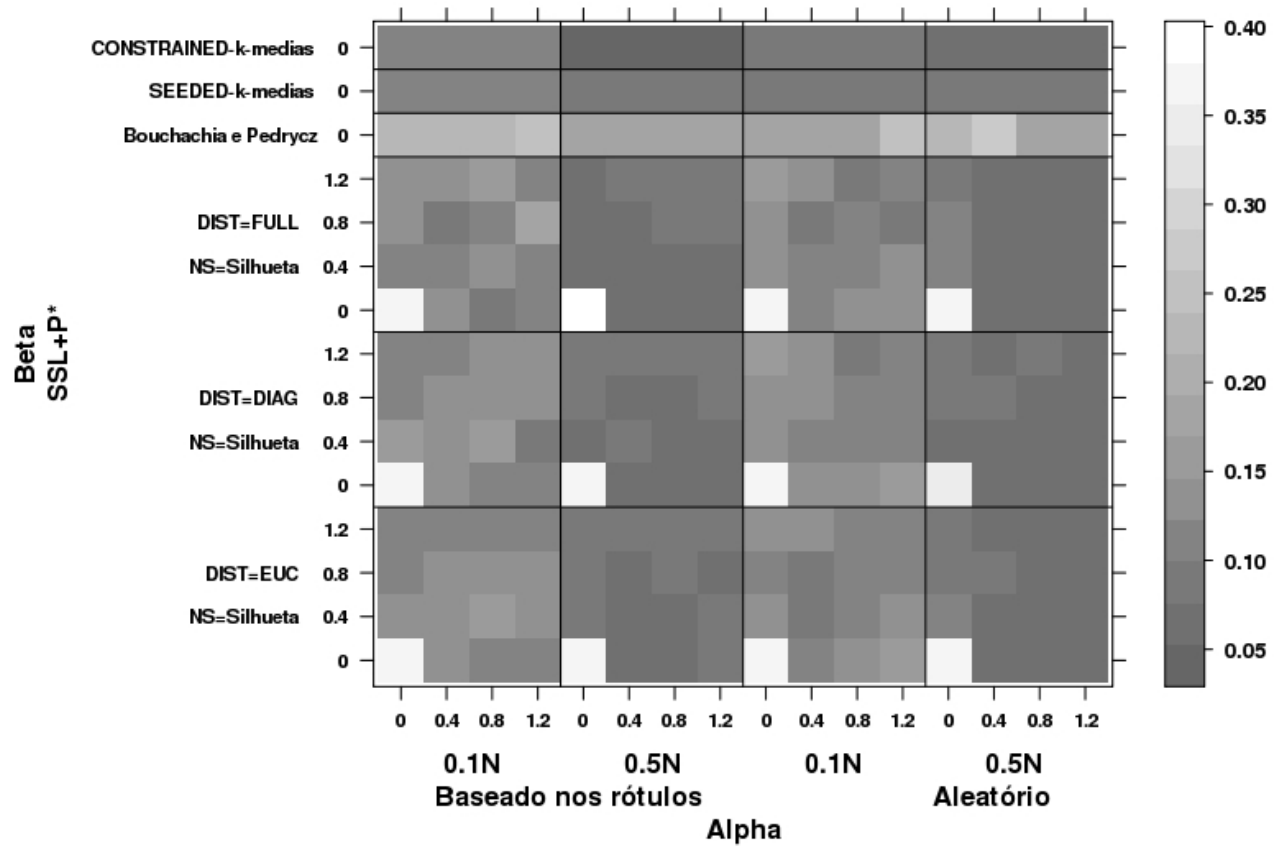

Figura 5.11: Gráfico do Erro de Classificação para a base Sintética-4 com a técnica SSL+P* em função dos valores de $\alpha$ e $\beta$ para as variações de métrica de distância (euclidiana (EUC), euclidiana ponderada (DIAG) e completamente adaptativa (FULL)), quantidades de dicas $(0.1 N$ e $0.5 N)$ e forma de produção das dicas (aleatória ou baseada nos rótulos disponíveis), em comparação com as técnicas propostas por Basu et al. (2002) e Bouchachia e Pedrycz (2003).

Os números de clusters resultantes da técnica SSL+P*, para a base Sintética-4, referentes aos resultados presentes na Figura 5.11 são 
apresentados na Figura 5.12. Os resultados indicam que valores altos de $\beta$ e $\alpha$ induzem o algoritmo $\mathrm{SSL}+\mathrm{P}^{*}$ a resultar em valores altos para número de clusters. Quando nenhuma supervisão é empregada, ou seja, $\alpha=0$ e $\beta=0$, o número de clusters resultante é igual a 3 , valor original para esta base de dados. Comparando estes valores com os resultados da Figura 5.11, nota-se que valores altos para número de clusters levam a menores Erros de Classificação.

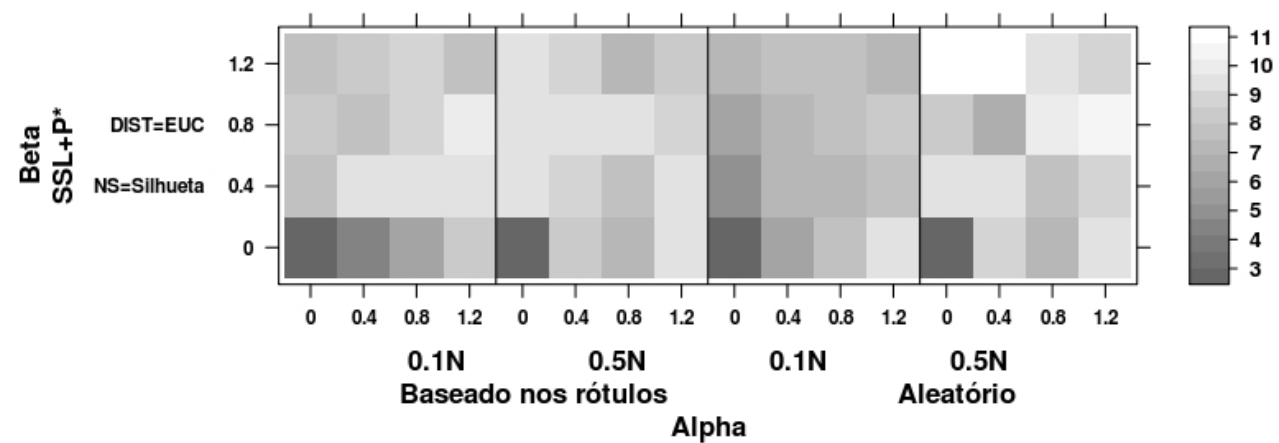

Figura 5.12: Gráfico dos números de clusters estimados pela técnica SSL+P* para a base Sintética- 4 em função dos valores de $\alpha$ e $\beta$ para as variações quantidades de DCPs $(0.1 N$ e $0.5 N)$ e forma de produção delas (aleatória ou baseada nos rótulos disponíveis).

A Figura 5.13 exibe os resultados da técnica SSL+P* medidos de acordo com o Erro de Classificação para a base Íris. Com essa base, o algoritmo SSL+P* produziu os melhores resultados. O aumento da quantidade de DCPs permitiu uma leve melhora nas duas formas de produção, aleatória ou baseada nos rótulos. Os valores de $\alpha$ e $\beta$ não influenciaram significativamente, principalmente para $0.5 \mathrm{~N}$ de DCPs e quando se utiliza distância adaptativa e exceto quando $\alpha=0$ e $\beta=0$, o que resulta em um Erro de Classificação maior, próximo de 0.35 .

Os números de clusters resultantes da técnica SSL+P*, para a base Íris, referentes aos resultados presentes na Figura 5.13 são apresentados na Figura 5.14. Aqui, repetiu-se a situação observada para a base de dados Sintética-4, onde valores altos de $\alpha$ e $\beta$ induziram o algoritmo SSL+P* a resultar em valores altos para número de clusters resultando em menores Erros de Classificação, observando os resultados da Figura 5.13

A Figura 5.15 exibe os resultados medidos quanto ao Erro de Classificação e a Figura 5.16 contém os números de clusters resultantes para a base Sintética-3. Para esta base de dados, os melhores resultados de Erro de Classificação foram alcançados pelo SSL+P*, particularmente, em situações em que o número de clusters resultante é alto. O algoritmo proposto por Bouchachia e Pedrycz (2003) alcança valores parecidos, empregando um cluster para cada classe. Aplicar o algoritmo SSL+P* a essa base produziu o mesmo cenário curioso observado na Figura 5.9, onde o emprego de DCPs 


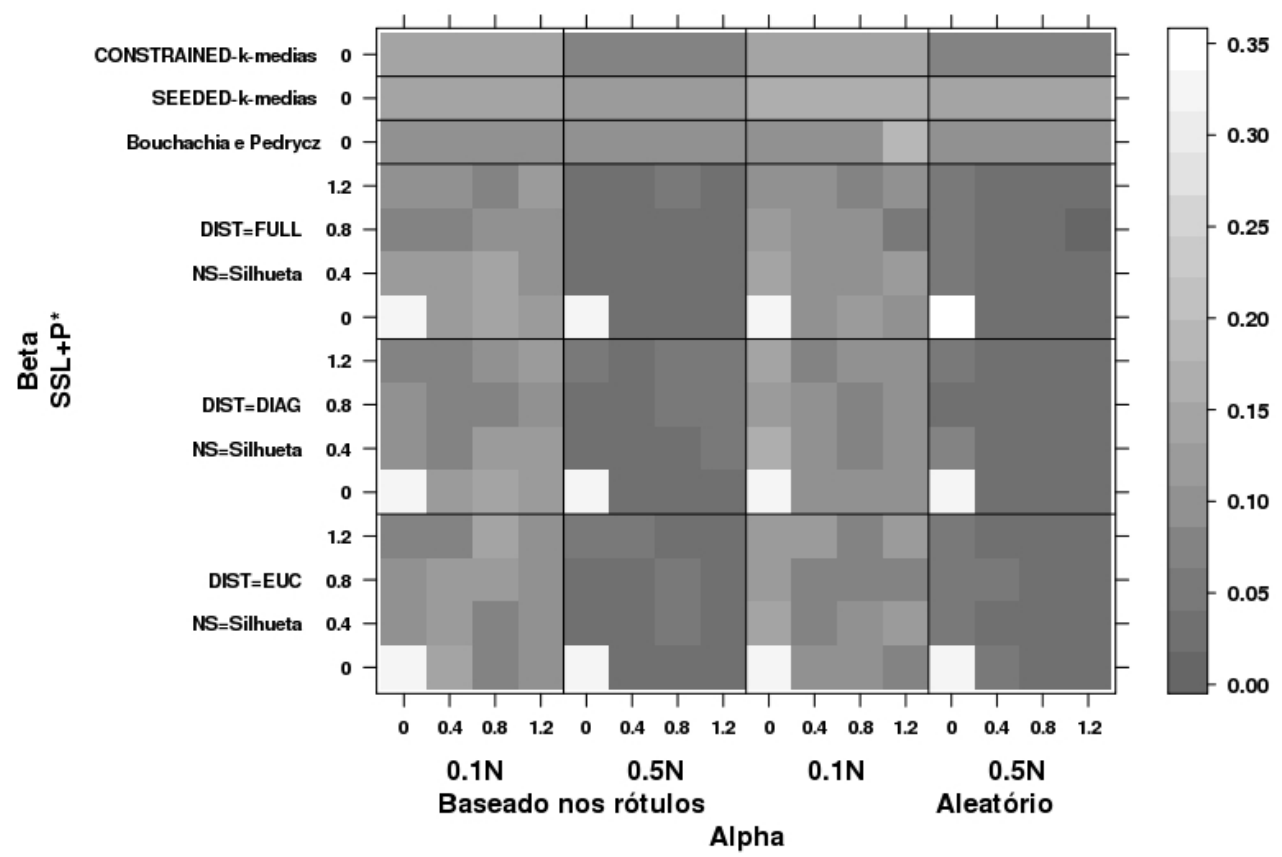

Figura 5.13: Gráfico do Erro de Classificação para a base Íris com a técnica SSL+P* em função dos valores de $\alpha$ e $\beta$ para as variações de métrica de distância (euclidiana (EUC), euclidiana ponderada (DIAG) e completamente adaptativa (FULL)), quantidades de dicas $(0.1 N$ e $0.5 N)$ e forma de produção das dicas (aleatória ou baseada nos rótulos disponíveis), em comparação com as técnicas propostas por Basu et al. (2002) e Bouchachia e Pedrycz (2003).

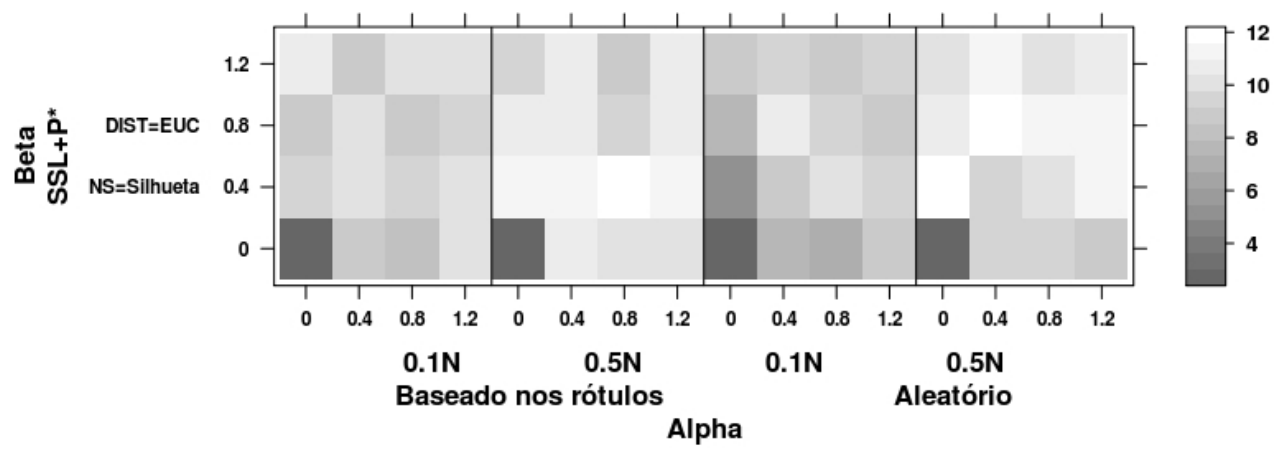

Figura 5.14: Gráfico dos números de clusters estimados pela técnica SSL+P* para a base Íris em função dos valores de $\alpha$ e $\beta$ para as variações de quantidades de dicas $(0.1 N$ e $0.5 N)$ e forma de produção das dicas (aleatória ou baseada nos rótulos disponíveis).

cujos valores de proximidade são baseados nos rótulos com $\beta=0$, ou seja, quando os valores de proximidade não são levados em consideração, são produzidos melhores resultados e, neste caso, maiores valores de número de cluster. Isso não acontece quando são empregadas DCPs de proximidade selecionadas aleatoriamente, porém o resultado permanece inalterado. Nesta base, a distância adaptativa tornou os resultados levemente menos sensíveis às variações dos parâmetros $\alpha$ e $\beta$.

A Figura 5.17 exibe os resultados medidos quanto ao Erro de Classificação e a Figura 5.18 contém os números de clusters resultantes para a base 


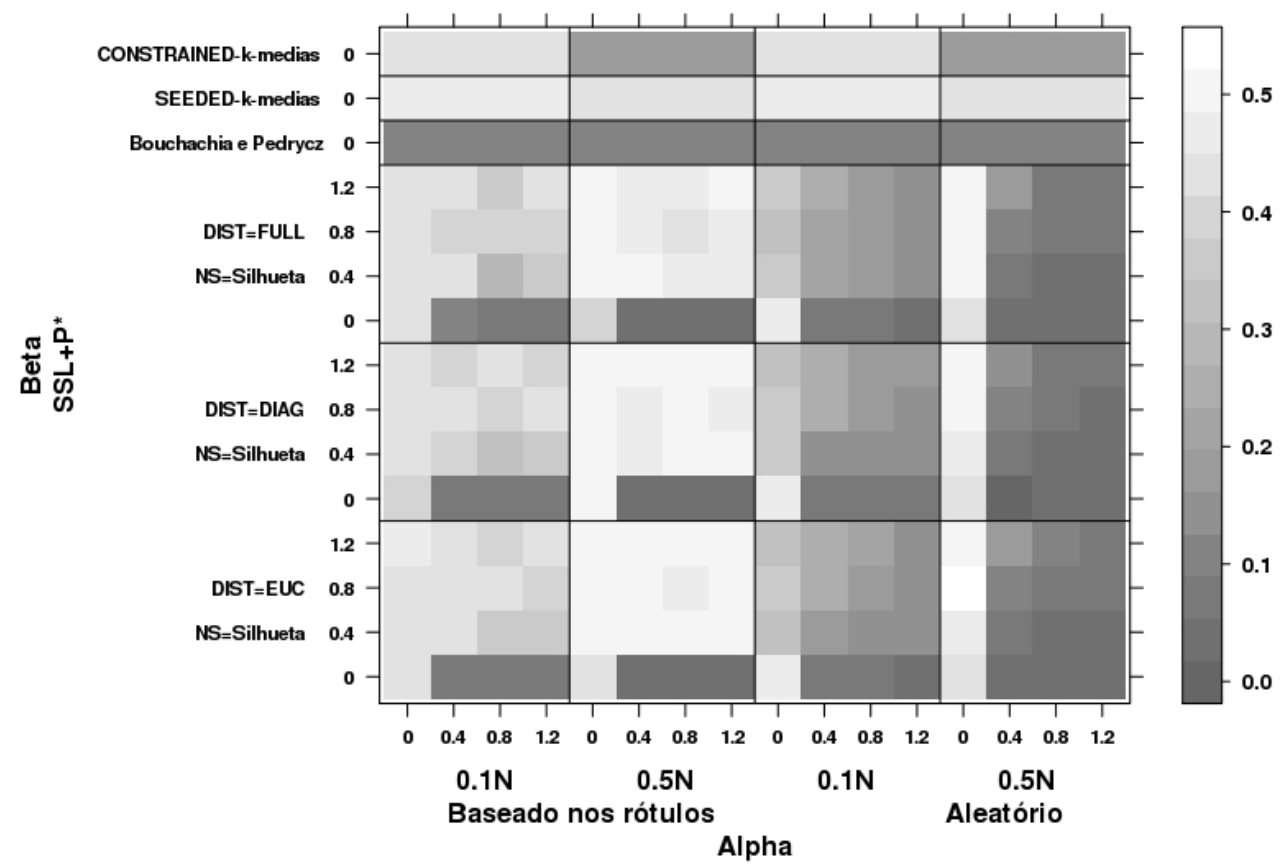

Figura 5.15: Gráfico do Erro de Classificação para a base Sintética-3 com a técnica SSL+P* em função dos valores de $\alpha$ e $\beta$ para as variações de métrica de distância (euclidiana (EUC), euclidiana ponderada (DIAG) e completamente adaptativa (FULL)), quantidades de dicas $(0.1 N$ e $0.5 N)$ e forma de produção das dicas (aleatória ou baseada nos rótulos disponíveis), em comparação com as técnicas propostas por Basu et al. (2002) e Bouchachia e Pedrycz (2003).

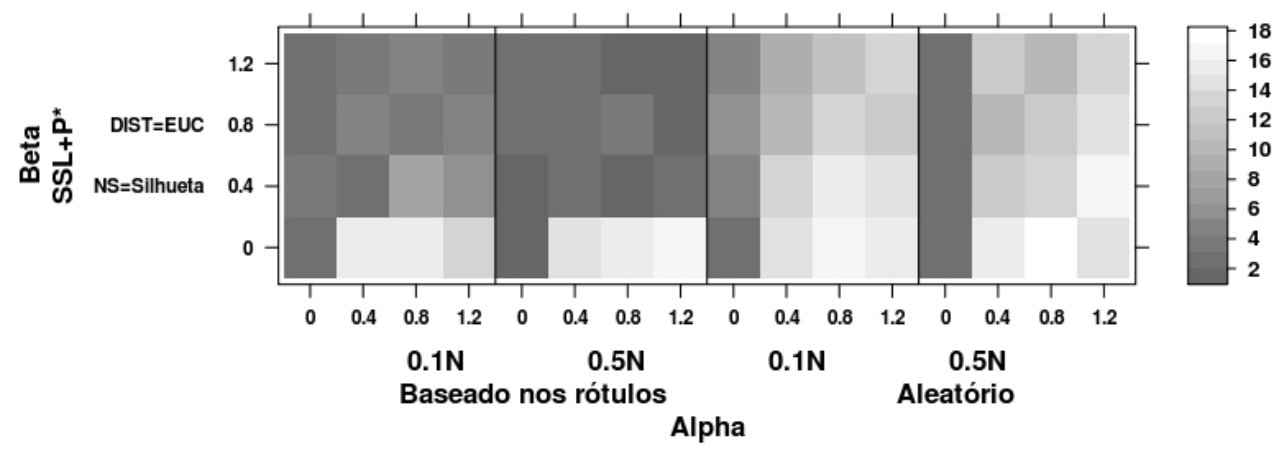

Figura 5.16: Gráfico dos números de clusters estimados pela técnica SSL+P* para a base Sintética-3 em função dos valores de $\alpha$ e $\beta$ para as variações de quantidades de dicas $(0.1 N$ e $0.5 N)$ e forma de produção das dicas (aleatória ou baseada nos rótulos disponíveis).

Wine. Para esta base, as técnicas SSL+P*, CONSTRAINED- $k$-médias e SEEDED- $k$-médias alcançaram os melhores resultados. As variações de parâmetros $\alpha$ e $\beta$ não influenciaram no Erro de Classificação do SSL+P*, mas sim nos números de clusters resultantes, sendo que $\alpha=0$ e $\beta=0$ induziram o SSL+P* a resultar em um baixo número de clusters. Porém isso não resultou em piora de performance em termos de Erro de Classificação, como aconteceu com outras bases. O emprego da distância adaptativa não influenciou muito os resultados, exceto que a distância euclidiana ponderada produziu resultados levemente piores que as demais, euclidiana e completamente 


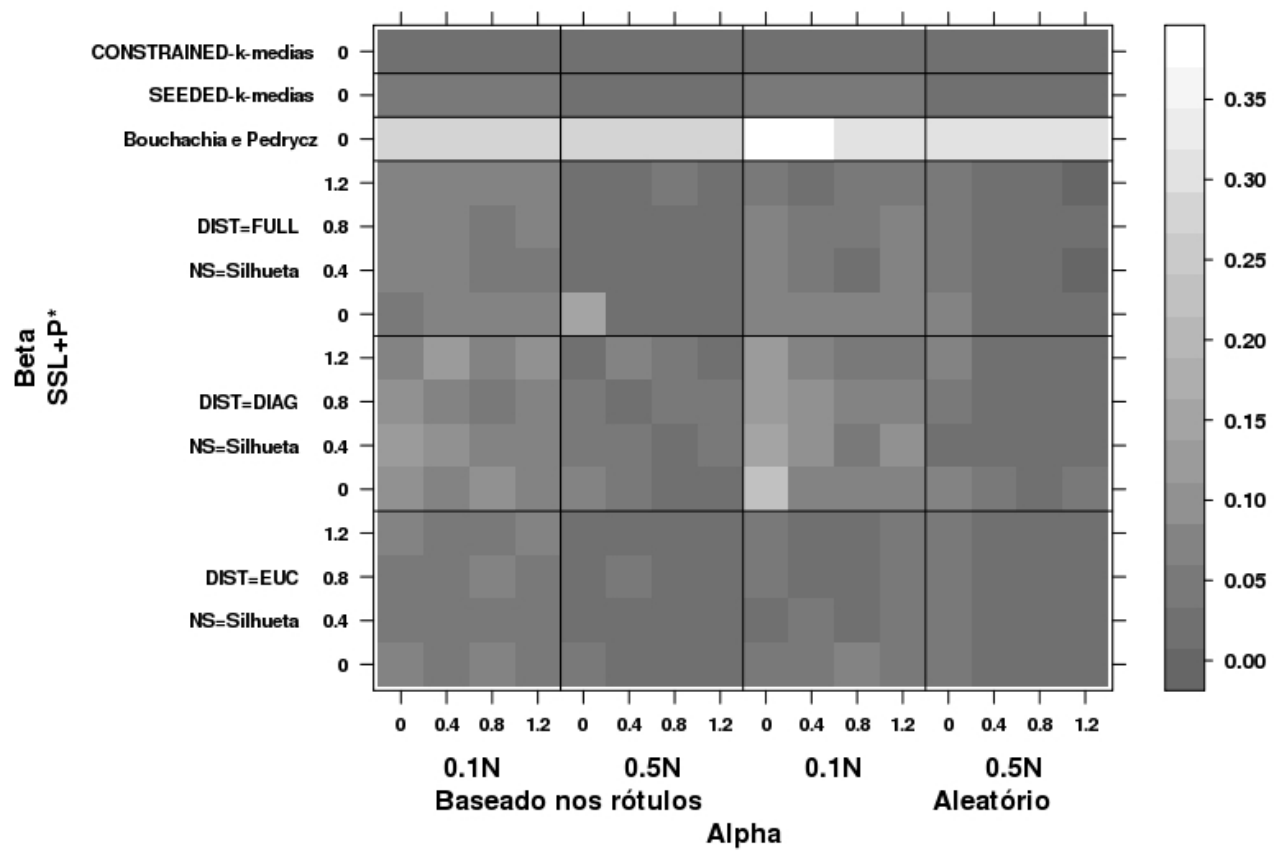

Figura 5.17: Gráfico do Erro de Classificação para a base Wine com a técnica SSL+P* em função dos valores de $\alpha$ e $\beta$ para as variações de métrica de distância (euclidiana (EUC), euclidiana ponderada (DIAG) e completamente adaptativa (FULL)), quantidades de dicas $(0.1 N$ e $0.5 N)$ e forma de produção das dicas (aleatória ou baseada nos rótulos disponíveis), em comparação com as técnicas propostas por Basu et al. (2002) e Bouchachia e Pedrycz (2003).

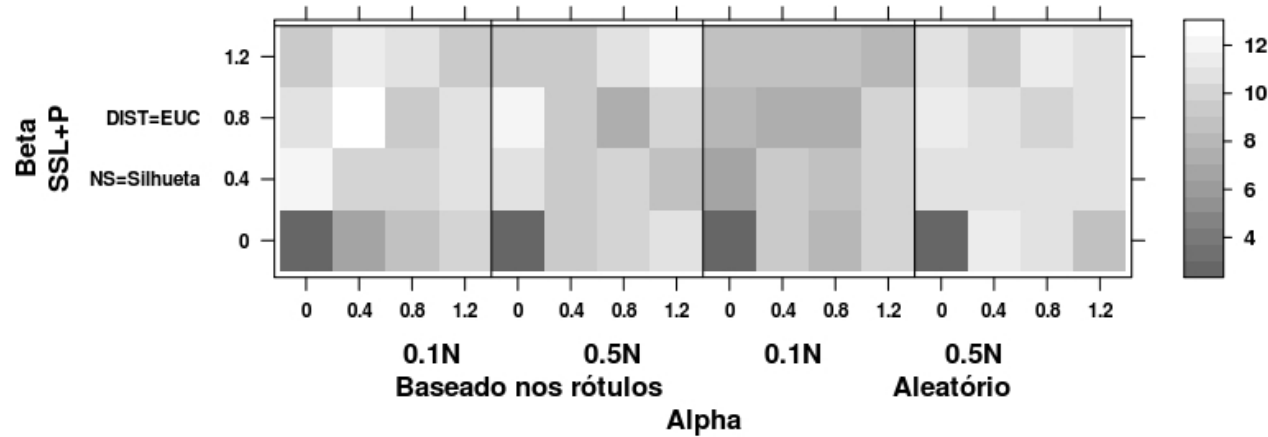

Figura 5.18: Gráfico dos números de clusters estimados pela técnica SSL+P* para a base Wine em função dos valores de $\alpha$ e $\beta$ para as variações de quantidades de dicas $(0.1 N$ e $0.5 N)$ e forma de produção das dicas (aleatória ou baseada nos rótulos disponiveis).

adaptativa.

Seguindo a modo de exibição da Tabela 5.3, as Tabelas 5.11 e 5.12 exibem o número de vitórias, empates e derrotas das técnicas listadas na primeira coluna, em comparação com as técnicas listadas na primeira linha para o emprego de dicas deduzidas e aleatórias, respectivamente. As técnicas são comparadas em 128 situações: 4 bases de dados $\times 16$ variações dos parâmetros $\alpha$ e $\beta \times 2$ quantidades de dicas.

Aplicando o teste de Nemenyi com significância estatística de 90\% e 95\% obtem-se o resultado mostrado nas Tabelas 5.13 e 5.14, seguindo a forma de 
Tabela 5.11: Tabela de vitórias/empates/derrotas das técnicas listadas na primeira coluna, em relação àquelas listadas na primeira linha comparando as técnicas de referência e as variações do SSL+P* utilizando de dicas aleatórias.

\begin{tabular}{l||c|c|c|c|c|c}
\hline \hline & $\begin{array}{c}\text { NS = Silh. } \\
\text { Dist.= Euc. }\end{array}$ & $\begin{array}{c}\text { NS = Silh. } \\
\text { Dist.= Diag. }\end{array}$ & $\begin{array}{c}\text { NS = Silh. } \\
\text { Dist.= Full }\end{array}$ & $\begin{array}{c}\text { CONST. } \\
\text { k-médias }\end{array}$ & $\begin{array}{l}\text { SEEDED } \\
\text { k-médias }\end{array}$ & $\begin{array}{c}\text { Bouchachia } \\
\text { \& Pedrycz }\end{array}$ \\
\hline \hline NS = Silh., Dist. = Euc. & - & $73 / 4 / 51$ & $57 / 4 / 67$ & $44 / 0 / 84$ & $78 / 1 / 49$ & $93 / 0 / 35$ \\
NS = Silh., Dist.= Diag. & $51 / 4 / 73$ & - & $46 / 2 / 80$ & $49 / 1 / 78$ & $72 / 0 / 56$ & $92 / 0 / 36$ \\
NS = Silh., Dist.= Full & $67 / 4 / 57$ & $80 / 2 / 46$ & - & $52 / 0 / 76$ & $83 / 0 / 45$ & $91 / 0 / 37$ \\
CONST. k-médias & $84 / 0 / 44$ & $78 / 1 / 49$ & $76 / 0 / 52$ & - & $128 / 0 / 0$ & $80 / 0 / 48$ \\
SEEDED k-médias & $49 / 1 / 78$ & $56 / 0 / 72$ & $45 / 0 / 83$ & $0 / 0 / 128$ & - & $64 / 0 / 64$ \\
Bouchachia \& Pedrycz & $35 / 0 / 93$ & $36 / 0 / 92$ & $37 / 0 / 91$ & $48 / 0 / 80$ & $64 / 0 / 64$ & - \\
\hline \hline
\end{tabular}

Tabela 5.12: Tabela de vitórias/empates/derrotas das técnicas e variações do SSL+P* listadas na primeira coluna, em relação àquelas listadas na primeira linha no caso de utilização de dicas aleatórias.

\begin{tabular}{l||c|c|c|c|c|c}
\hline \hline & $\begin{array}{c}\text { NS = Silh. } \\
\text { Dist.= Euc. }\end{array}$ & $\begin{array}{c}\text { NS = Silh. } \\
\text { Dist.= Diag. }\end{array}$ & $\begin{array}{c}\text { NS = Silh. } \\
\text { Dist.= Full }\end{array}$ & $\begin{array}{c}\text { CONST. } \\
\text { k-médias }\end{array}$ & $\begin{array}{c}\text { SEEDED } \\
\text { k-médias }\end{array}$ & $\begin{array}{c}\text { Bouchachia } \\
\text { \& Pedrycz }\end{array}$ \\
\hline \hline NS = Silh., Dist. = Euc. & - & $74 / 5 / 49$ & $65 / 4 / 59$ & $69 / 3 / 56$ & $89 / 1 / 38$ & $102 / 0 / 26$ \\
NS = Silh., Dist.= Diag. & $49 / 5 / 74$ & - & $46 / 6 / 76$ & $58 / 0 / 70$ & $80 / 1 / 47$ & $102 / 0 / 26$ \\
NS = Silh., Dist.= Full & $59 / 4 / 65$ & $76 / 6 / 46$ & - & $64 / 1 / 63$ & $87 / 0 / 41$ & $102 / 0 / 26$ \\
CONST. k-médias & $56 / 3 / 69$ & $70 / 0 / 58$ & $63 / 1 / 64$ & - & $128 / 0 / 0$ & $84 / 0 / 44$ \\
SEEDED k-médias & $38 / 1 / 89$ & $47 / 1 / 80$ & $41 / 0 / 87$ & $0 / 0 / 128$ & - & $68 / 0 / 60$ \\
Bouchachia \& Pedrycz & $26 / 0 / 102$ & $26 / 0 / 102$ & $26 / 0 / 102$ & $44 / 0 / 84$ & $60 / 0 / 68$ & - \\
\hline \hline
\end{tabular}

exibição da Tabela 5.4.

Tabela 5.13: Testes estatísticos de Friedman e Nemenyi dos resultados das técnicas de referência e das variações do SSL+P* utilizando de dicas deduzidas ("+" significa diferença estatística 90\% e “*” 95\%).

\begin{tabular}{l||c|c|c|c|c|c}
\hline \hline & NS = Silh. & $\begin{array}{c}\text { NS = Silh. } \\
\text { Dist.= Euc. }\end{array}$ & $\begin{array}{c}\text { NS = Silh. } \\
\text { Dist.= Diag. }\end{array}$ & $\begin{array}{c}\text { CONST. } \\
\text { Dist. = Full }\end{array}$ & $\begin{array}{c}\text { SEEDED } \\
\text { k-médias }\end{array}$ & $\begin{array}{c}\text { Bouchachia } \\
\text { \& Pedrycz }\end{array}$ \\
\hline \hline NS = Silh., Dist. = Euc. & & & & $*$ & & \\
NS = Silh., Dist.= Diag. & & & & $*$ & & \\
NS = Silh., Dist.= Full & & & & & & \\
CONST. k-médias & $*$ & $*$ & $*$ & $*$ & & \\
SEEDED k-médias & $*$ & $*$ & $*$ & $*$ & & \\
Bouchachia \& Pedrycz & $*$ & $*$ & $*$ & $*$
\end{tabular}

Observando os resultados apresentados nesta seção, é possível observar que a técnica SSL+P, aplicada a bases com número de clusters conhecido, é capaz de produzir resultados tão bons ou melhores do que técnicas comparadas. Os resultados obtidos com a técnica $\mathrm{SSL}+\mathrm{P}^{*}$ revelaram uma tendência em que os melhores resultados em termos de Erro de Classificação estão, na maioria das vezes, associados com altos valores de número de clusters resultantes. Também foi possivel observar que ambos, SSL+P e SSL+P*, não são muito sensiveis às variações dos parâmetros $\alpha \mathrm{e} \beta$. 
Tabela 5.14: Testes estatísticos de Friedman e Nemenyi dos resultados das técnicas de referência e das variações do SSL+P* utilizando de dicas aleatórias ("+" significa diferença estatística 90\% e “*” 95\%).

\begin{tabular}{l||c|c|c|c|c|c}
\hline \hline & $\begin{array}{c}\text { NS = Silh. } \\
\text { Dist.= Euc. }\end{array}$ & $\begin{array}{c}\text { NS = Silh. } \\
\text { Dist.= Diag. }\end{array}$ & $\begin{array}{c}\text { NS = Silh. } \\
\text { Dist.= Full }\end{array}$ & $\begin{array}{c}\text { CONST. } \\
\text { k-médias }\end{array}$ & $\begin{array}{c}\text { SEEDED } \\
\text { k-médias }\end{array}$ & $\begin{array}{c}\text { Bouchachia } \\
\text { \& Pedrycz }\end{array}$ \\
\hline \hline NS = Silh., Dist. = Euc. & & & & & & \\
NS = Silh., Dist.= Diag. & & & & & & \\
NS = Silh., Dist.= Full & & & & & & \\
CONST. k-médias & $*$ & $*$ & $*$ & $*$ & & \\
SEEDED k-médias & $*$ & $*$ & $*$ & $*$ & & \\
Bouchachia \& Pedrycz & $*$ & $*$ & $*$ & & & \\
\hline \hline
\end{tabular}

\subsection{Otimização baseada em população}

Nesta seção, são apresentados os resultados experimentais das abordagens propostas na área de Otimização baseada em População (OBP): as duas versões modificadas do algoritmo PSO, DPSO-1 e DPSO-2, apresentadas na Seção 4.4.2. São também apresentados resultados obtidos com as duas formas de inicialização de população de centróides descritas na Seção 4.4.1. A seguir, serão apresentadas as bases de dados, a metodologia seguida para realização dos experimentos e os resultados alcançados.

\subsection{Bases de dados}

Para os experimentos com os algoritmos DPSO-1 e DPSO-2, foram empregadas as bases Sintética-1 e Sintética-2, descritas na Seção 5.2.1. As investigações com as formas de inicialização também utilizaram a base Sintética-1 e uma base sintética adicional, semelhante a Sintética-2, denominada Sintética-5. A base Sintética-5 também foi criada com distribuição gaussiana multivariada com clusters de forma esférica de acordo com as configurações exibidas na Tabela 5.15.

Tabela 5.15: Configurações para criação da base de dados Sintética-5.

\begin{tabular}{l||c}
\hline \hline No. de Clusters & 5 \\
\hline No. de Atributos & 2 \\
\hline No. de Exemplos por Cluster & 50 \\
\hline & $(2.5,7.5)$ \\
& $(5.0,5.0)$ \\
Protótipos & $(7.5,7.5)$ \\
& $(2.5,2.5)$ \\
& $(7.5,2.5)$ \\
\hline \hline
\end{tabular}




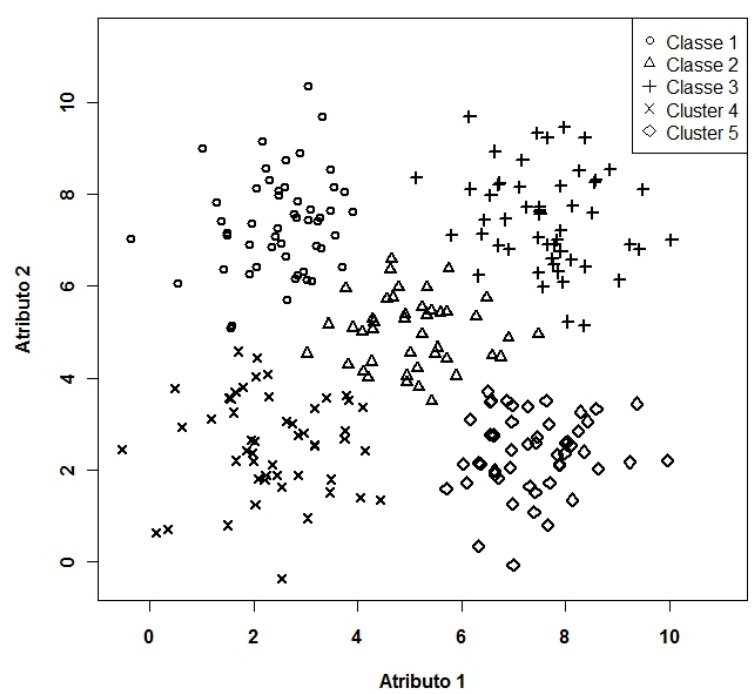

Figura 5.19: Gráfico da base de dados Sintética-5.

\subsubsection{Metodologia}

As 4 formas de inicialização da população de partículas propostas nesta Tese foram comparadas com a forma aleatória, mais freqüentemente utilizada na literatura. As 5 alternativas de inicialização (incluindo a inicialização aleatória) foram aplicadas às duas bases de dados Sintética-1 e Sintética-5, com seus valores originais para número de clusters e representação de protótipos baseada em centróides. Como algoritmo de OBP, foi utilizado o PSO tradicional (Kennedy e Eberhart, 2001) com os seguintes parâmetros: iter $_{\max }=200, c_{1}=c_{2}=2, w=0.9$, como sugerido por Shi e Eberhart (1998), e tamanho da população igual a 100. Duas diferentes funções de aptidão foram empregadas, Reconstrução e FDB, descritas na Seção 4.2. Cada experimento foi realizado 5 vezes e os resultados são avaliados quanto a:

- Melhor aptidão da população final;

- Aptidão média da primeira população;

- Número médio de gerações necessário para a convergência.

Os algoritmos DPSO-1 e DPSO-2 foram aplicados às bases Sintética-1 e Sintética-2, com as funções de aptidão Reconstrução, FDB e Xie-Beni. Dois tipos de representação de protótipos foram empregados: baseada em medóides e baseada em centróides, da mesma forma como explicado na Seção 5.2.2. O desempenho desses algoritmos foi comparado com o PSO tradicional e com a versão do PSO introduzida por Shi e Eberhart (1998). Os parâmetros empregados para cada uma das versões do PSO foram: 
- PSO tradicional: iter $_{\max }=200, c_{1}=c_{2}=2, w=0.9$ e tamanho da população igual a 100.

- PSO $\operatorname{com} w$ decrescente: iter $_{\max }=200, c_{1}=c_{2}=2$ e $w_{\min }=0.2, w_{\max }=0.9 \mathrm{e}$ tamanho da população igual a 100.

- DPSO-1 e DPSO-2: $c_{1}^{o}=c_{2}^{o}=2, \rho=5, t=8$ e tamanho da população igual a 100.

Para todas as versões do PSO comparadas, foi aplicada a restrição de condição de parada que exige que a melhor aptidão da última geração da população seja, necessariamente, melhor do que a melhor aptidão da população inicial. Quanto aos valores para número de clusters, foi considerado o intervalo $[3,16]$. O desempenho das diferentes versões do PSO foi medido de acordo com o Erro de Proximidade, descrito na Seção 5.2.2 (Equação (5.2)).

\subsubsection{Resultados}

A seguir, serão apresentados os resultados dos experimentos comparando as formas de inicialização de população de centróides. Cada experimento foi repetido 5 vezes e, nas Tabelas 5.16 e 5.17, são exibidos as médias e desvios-padrão da aptidão final, a aptidão média da primeira geração, e o número médio de gerações necessárias para a convergência.

Com a base Sintética-1, a alternativa Centróides-3 superou as demais na maioria das situações, exceto, para aptidão média na primeira geração e utilização da função FDB como aptidão, quando a forma Aleatória obteve o melhor resultado. Esse melhor resultado, entretanto, foi bem próximo do valor alcançado por Centróides-3 e Medóides.

Tabela 5.16: Comparação das formas de inicialização para base de dados Sintética-1, onde os melhores resultados estão destacados.

\begin{tabular}{l||l||r|r|r}
\hline \hline Função de aptidão & Inicialização & Aptidão final & Aptidão média da 1a geração & Número de gerações \\
\hline \hline \multirow{4}{*}{ Reconstrução } & Aleatória & $19.46( \pm 0.15)$ & $139.31( \pm 9.89)$ & $73.80( \pm 57.59)$ \\
\cline { 2 - 5 } & Centróides-1 & $29.85( \pm 6.31)$ & $141.95( \pm 0.60)$ & $223.40( \pm 110.63)$ \\
\cline { 2 - 5 } & Medóides & $19.45( \pm 0.10)$ & $112.07( \pm 9.61)$ & $62.00( \pm 31.39)$ \\
\cline { 2 - 5 } & Centróides-2 & $19.74( \pm 0.21)$ & $109.92( \pm 0.53)$ & $64.80( \pm 14.94)$ \\
\cline { 2 - 5 } & Centróides-3 & $\mathbf{1 9 . 3 9}( \pm 0.00)$ & $\mathbf{6 7 . 6 8}( \pm 2.68)$ & $37.00( \pm 4.00)$ \\
\hline \hline \multirow{4}{*}{ FDB } & Aleatória & $0.20( \pm 0.03)$ & $\mathbf{0 . 8 1}( \pm 0.07)$ & $27.60( \pm 4.51)$ \\
\cline { 2 - 5 } & Centróides-1 & $0.36( \pm 0.09)$ & $6.47( \pm 0.26)$ & $63.80( \pm 13.33)$ \\
\cline { 2 - 5 } & Medóides & $\mathbf{0 . 1 8}( \pm 0.00)$ & $1.00( \pm 0.04)$ & $22.40( \pm 2.07)$ \\
\cline { 2 - 5 } & Centróides-2 & $0.49( \pm 0.13)$ & $6.25( \pm 0.73)$ & $40.20( \pm 15.63)$ \\
\cline { 2 - 5 } & Centróides-3 & $\mathbf{0 . 1 8}( \pm 0.00)$ & $1.27( \pm 0.09)$ & $\mathbf{1 9 . 4 0}( \pm 1.52)$ \\
\hline \hline
\end{tabular}

Nos experimentos realizados com a base Sintética-5, a técnica Centróides-3 também obteve os melhores resultados na maioria das situações. Mesmo 
nas demais situações, Centróides-3 obteve valores bastante próximos dos melhores alcançados pelas outras formas de inicialização.

Tabela 5.17: Comparação das formas de inicialização para base de dados Sintética-5, onde os melhores resultados estão destacados.

\begin{tabular}{l||l||r|r|r}
\hline \hline Função de aptidão & Inicialização & Aptidão final & Aptidão média da 1 ${ }^{a}$ geração & Número de gerações \\
\hline \hline \multirow{4}{*}{ Reconstrução } & Aleatória & $25.23( \pm 0.72)$ & $11.55( \pm 8.56)$ & $64.40( \pm 36.07)$ \\
\cline { 2 - 5 } & Centróides-1 & $30.92( \pm 5.18)$ & $233.34( \pm 0.96)$ & $160.20( \pm 69.14)$ \\
\cline { 2 - 5 } & Medóides & $\mathbf{2 4 . 5 5}( \pm 0.53)$ & $103.22( \pm 7.06)$ & $70.00( \pm 41.09)$ \\
\cline { 2 - 5 } & Centróides-2 & $33.37( \pm 9.65)$ & $203.05( \pm 3.25)$ & $143.00( \pm 78.43)$ \\
\cline { 2 - 5 } & Centróides-3 & $25.32( \pm 0.46)$ & $\mathbf{7 4 . 5 2}( \pm 5.28)$ & $\mathbf{5 6 . 0 0}( \pm 26.12)$ \\
\hline \hline \multirow{4}{*}{ FDB } & Aleatória & $\mathbf{0 . 1 9}( \pm 0.01)$ & $\mathbf{0 . 6 9}( \pm 0.07)$ & $29.20( \pm 2.95)$ \\
\cline { 2 - 5 } & Centróides-1 & $0.23( \pm 0.03)$ & $6.21( \pm 1.23)$ & $47.60( \pm 13.45)$ \\
\cline { 2 - 5 } & Medóides & $\mathbf{0 . 1 9}( \pm 0.01)$ & $0.81( \pm 0.12)$ & $26.20( \pm 2.59)$ \\
\cline { 2 - 5 } & Centróides-2 & $0.22( \pm 0.02)$ & $2.93( \pm 0.45)$ & $35.80( \pm 5.17)$ \\
\cline { 2 - 5 } & Centróides-3 & $0.20( \pm 0.00)$ & $0.71( \pm 0.07)$ & $\mathbf{2 2 . 4 0}( \pm 4.28)$ \\
\hline \hline
\end{tabular}

Na sequência, são exibidos os resultados comparando as duas versões modificadas do algoritmo PSO propostas, DPSO-1 e DPSO-2 com a versão tradicional e com a versão desenvolvida por Shi e Eberhart (1998). A Figura 5.20 exibe os resultados para a base de dados Sintética-1:

Em geral, o desempenho das 4 versões do PSO comparadas apresentam performance semelhante quando aplicadas na base Sintética-1. As versões propostas, DPSO-1 e DPSO-2 fornecem os melhores resultados em diversas situações. Principalmente quando a função de aptidão utilizada é a Xie-Beni.

A Figura 5.21 exibe os resultados para a base Sintética-2. As 4 versões do PSO testadas na base Sintética-2 também forneceram resultados semelhantes. Porém, com essa base, as melhorias fornecidas pelas versões propostas ficam um pouco mais evidentes, já que na maioria das situações o menor Erro de Proximidade é fornecido por DPSO-1 ou DPSO-2.

Para facilitar a visualização dos resultados, a Tabela 5.18 contém o número de vitórias, empates e derrotas das técnicas listadas na primeira coluna, em comparação com as técnicas listadas na primeira linha. Na Tabela 5.18, as técnicas são comparadas nas 72 situações: 2 bases de dados $\times 6$ números de clusters $\times 2$ representações de protótipos $\times 3$ funções de aptidão. Por exemplo, o valor "46/0/26" na terceira linha da segunda coluna significa que o algoritmo DPSO-1 ganhou 46 e perdeu 26 vezes para o algoritmo PSO com $w$ descendente. Também vale destacar a comparação do DPSO-1 com o PSO tradicional, significando que o primeiro obteve melhores resultados em 44 das situações e piores resultados em 28. Outro resultado pode ser observado na comparação entre o DPSO-2 e o PSO com $w$ descendente, quando o primeiro forneceu melhores resultados em 44 situações e piores em apenas 28. Estes valores sugerem que as técnicas propostas, DPSO-1 e DPSO-2 proporcionam melhores resultados do que as técnicas tradicionais quando utilizadas em 


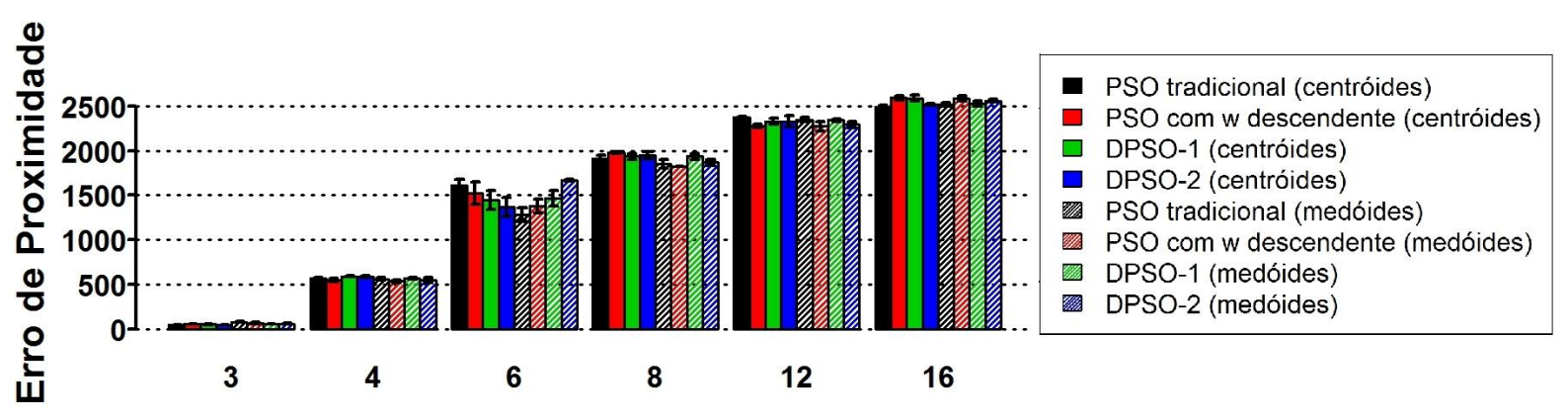

Número de clusters

(a) Índice Erro de Proximidade para a função de aptidão Reconstrução

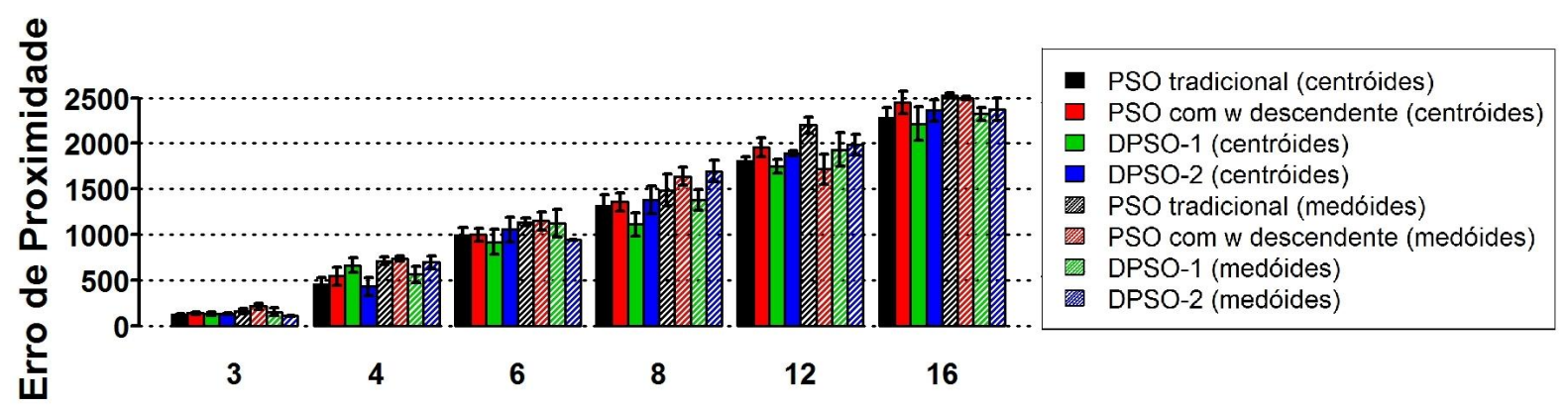

Número de clusters

(b) Índice Erro de Proximidade para a função de aptidão FDB

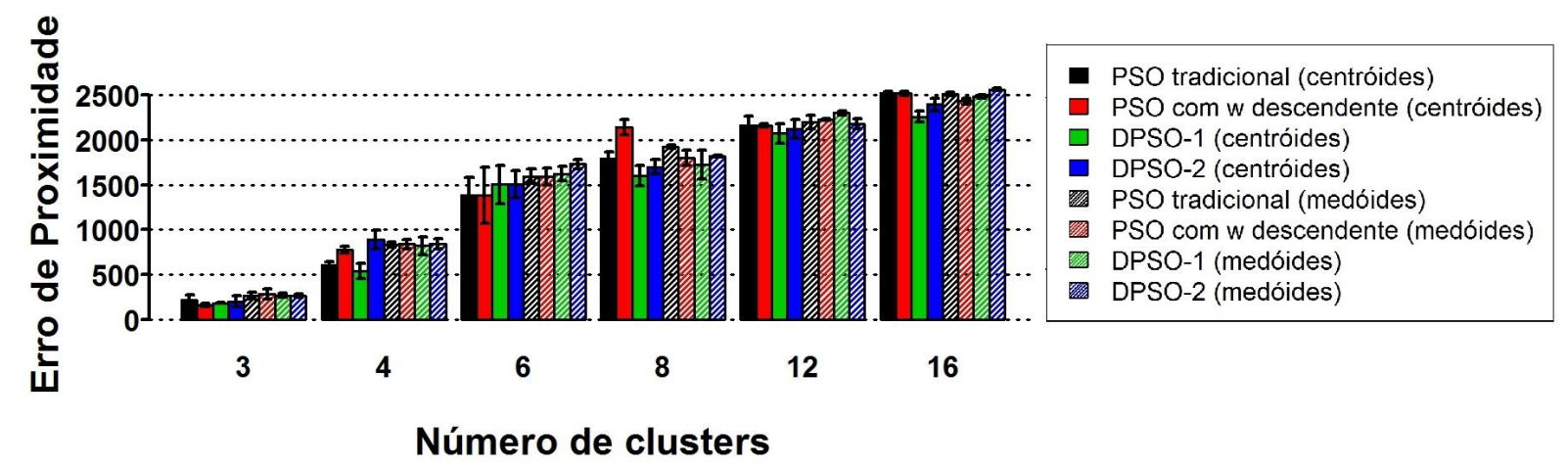

(c) Índice Erro de Proximidade para a função de aptidão Xie-Beni

Figura 5.20: Gráficos da medida de avaliação Erro de Proximidade para a base Sintética 1 em função do número de clusters para os critérios de aptidão Reconstrução, FDB e Xie-Beni utilizando os algoritmos: PSO tradicional, PSO com $w$ descendente, DPSO-1 e DPSO-2 com representação de protótipos baseada em e medóides.

tarefas de $\mathrm{AD}$ para os conjuntos de dados testados.

Aplicando o teste de Friedman e Nemenyi com significância estatística de 90\% e 95\% obteve-se que o DPSO-1 obteve melhores resultados do que o PSO com $w$ decrescente com diferença significantemente estatística de 95\%. 


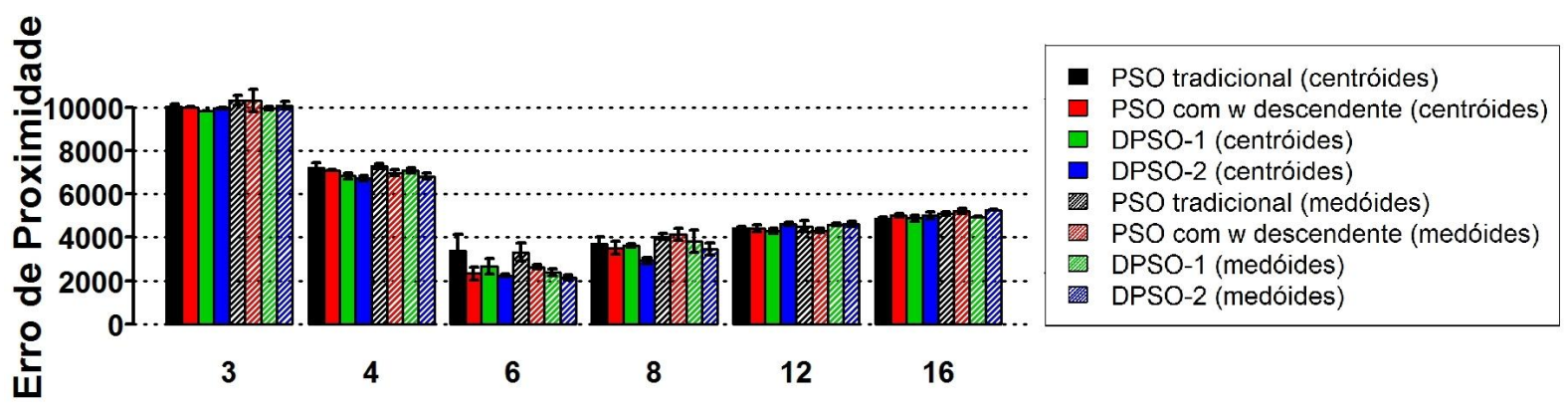

Número de clusters

(a) Índice Erro de Proximidade para a função de aptidão Reconstrução

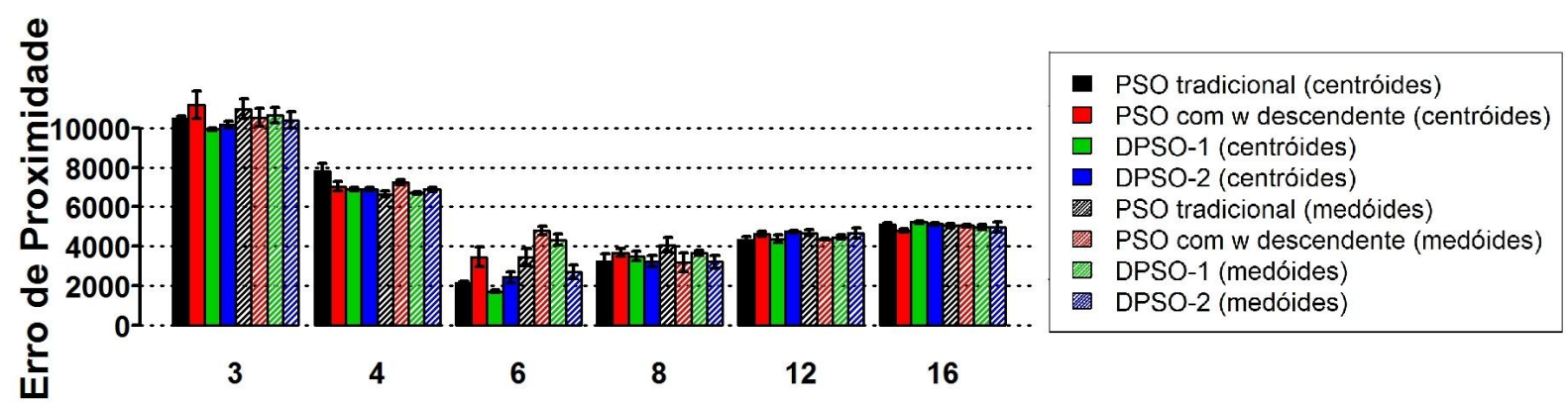

Número de clusters

(b) Índice Erro de Proximidade para a função de aptidão FDB

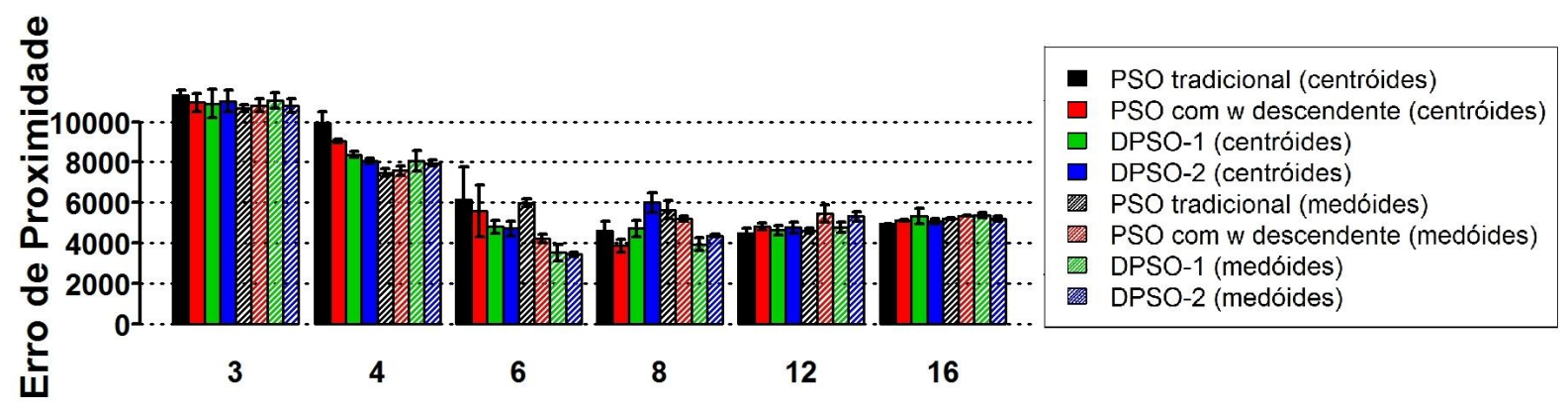

Número de clusters

(c) Índice Erro de Proximidade para a função de aptidão Xie-Beni

Figura 5.21: Gráficos da medida de avaliação Erro de Proximidade para a base Sintética 2 em função do número de clusters para os critérios de aptidão Reconstrução, FDB e Xie-Beni utilizando os algoritmos: PSO tradicional, PSO com $w$ descendente, DPSO-1 e DPSO-2 com representação de protótipos baseada em e medóides.

Tabela 5.18: Tabela de vitórias/empates/derrotas das versões do PSO listadas na primeira coluna, em relação àquelas listadas na primeira linha.

\begin{tabular}{l||c|c|c|c}
\hline \hline & PSO tradicional & PSO com $w$ descendente & DPSO-1 & DPSO-2 \\
\hline \hline PSO tradicional & - & $39 / 0 / 33$ & $28 / 0 / 44$ & $34 / 0 / 38$ \\
PSO com $w$ descendente & $33 / 0 / 39$ & - & $26 / 0 / 46$ & $28 / 0 / 44$ \\
DPSO-1 & $44 / 0 / 28$ & $46 / 0 / 26$ & - & $38 / 0 / 34$ \\
DPSO-2 & $38 / 0 / 34$ & $44 / 0 / 28$ & $34 / 0 / 38$ & - \\
\hline \hline
\end{tabular}




\subsection{Análise automática de clusters de dados biomédicos}

Nesta seção, são descritos os experimentos realizados na área de MT com o objetivo de avaliar a abordagem de análise de clusters de genes proposta na Seção 4.5 .

\subsubsection{Bases de dados}

Foram utilizados resumos de artigos sobre a levedura Saccharomyces cerevisiae, coletados em uma base de dados específica sobre os genes dessa levedura, a SGD (http://www.yeastgenome.org/). Os registros de genes presentes na base de dados SGD fornecem links para artigos científicos sobre esses genes. A maioria desses links aponta para resumos de artigos registrados na PubMed (http://www.ncbi.nlm.nih.gov/entrez/ query. $f \mathrm{cg} i$ ? $\mathrm{DB}=\mathrm{pubmed}$ ). Estes resumos foram coletados e rotulados com o nome do gene descrito por eles. Após a coleta dos textos, foram conservadas apenas as classes contendo acima de 100 textos, resultando em 7 classes, referentes aos genes: pho5, ho, rad51, pma1, suc2, cyc1 e rap1, com um total de 1114 textos. Esta base de textos foi utilizada para avaliar o desempenho de classificadores, quando utilizados para a tarefa de auxílio na coleta de textos sobre entidades biológicas, no caso, genes da levedura Saccharomyces cerevisiae.

Esta base também é utilizada para avaliar a abordagem para análise de clusters de genes, proposta na Seção 4.5. Para isso, os textos são rotulados de outra maneira. De acordo com a descrição da técnica, cada texto deve ser rotulado com o nome do cluster ao qual pertence o gene descrito pelo texto. Para isso, dois diferentes agrupamentos foram utilizados:

1. Agrupamento de genes da levedura Saccharommyces cerevisiae proposto por Spellman et al. (1998). Nesse trabalho, foi aplicado um algoritmo de agrupamento hierárquico aos genes da levedura Saccaromyces cerevisiae. Spellman et al. (1998) sugeriram que os genes agrupados se comportam de maneira semelhante em determinados ciclos de vida da célula da levedura, que dão nome aos sete clusters utilizados: $\operatorname{clb} 2, \operatorname{cln} 2$, histone, mat, mcm, met e sic 1 .

2. Agrupamento de genes da levedura Saccharommyces cerevisiae proposto por Eisen et al. (1998). Nesse trabalho, um algoritmo de agrupamento hierárquico foi aplicado aos genes da levedura Saccharomyces cerevisiae. Os autores desse trabalho sugeriram que os genes agrupados 
compartilham funções em processos celulares. As informações sobre os clusters propostos, fornecidas em Eisen et al. (1998), estão resumidas na Tabela 5.19.

Tabela 5.19: Clusters de genes definidos no trabalho de Eisen et al. (1998).

\begin{tabular}{|c|c|c|}
\hline Cluster & $N^{o}$ of Genes & Descrição \\
\hline$\overline{\mathrm{B}}$ & 11 & Genes envolvidos na formação e funcionamento do centrossomo \\
\hline $\mathrm{C}$ & 27 & $\begin{array}{l}\text { Genes codificadores da maioria dos componentes } \\
\text { proteassoma }\end{array}$ \\
\hline $\mathrm{D}$ & 14 & Genes envolvidos no splicing do mRNA \\
\hline $\mathrm{E}$ & 17 & Genes codificadores das enzimas da glicólise \\
\hline $\mathrm{F}$ & 22 & $\begin{array}{l}\text { Genes codificadores das proteínas da mitocôndria; e alguns } \\
\text { genes envolvidos na respiração }\end{array}$ \\
\hline G & 15 & $\begin{array}{l}\text { Genes participantes da síntese de ATP; também alguns genes } \\
\text { participantes da fosforilação oxidativa }\end{array}$ \\
\hline $\mathrm{H}$ & 8 & Genes codificadores das proteínas da cromatina \\
\hline I & 126 & $\begin{array}{l}\text { Genes codificadores das proteínas do ribossomo e proteínas } \\
\text { envolvidas nas etapas de iniciação e prolongação da síntese do } \\
\text { tRNA }\end{array}$ \\
\hline $\mathrm{J}$ & 5 & $\begin{array}{l}\text { Genes codificadores das proteínas envolvidas na iniciação e } \\
\text { regulação da replicação do DNA }\end{array}$ \\
\hline $\mathrm{K}$ & 16 & $\begin{array}{l}\text { Genes envolvidos no ciclo do ácido tricarboxílico (TCA - } \\
\text { Tricarboxylic acid cycle) e na fosforilação oxidativa }\end{array}$ \\
\hline
\end{tabular}

Para analisar o segundo agrupamento de genes (proposto por Eisen et al. (1998)), uma nova base de textos foi coletada. Os textos foram coletados de maneira semelhante, porém, menos textos foram coletados. O registro de cada gene, nessa base, possui uma página principal onde são exibidas as principais referências bibliográficas sobre o gene. Neste experimento, os resumos de apenas estas referências foram coletadas. A Tabela 5.20 mostra a quantidade de resumos por cluster na coleção obtida.

Tabela 5.20: Coleção de textos sobre os genes dos clusters de Eisen et al. (1998).

\begin{tabular}{lcccccccccc}
\hline Cluster & $\mathrm{B}$ & $\mathrm{C}$ & $\mathrm{D}$ & $\mathrm{E}$ & $\mathrm{F}$ & $\mathrm{G}$ & $\mathrm{H}$ & $\mathrm{I}$ & $\mathrm{J}$ & $\mathrm{K}$ \\
$N^{\circ}$ de resumos & 70 & 70 & 43 & 138 & 33 & 61 & 54 & 124 & 61 & 22 \\
\hline
\end{tabular}

\subsubsection{Metodologia}

Para os experimentos realizados nesta Tese, os textos foram submetidos à ferramenta PreTexT (Matsubara et al., 2003) para serem transformados em tabelas atributo-valor. Essa ferramenta realiza os procedimentos tradicionais de pré-processamento de textos: corte de stopwords, stemização e definição de valores mínimo e máximo de freqüencia de palavras nos textos. Palavras que ocorrem menos de três vezes na coleção de textos foram descartadas. $O$ valor de cada atributo é a freqüência com que a respectiva palavra ocorre no texto. 
Para o experimento com os textos rotulados por gene, duas tabelas atributo-valor foram produzidas. Uma delas contém todas as palavras selecionadas pela ferramenta PreTexT. A outra conserva apenas palavras que possuem registro na ontologia sobre biologia molecular Gene Ontology (GO) (The Gene Ontology Consortium, 2000). O objetivo desse procedimento é eliminar palavras irrelevantes do conjunto de atributos.

Três classificadores foram considerados para esse experimento: C4.5, C4.5 Rules e SVM (Haykin, 1998; Lorena e Carvalho, 2003). SVMs, em especial, são conhecidos por apresentarem boa capacidade de generalização em aplicações com um grande número de atributos, que é o caso da maioria dos conjuntos de dados relacionados a processamento de textos. A ferramenta Discover (Prati, 2003) foi utilizada para auxiliar o particionamento dos dados e realizar o treinamento dos classificadores. Para o experimento realizado com os clusters propostos por Eisen et al. (1998), a tabela atributo-valor referente aos textos foi criada de duas maneiras:

- Seguindo a abordagem de Luhn. De acordo com Luhn (1958), a importância de uma determinada palavra para discriminar textos está intimamente relacionada com sua freqüência. Além disso, essa "distribuição de importância" tem um pico em algum lugar no gráfico de freqüências próximo à mediana. Por causa disso, devem ser selecionadas as palavras ao redor desse pico, por meio da definição de uma faixa de freqüência permitida.

- Seguindo a abordagem baseada em proporção. Outros autores propuseram o uso do conjunto inteiro de palavras. Nesse caso, cada palavra deve ter um peso inversamente proporcional a sua freqüência (Rijsbergen, 1979)

Foram consideradas 8 variações de faixa de freqüências e todas as palavras ponderadas de acordo com suas freqüências.

Como algoritmo de aprendizado supervisionado simbólico utilizado para a abordagem de análise de clusters, foi empregado o C4.5 rules e PART (Witten e Frank, 2005), para aprendizado de regras de decisão, e o C4.5, para aprendizado de árvores de decisão. Os resultados foram avaliados de acordo com as taxas de acurácia de classificação obtidas de acordo com a abordagem de teste $k$-fold cross-validation (Duda et al., 2001) com número de folds igual a 10 folds. A informação contida nas regras e árvores de decisão também foram comparadas com as informações fornecidas por Spellman et al. (1998) e Eisen et al. (1998) sobre os clusters de genes encontrados nesses trabalhos. 


\subsubsection{Resultados}

As taxas de acurácia obtidas do treinamento dos classificadores C4.5, C4.5 Rules e SVM com os textos rotulados por genes estão ilustradas na Tabela 5.21. Na mesma tabela, é informado o número de atributos de cada conjunto de dados. Nota-se que a precisão do C4.5 aumentou $14.91 \%$ após a utilização da ontologia e que a precisão dos outros classificadores não mudou muito. Porém, o desvio padrão diminuiu para os algoritmos C4.5 e SVM, o que indica que a taxa de erro calculada é mais estável. Esses resultados não correspondem exatamente ao esperado. Esperava-se que a precisão aumentasse significantemente com a utilização da ontologia.

Tabela 5.21: Taxas de acerto (média e desvio padrão entre os folds) e número de atributos.

\begin{tabular}{l|ccc|c}
\hline \hline & C4.5 & C4.5rules & SVM & $\mathrm{N}^{o}$ de atributos \\
\hline Todas as palavras & $63.01 \%(5.40)$ & $77.47 \%(3.42)$ & $85.47 \%(3.45)$ & 7297 \\
Palavras presentes na GO & $77.92 \%(3.30)$ & $77.38 \%(3.45)$ & $85.01 \%(2.9)$ & 4745 \\
\hline \hline
\end{tabular}

Uma abordagem semelhante foi investigada por Raychaudhuri et al. (2002), em que textos são classificados em categorias que representam processos celulares, como meiose, biogenese, etc. Foram utilizados os classificadores Máxima Entropia, Naïve Bayes e Nearest Neighbor. A melhor taxa de acerto obtida nesse trabalho foi 72.83\%, utilizando o classificador de Máxima Entropia. Enquanto que, no experimento descrito nesta seção, utilizando o algoritmo SVM, foi possivel obter uma taxa de acerto de $85.47 \%$.

A Tabela 5.22 exibe as taxas de acerto obtidas pelo treinamento do algoritmo C4.5rules com os textos rotulados de acordo com os clusters de Spellman et al. (1998).

Tabela 5.22: Taxas de acerto (média e desvio padrão entre os folds) e números de atributos.

\begin{tabular}{l|cc}
\hline \hline & Média de acerto (desvio padrão) & $\mathrm{N}^{o}$ de atributos \\
\hline Todas as palavras & $39.64 \%(2.82)$ & 10162 \\
Palavras presentes na GO & $41.39 \%(2.97)$ & 6732 \\
\hline \hline
\end{tabular}

Algumas das regras foram analisadas e comparadas com as características de cada cluster de genes publicadas por Spellman et al. (1998). De acordo com Spellman et al. (1998), o cluster "clb2" contém muitos genes envolvidos na mitose. A regra a seguir, produzida pelo C4.5rules, está de acordo com essa informação. 
A regra diz que, se a freqüência da palavra "mitot_cyclin" for maior do que O no texto, então esse texto descreve um gene pertencente ao cluster "clb2".

Outro exemplo diz respeito ao cluster "met". Ainda segundo Spellman et al. (1998), 50\% dos genes pertencentes a esse cluster estão envolvidos na biosíntese da metionina. A regra a seguir corrobora essa informação.

Rule 268:

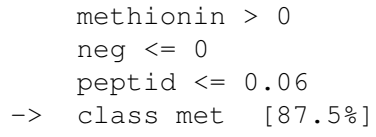

A regra diz que, em um texto, se a palavra "methionin" tiver freqüência maior do que 0 , a palavra "neg" tiver freqüência menor ou igual a 0 e a palavra "peptid" tiver freqüência menor ou igual a 0.06, o texto descreve um gene pertencente ao cluster "met".

Não foi possível a realização nesta Tese de uma análise completa das regras pelo fato de que em Spellman et al. (1998) não é fornecida uma informação completa sobre os clusters de genes.

O experimento com os clusters propostos por Eisen et al. (1998) destinou-se a cobrir esta lacuna, empregando um conjunto de clusters diferente, que apresentam uma maior quantidade de informações publicadas.

A Tabela 5.23 mostra as médias de acerto e desvio padrão resultantes do treinamento do algoritmo PART.

Tabela 5.23: Performance do treinamento das regras de decisão.

\begin{tabular}{ccc}
\hline$N^{o}$ de atributos & Média de acerto & Desvio Padrão \\
\hline 151 & 75.31 & 04.18 \\
454 & 76.78 & 03.34 \\
736 & 79.88 & 03.31 \\
1036 & 81.36 & 03.31 \\
2212 & 80.32 & 04.22 \\
4116 & 83.00 & 03.61 \\
6363 & 83.30 & 04.92 \\
11224 & 82.85 & 03.52 \\
12329 (palavras ponderadas) & 81.81 & 02.85 \\
\hline
\end{tabular}

Como pode ser observado, a tabela contendo 4116 atributos produziu o melhor resultado. As regras e a árvore treinadas com essa tabela foram analisadas com o intuito de encontrar similaridades com as informações sobre os clusters fornecidas por Eisen et al. (1998). Foram verificadas apenas as palavras que aparecem na condições (regras) ou nós (árvore) na forma "palavra $>$ frequencia" ou "palavra $>=$ frequencia". Por exemplo, considerando a regra a seguir, apenas a palavra "cytochrome" seria levada em consideração:

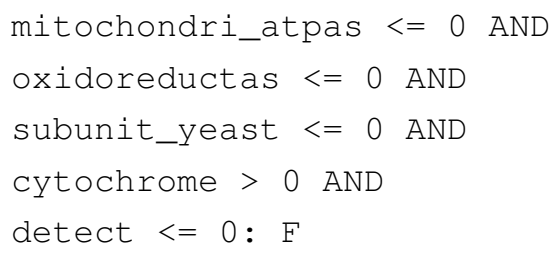


Não é descartada a possibilidade de que condições e nós testando a ausência de palavras possam também ser úteis na descoberta do significado dos clusters. Porém, para simplificar a avaliação dos resultados, apenas testes de presença de palavras foram analisados. O objetivo é definir se essas palavras podem fornecer um resumo sobre o significado de cada cluster.

Na Tabela 5.24, estão listadas todas as palavras, em sua forma stemizada, consideradas relacionadas com o significado do respectivo cluster. 


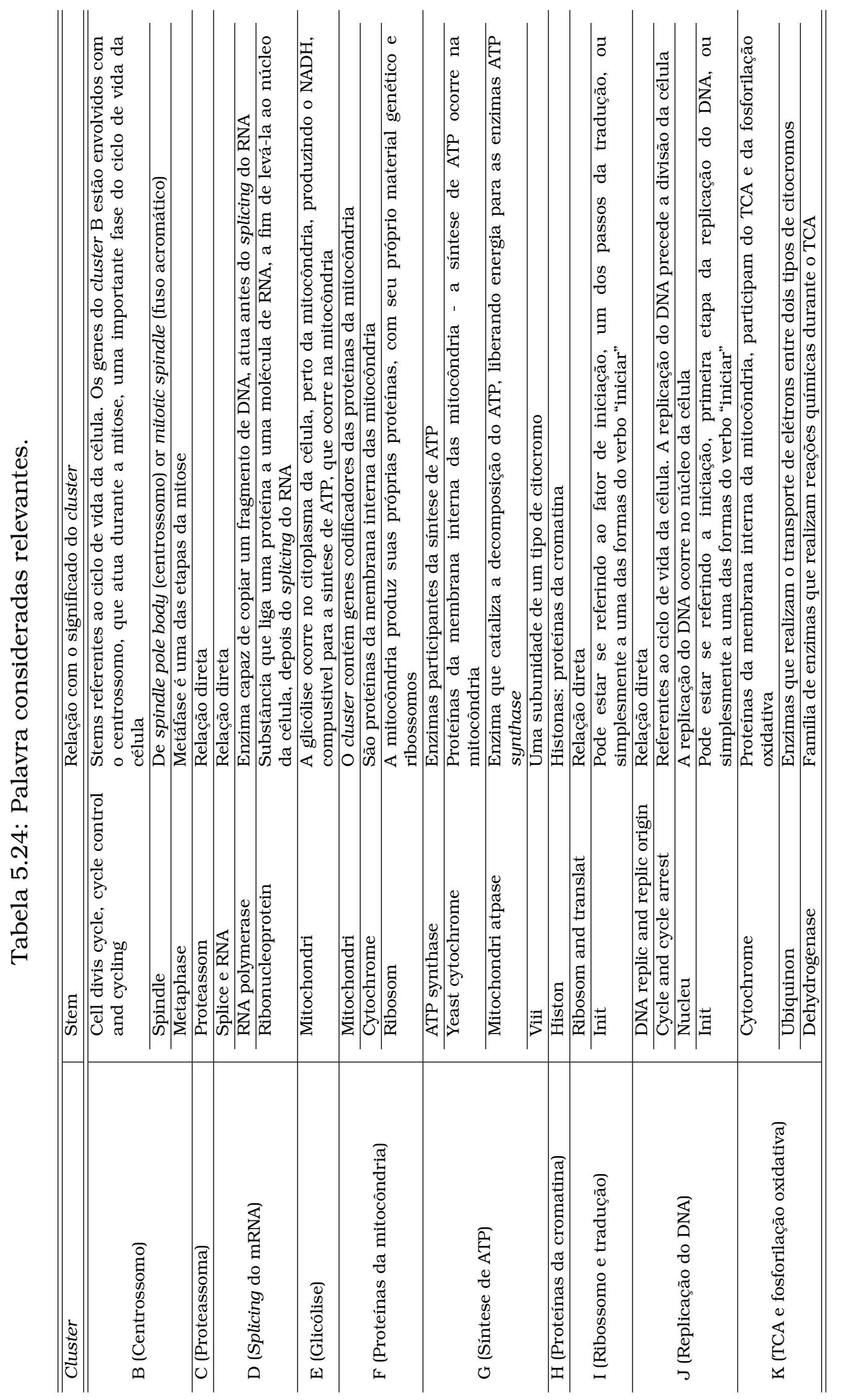


O algoritmo forneceu palavras significativas para quase todos os clusters. Apenas o significado do cluster "E" não pode ser inferido a partir de sua única palavra "mitochondri". Em vista disso, pode-se concluir que o recall deste experimento é 90\%. A média de acerto foi medida com base na proporção de palavras consideradas relevantes entre todas as palavras encontradas nas condições e nós testando sua presença. A Tabela 5.25 contém esses valores.

Tabela 5.25: Médias de acerto por cluster e total.

\begin{tabular}{|c|c|c|c|c|c|c|c|c|c|c|c|}
\hline cluster & $\mathrm{B}$ & $\mathrm{C}$ & $\mathrm{D}$ & $\mathrm{E}$ & $\mathrm{F}$ & $\mathrm{G}$ & $\mathrm{H}$ & I & $\mathrm{J}$ & $\mathrm{K}$ & Total(Desvio Padrão) \\
\hline acerto & 0,50 & 1,00 & 0,33 & 0,16 & 1,00 & 0,57 & 1,00 & 0,43 & 0,67 & 0,75 & $0,52(0,30)$ \\
\hline
\end{tabular}

Todas as sub-árvores enraizadas em nós que testam a presença de palavras foram analisadas a fim de verificar se os clusters em suas folhas estão relacionadas com a palavra em sua raiz. $71 \%$ do total de sub-árvores satisfizeram essa condição. Elas estão brevemente descritas na Tabela 5.26.

Tabela 5.26: Sub-árvores relevantes.

\begin{tabular}{ccl}
\hline \hline Palavra (raíz da sub-árvore) & Leva aos clusters (folhas) & Descrição \\
\hline \hline Cycle arrest & B e J & $\begin{array}{l}\text { Ambos clusters estão relacionados com a mitose, } \\
\text { última fase do ciclo de vida da célula }\end{array}$ \\
\hline Mitochondri & $\mathrm{D}, \mathrm{E}, \mathrm{F} \mathrm{e} \mathrm{K}$ & $\begin{array}{l}\text { Todos estes clusters estão relacionados com a } \\
\text { mitocôndria (onde também ocorre o splicing do } \\
\text { mRNA, pois ela produz suas próprias proteinas) }\end{array}$ \\
\hline Init & $\mathrm{I} \mathrm{e} \mathrm{J}$ & $\begin{array}{l}\text { Ambos clusters estaõ relacionados com etapas } \\
\text { chamadas "iniciação" (tradução e replicação do } \\
\text { DNA) }\end{array}$ \\
\hline DNA replic & B e J & $\begin{array}{l}\text { Ambos clusters estão relacionados com a mitose da } \\
\text { célula, etapa em que a replicação do DNA ocorre }\end{array}$ \\
\hline Ribosom & F e I & $\begin{array}{l}\text { Clusters respectivamente relacionaos com } \\
\text { ribossomos da mitocôndria e do citoplasma da } \\
\text { célula }\end{array}$ \\
\hline \hline
\end{tabular}

A maioria das palavras consideradas irrelevantes são palavras comuns da língua inglesa, ou conceitos básicos de biologia molecular. Um outro teste foi realizado, adicionado essas palavras comuns a stoplist. Uma nova tabela de atributo-valor foi produzida, resultando em 5725 atributos. As regras e árvore de decisão foram re-treinadas. Palavras diferentes começaram a aparecer em testes de presença, algumas delas consideradas relevantes. Das primeira 32 palavras relevantes (Tabela 5.24), 6 passaram a não ser exibidas e 17 novas palavras relevantes foram fornecidas. Elas são descritas na Tabela 5.27.

Entre as 5 primeiras sub-árvores, 2 não foram exibidas na nova árvore. Uma nova sub-árvore relevante foi produzida, e uma sub-árvore relevante ganhou uma folha nova e relevante, como pode ser visto na Tabela 5.28.

Outras palavras irrelevantes passaram a ser utilizadas pelas regras e árvore. Se esse segundo teste for considerado um segundo passo da abordagem, a média de acerto total passa a ser $47 \%$ para as palavras e $70 \%$ para as sub-árvores. O significado do cluster $\mathrm{E}$ continua sem poder ser inferido, assim o recall continua sendo o mesmo (90\%). Como pode 
Tabela 5.27: Novas palavras relevantes.

\begin{tabular}{|c|c|c|}
\hline Cluster & Palavra & Relação \\
\hline \multirow{3}{*}{ B (Centrossomo) } & $\begin{array}{l}\text { Anaphase } \\
\text { promot }\end{array}$ & $\begin{array}{lllll}\text { De anaphase promoting complex, } & \text { um } & \text { complexo } & \text { de } \\
\text { proteínas ativadas durante a mitose }\end{array}$ \\
\hline & Cytokinesi & Divisão do citoplasma durante a mitose \\
\hline & Septin & $\begin{array}{l}\text { Tipo de proteína que forma a estrutura em forma de anel } \\
\text { no local da citocinese }\end{array}$ \\
\hline \multirow{4}{*}{ D (Splicing do mRNA) } & TBP & $\begin{array}{l}\text { Subunidades de uma proteína que se liga ao DNA durante } \\
\text { a iniciação da transcrição }\end{array}$ \\
\hline & $\begin{array}{l}\text { Gene } \\
\text { transcript }\end{array}$ & Ocorre antes do splicing \\
\hline & rRNA & RNA ribossômico, decodifica o mRNA em aminoácidos \\
\hline & Chromatin & A estrutura da cromatina influencia na transcrição do RNA \\
\hline E (Glicólise) & Phosphatas & $\begin{array}{l}\text { Enzimas capazes de remover o fosfato de ácidos nucléicos } \\
\text { como o ATP, liberando energia, utilizada na glicólise }\end{array}$ \\
\hline G (Síntese do ATP) & $\begin{array}{l}\text { Oxidas } \\
\text { and oxidas } \\
\text { subunit }\end{array}$ & $\begin{array}{l}\text { Oxidases são enzimas que catalizam reações onde o } \\
\text { oxigênio é convertido em água. Um exemplo é o citocromo } \\
\text { c, que realiza esta função durante a síntese de ATP. }\end{array}$ \\
\hline \multirow{3}{*}{$\begin{array}{l}\text { I (Ribossomo } \\
\text { tradução) }\end{array}$} & $\begin{array}{l}\text { Ribosom } \\
\text { gene, ribosom } \\
\text { subunit and } \\
\text { yeast ribosom }\end{array}$ & Diretamente relacionados com o ribossomo \\
\hline & $\begin{array}{l}\text { Duplic gene, } \\
\text { elong factor, } \\
\text { tRNA }\end{array}$ & Relacionados com a tradução \\
\hline & Cerevisia initi & Refere-se ao fator de iniciação da transcrição \\
\hline
\end{tabular}

Tabela 5.28: Nova sub-árvore e sub-árvore antiga modificada

\begin{tabular}{ccl}
\hline \hline Palavra (raíz da sub-árvore) & Leva aos clusters (folhas) & Descrição \\
\hline \hline Cytochrome & $\mathrm{F}, \mathrm{G}$ e K & $\begin{array}{l}\text { Todos os clusters relacionados com } \\
\text { processos que ocorrem na mitocôndria, } \\
\text { onde se situam os citocromos }\end{array}$ \\
\hline Mitochondri & $\mathrm{D}, \mathrm{E}, \mathrm{F}, \mathrm{G}$ (novo) e K & $\begin{array}{l}\text { Ocluster G também se refere a um processo } \\
\text { que ocorre na mitocôndria }\end{array}$ \\
\hline \hline
\end{tabular}

ser observado, as médias de acerto diminuíram um pouco, porém palavras novas e relevantes foram reveladas. O que indica que esse passo deveria ser realizado repetidamente, a fim de explorar todas as possíveis palavras relevantes. Essa é uma das facilidades planejadas para integrarem o sistema destinado a englobar todas as abordagens propostas neste trabalho. Permitir que o usuário exclua palavras que considera irrelevantes para o domínio de aplicação da técnica.

Entre os trabalhos que aplicam abordagens semelhantes a essa, o mais similiar é o trabalho realizado por Blaschke et al. (2001). Nesse trabalho, também foram empregados os clusters definidos por Eisen et al. (1998). A saída desse trabalho compreende palavras e frases consideradas importantes para o significado dos clusters. Porém, não é possível realizar uma comparação exata, pois os autores não realizaram uma avaliação quantitativa e qualitativa. Eles apenas apresentaram algumas palavras e frases retornadas pela técnica, sem avaliar sua real relevância. Portanto, pôde-se apenas observar que os resultados foram semelhantes. Grande quantidade das palavras exibidas por Blaschke et al. (2001) foram também extraídas pela aplicação da abordagem investigada no experimento realizado nesta Tese. 


\subsection{Considerações finais}

Neste capítulo, foram descritas as análises experimentais para avaliar as abordagens propostas no Capítulo 4. Os experimentos envolvendo $\mathrm{AD}$ não-supervisionado indicam que o PSO utilizando a Silhueta como função de aptidão apresenta bons resultados. Nos experimentos relacionados ao $\mathrm{AD}$ semi-supervisionado, a técnica $\mathrm{SSL}+\mathrm{P}$ apresentou resultados competitivos com as técnicas comparadas, enquanto que embora a técnica SSL+P* tenha super-estimado o número de clusters, a mesma obteve bons resultados em termos de Erro de Classificação. Em relação à otimização baseada em população, os resultados dos experimentos mostram que as técnicas DPSO-1 e DPSO-2 obtiveram resultados melhores que a técnica PSO com $w$ descendente. Por fim, a investigação realizada na análise de clusters de dados biomédicos apresentou resultados interessantes e de acordo com o que é descrito na literatura. 


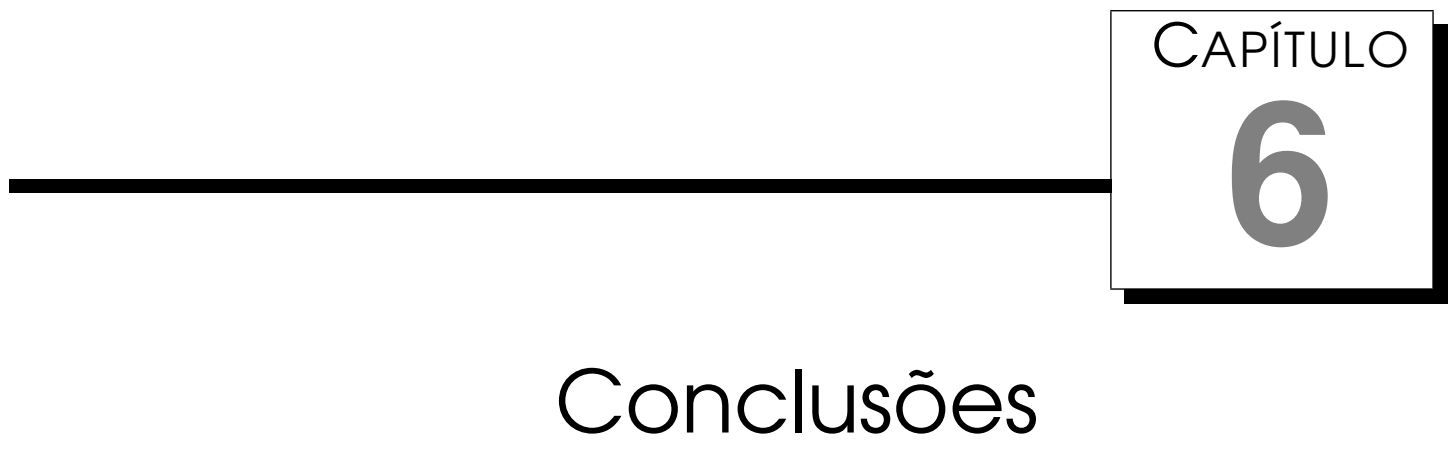

Esta Tese considera um cenário em que deseja-se agrupar dados de maneira a revelar e analisar estruturas desconhecidas de entidades de alguma forma relacionadas. Conceitos de diversas áreas de conhecimento podem ser empregados para construir um arcabouço de abordagens com o intuito de aprimorar tal cenário. Neste trabalho, foram englobados conceitos de Agrupamento de Dados (AD) fuzzy, com e sem o emprego de supervisão parcial, Otimização baseada em População (OBP) e Mineração de Textos (MT).

Este trabalho de Doutorado fornece contribuições em cada uma dessas áreas. A Seção 6.1 resume cada uma dessas contribuições. A Seção 6.2 apresenta algumas possibilidades de pesquisa sugeridas ao longo do desenvolvimento deste trabalho.

\subsection{Contribuições}

$\mathrm{Na}$ área de $\mathrm{AD}$, foi realizada uma análise abrangente da utilização de alguns dos principais índices de validação para guiar a formação de agrupamentos fuzzy de dados. Um algoritmo de OBP foi proposto e investigado para evoluir uma população de clusters (no caso, representados por protótipos) com o objetivo de a encontrar o agrupamento ideal de acordo com um critério de aptidão. Alguns dos principais índices de validação de $\mathrm{AD}$ encontrados na literatura foram considerados como critério de aptidão. Existem trabalhos na literatura que utilizam esse tipo de abordagem (associação de um algoritmo de OBP com algum índice de validação como critério de aptidão) (Hruschka et al., 2009; Egan et al., 1998; Yi et al., 2006; Chen e Zhao, 2009; Cui et al., 2005). Entretanto, a maioria deles se concentra na investigação da utilização de um 
índice de validação apenas. A análise realizada neste trabalho possui alguns diferenciais:

- Dois tipos de representação de protótipos foram considerados: centróides e medóides;

- No processo de otimização, foi permitida a adaptação de pesos para os atributos dos dados;

- Cinco índices de validação bastante utilizados pela comunidade científica foram investigados;

- A análise foi realizada no contexto de $\mathrm{AD}$ fuzzy, sendo que a maioria dos trabalhos que investigaram abordagens semelhantes está situada no contexto de $\mathrm{AD}$ hard $^{1}$. Dessa forma, 3 dos 5 índices analisados foram adaptados para esse contexto de AD: Silhueta, VRC e Davies-Bouldin.

- Os experimentos consideraram diversos valores para números de clusters, ao invés de empregar "números mágicos" ou considerar um cluster para cada classe, no caso de bases de dados de classificação.

Durante a realização dessa análise, foi observado que, em alguns casos, o algoritmo de OBP utilizado, o PSO, produzia melhores resultados para a representação de protótipos baseada em medóides, o que não é natural, pois a representação baseada em centróides permite o acesso a todo o espaço dimensional dos dados, incluindo os pontos onde se localizam os medóides. Com o objetivo de investigar esse problema, foram desenvolvidas duas versões modificadas do algoritmo PSO: DPSO-1 e DPSO-2, onde alguns parâmetros do PSO são modificados dinamicamente durante o processo de otimização. Esses algoritmos, aplicados a duas bases de dados, superaram, na maioria dos casos, a versão original do PSO (Kennedy e Eberhart, 1995) e outra versão bastante referenciada na literatura, introduzida por Shi e Eberhart (1998). Outra contribuição na área de algoritmos de OBP foi o desenvolvimento de 4 abordagens diferentes para a inicialização da população de partículas empregada pelo PSO. Uma dessas abordagens, a Centróides-3, se destacou consideravelmente em experimentos comparando todas elas com a tradicional forma aleatória de inicialização. Essa abordagem foi utilizada na maioria dos experimentos realizados para esta Tese envolvendo algoritmos de OBP.

$\mathrm{Na}$ área de $\mathrm{AD}$ semi-supervisionado, foram propostas duas abordagens, denominadas SSL+P e SSL+P*. Ambas possuem como principal característica a capacidade de lidar com Dicas de Conhecimento Prévio (DCPs) em duas formas: dados rotulados e informação sobre grau de proximidade de pares de

\footnotetext{
${ }^{1}$ Forma de agrupamento onde cada exemplo de dado pode pertencer a apenas um cluster.
} 


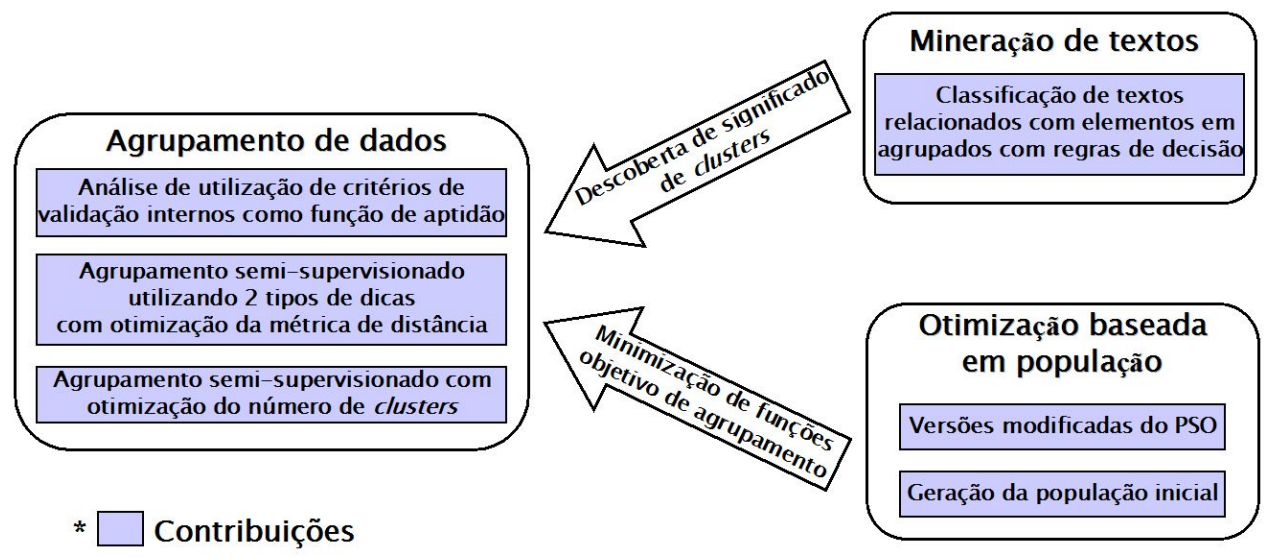

Figura 6.1: Contribuições da Tese.

exemplos. Outra característica compartilhada por ambas é a capacidade de adaptar a métrica de distância aos dados. A técnica SSL+P necessita que seja informado o número de clusters, já a SSL+P* foi desenvolvida para eliminar essa necessidade. Experimentos realizados fornecem indícios de que elas são capazes de alcançar resultados tão bons ou melhores do que 3 abordagens bastante referenciadas na literatura.

Por fim, foi proposta uma abordagem de MT para a análise de clusters de dados de um domínio específico, no caso, biologia molecular. Na abordagem proposta, depois que uma determinada partição é encontrada por um algoritmo de $\mathrm{AD}$, uma justificativa semântica para os resultados obtidos é fornecida. Isso é feito por meio da aplicação de métodos de MT às informações textuais disponibilizadas digitalmente e relacionadas com as entidades representadas nos dados. Assim, pode-se, supostamente, identificar as relações compartilhadas pelos exemplos em cada cluster. Essa abordagem foi aplicada a clusters de genes propostos na literatura biomédica. Os resultados obtidos foram comparados com as informações publicadas sobre esses clusters e diversas correspondências foram constatadas.

Dessa forma, este trabalho possui contribuições em diversas etapas de um processo de agrupamento de dados. Um resumo dessas contribuições e como elas se relacionam pode ser visto na Figura 6.1.

\subsection{Trabalhos futuros}

Os próximos passos para dar continuidade a este trabalho devem incluir a investigação de algumas idéias que surgiram no decorrer da pesquisa e a realização de análises mais detalhadas de alguns pontos específicos relacionados com as abordagens propostas. A seguir, alguns desses passos são brevemente discutidos.

As versões modificadas do algoritmo PSO propostas, DPSO-1 e DPSO-2, 
necessitam do ajuste de alguns parâmetros. Futuramente, será realizada uma análise da sensibilidade desses algoritmos em relação a variações dos valores desses parâmetros.

As abordagens de $\mathrm{AD}$ semi-supervisionado propostas, SSL+P e SSL+P*, consistem na otimização de uma função-objetivo composta pela ponderação de três termos e, portanto, dois parâmetros de escala devem ser definidos. Planeja-se investigar o uso das abordagens de otimização multi-objetivo Pareto (Coello et al., 2006) e Lexicográfica (Freitas, 2004) para eliminar a necessidade de escolha de valores para esses parâmetros. Ainda sobre as abordagens de $\mathrm{AD}$ semi-supervisionado, os experimentos realizados levaram em conta apenas bases de dados sintéticas e do repositório UCI. Planeja-se analisar a aplicação dessas técnicas a dados de biologia molecular.

Com relação à parte de MT deste trabalho, duas idéias devem ser investigadas:

- Utilizar $\mathrm{AD}$ fuzzy em base de textos para selecionar os termos que melhor descrevem os clusters de dados já formados: em um conjunto de textos, em que um ou mais textos estão relacionados com um elemento dos clusters já formados, é selecionado o conjunto de atributos (termos) que produz o particionamento de textos mais próximo do agrupamento de elementos formado. Esses clusters de termos são, então, utilizados como atributos para produção de regras de decisão que possam ajudar a identificar o significado de cada cluster.

- Utilizar MT para produção de dicas para Agrupamento semi-supervisionado: essa idéia foi discutida em conjunto com o Professor Witold Pedrycz, da Universidade de Alberta, Canada, e consiste em investigar a possibilidade de produzir automaticamente dicas de proximidade entre exemplo de dados com base na Mineração de Textos relacionados com os dados. Uma das formas de extrair esse tipo de informação é pela medição do nível de co-ocorrência de palavras em textos e frases e da comparação entre textos relacionados com os dados.

Os pontos apresentados nesta seção deverão ser investigados futuramente como parte de um projeto de Pós-doutorado. 


\section{Referências Bibliográficas}

Alizadeh, A. A.; Eisen, M. B.; Davis, R. E.; Ma, C.; Lossos, I. S.; Rosenwald, A.; Boldrick, J. C.; Sabet, H.; Tran, T.; Yu, X.; Powell, J. I.; Yang, L.; Marti, G. E.; Moore, T.; Hudson, J.; Lu, L.; Lewis, D. B.; Tibshirani, R.; Sherlock, G.; Chan, W. C.; Greiner, T. C.; Weisenburger, D. D.; Armitage, J. O.; Warnke, R.; Levy, R.; Wilson, W.; Grever, M. R.; Byrd, J. C.; Botstein, D.; Brown, P. O.; Staudt, L. M. (2000). Distinct types of diffuse large b-cell lymphoma identified by gene expression profiling. Nature, v.403, n.6769, p.503-511.

Bader, G. D.; Betel, D.; Hogue, C. W. (2003). Bind: the biomolecular interaction network database. Nucleic Acids Res., v.31, n.1, p.248-250.

Bair, E.; Tibshirani, R. (2004). Semi-supervised methods to predict patient survival from gene expression data. PLoS Biology, v.2, n.4, p.511-522.

Basu, S.; Banerjee, A.; Mooney, R. (2002). Semi-supervised clustering by seeding. Proceedings of the 19th Intenational Conference on Machine Learning, p. 19-26.

Basu, S.; Mooney, R. J. (2003). Comparing and unifying search-based and similarity-based approaches to semi-supervised clustering. In Proceedings of the ICML-2003 Workshop on the Continuum from Labeled to Unlabeled Data in Machine Learning and Data Mining, p. 42-49.

Bezdek, J. C. (1981). Pattern recognition with fuzzy objective function algorithms. Ed. Prenum.

Blaschke, C.; Oliveros, J. C.; Valencia, A. (2001). Mining functional information associated with expression arrays. Funct Integr Genomics, v.1, n.4, p.256-268.

Blaschke, C.; Andrade, M. A.; Ouzounis, C.; Valencia, A. (1999). Automatic extraction of biological information fron scientific text: protein-protein interactions. Proc Int Conf Intell Syst Mol Biol, v. 30A, p. 60-67. 
Blum, A.; Lafferty, J.; Rwebangira, M.; Reddy, R. (2004). Cluster kernels for semisupervised learning. Proceedings of the 21th International Conference on Machine Learning, p. 92-100.

Bouchachia, A.; Pedrycz, W. (2003). A semi-supervised clutsering algorithm for data exploration. IFSA, p. 328-337.

Bouchachia, A.; Pedrycz, W. (2006a). Data clustering with partial supervision. Data Mining and Knowledge Discovery, v. 12, n.1, p.47-78.

Bouchachia, A.; Pedrycz, W. (2006b). Enhancement of fuzzy clustering by mechanisms of partial supervision. Fuzzy Sets and Systems, v.157, n.13, p.1733-1759.

Braga, A. P.; de Carvalho, A. C. P. L. F.; Ludemir, T. B. (2007). Redes Neurais Artificiais: Teoria e aplicações. Livros Técnicos e Científicos, 2 edição.

Bruce, R. (2001). A bayesian approach to semi-supervised learning. Proceedings of the Sixth Natural Language Processing Pacific Rim Symposioum - NLPRS-2001, p. 57-64.

Calinski, R. B.; J., H. (1974). A dendrite method for cluster analysis. Communications in Statistics, v.3, p.1-27.

Campello, R.; Hruschka, E. (2006). A fuzzy extension of the silhouette width criterion for cluster analysis. Fuzzy Sets and Systems, v.157, n.21, p.2858 -2875 .

Chen, D.; Zhao, C. (2009). Data-driven fuzzy clustering based on maximum entropy principle and pso. Expert Systems with Applications, v.36, n.1, p.625- 633 .

Coello, C. A. C.; Lamont, G. B.; Veldhuizen, D. A. V. (2006). Evolutionary Algorithms for Solving Multi-Objective Problems (Genetic and Evolutionary Computation). Springer-Verlag New York, Inc., Secaucus, NJ, USA.

Cui, X.; Potok, T.; Palathingal, P. (2005). Document clustering using particle swarm optimization. Swarm Intelligence Symposium, 2005. SIS 2005. Proceedings 2005 IEEE, p. 185 - 191.

Davies, D. L.; Bouldin, D. W. (1979). A cluster separation measure. Pattern Analysis and Machine Intelligence, IEEE Transactions on, v.1, n.2, p.224-227.

Deerwester, S.; Dumais, S. T.; Furnas, G. W.; Landauer, T. K.; Harshman, R. (1990). Indexing by latent semantic analysis. Journal of the American Society for Information Science, v.41, n.6, p.391-407. 
Demiriz, A.; Bennett, K.; Embrechts, M. (1999). Semi-supervised clustering using genetic algorithms. Dagli, C. H., editor, Intelligent Engineering Systems Through Artificial Neural Networks 9, p. 809-814. ASME Press.

Demšar, J. (2006). Statistical comparisons of classifiers over multiple data sets. Journal of Machine Learning Research, v.7, p.1-30.

Duda, R. O.; Hart, P. E.; Stork, D. G. (2001). Pattern Classification. John Wiley \& Sons.

Egan, M.; Krishnamoorthy, M.; Rajan, K. (1998). Comparative study of a genetic fuzzy c-means algorithm and a validity guided fuzzy c-means algorithm for locating clusters in noisy data. Evolutionary Computation Proceedings, 1998. IEEE World Congress on Computational Intelligence., The 1998 IEEE International Conference on, p. 440-445.

Eilbeck, K.; Brass, A.; Paton, N.; Hodgman, C. (1999). Interact: an object oriented protein-protein interaction database. Proc. Int. Conf. Intell. Syst. Mol. Biol., p. 87-94.

Eisen, M. B.; Spellman, P. T.; Brown, P. O.; Botstein, D. (1998). Cluster analysis and display of genome-wide expression patterns. Proceedings of the National Academy of Sciences of the United States of America, v.95, p.14863-14867.

Faceli, K.; Carvalho, A. C. P. L. F.; de Souto, M. C. P. (2005). Validação de algoritmos de agrupamento. Relatório Técnico 254, Instituto de Ciências Matemáticas e de Computação - USP. ftp://ftp.icmc.usp.br/pub/ BIBLIOTECA/rel_tec/RT_254.pdf.

Fayyad, U. (1996). Data mining and knowledge discovery: making sense out of data. IEEE Expert, v.11, n.5, p.20-25.

Fayyad, U.; Piatetsky-Shapiro, G.; Amith, S.; Smyth, P. (1996). From data mining to knowledge discovery: an overview. Press, A., editor, Advances in Knowledge Discovery and Data Mining, p. 1-34.

Freitas, A. A. (2004). A critical review of multi-objective optimization in data mining: a position paper. SIGKDD Explor. Newsl., v.6, p.77-86.

Friedman, C.; Kra, P.; Yu, H.; Krauthammer, M.; Rzhetsky, A. (2001). Genies: a natural-language processing system for the extraction of molecular pathways from journal articles. Bioinformatics, v.17, p.S74-S82. Supplement. 
Fukuda, K.; Tamura, A.; Tsunoda, T.; Takagi, T. (1998). Toward information extraction: identifying protein names from biological papers. Pacific Symposium on Biocomputing, p. 707-718.

Giles, J. T.; Wo, L.; Berry, M. W. (2003). Statistical Data Mining and Knowledge Discovery, chapter GTP (General Text Parser) Software for Text Mining, p. 457-473. CRC Press.

Goldberg, D. E. (1989). Genetic Algorithms in Search, Optimization and Machine Learning. Addison-Wesley Longman Publishing Co., Inc., Boston, MA, USA, 1st edição.

Greengrass, E. (2000). Information retrieval: A survey. Relatório técnico.

Gustafson, D. E.; Kessel, W. C. (1978). Fuzzy clustering with a fuzzy covariance matrix. Decision and Control including the 17th Symposium on Adaptive Processes, 1978 IEEE Conference on, v.17, p.761-766.

Hayes, P. (1992). Intelligent high-volume processing using shallow, domain-specific techniques. Text-based Intelligent Systems: Current Research and Practice in Information Extraction and Retrieval, p. 227-242.

Haykin, S. (1998). Neural Networks: A Comprehensive Foundation. Prentice Hall, 2 edição.

Hearst, M. (1999). Untangling text data mining. Proc. Of the 37th Annual Meeting of the Association for Computational Linguistics (ACL).

Homayouni, R.; Heinrich, K.; Wei, L.; Berry, M. W. (2005). Gene clustering by latent semantic indexing of medline abstracts. Bioinformatics, v.21, n.1, p. 104-115.

Hruschka, E.; Campello, R.; Freitas, A.; de Carvalho, A. (2009). A survey of evolutionary algorithms for clustering. Systems, Man, and Cybernetics, Part C: Applications and Reviews, IEEE Transactions on, v.39, n.2, p.133-155.

Jain, A. K.; Murty, M. N.; Flynn, P. J. (1999). Data clustering: a review. ACM Comput. Surv., v.31, n.3, p.264-323.

Jenssen, T. K.; Laegreid, A.; Komorowski, J.; Hovig, E. (2001). A literature network of human genes for high-throughput analysis of gene expression. Nature Genetics, v.28, n.1, p.21-28.

Kennedy, J.; Eberhart, R. (1995). Particle swarm optimization. Neural Networks, 1995. Proceedings., IEEE International Conference on, v. 4, p. 1942 -1948 vol.4. 
Kennedy, J.; Eberhart, R. C. (2001). Swarm Intelligence. Morgan Kaufmann.

Klawonn, F.; Keller, A. (1997). Fuzzy clustering with evolutionary algorithms. Proc. Seventh IFSA World Congress, V.2, p. 312-323.

Klein, D.; Kamvar, S.; Manning, C. (2002). From instance-level constraints to space-level constraints: Making the most of prior knowledge in data clustering. The Nineteenth International Conference on Machine Learning.

Krishnapuram, R.; Kim, J. (1999). A note on the gustafson-kessel and adaptive fuzzy clustering algorithms. Fuzzy Systems, IEEE Transactions on, v.7, n.4, p.453-461.

Lorena, A. C.; Carvalho, A. C. P. L. F. (2003). Introdução às máquinas de vetores suporte (support vector machines). Relatório Técnico 192, Instituto de Ciências Matemáticas e de Computação. ftp://ftp.icmc.usp.br/pub/ BIBLIOTECA/rel_tec/RT_192.pdf.

Luhn, H. P. (1958). The automatic creation of literature abstracts. IBM Journal of Research and Development, v.2, p.159-165.

MacQueen, J. B. (1967). Some methods for classification and analysis of multivariate observations. Proceedings of 5th Berkeley Symposium on Mathematical Statistics and Probability, p. 281-297.

Manning, C. D.; Schutze, H. S. (1999). Foundations of Statistical Natural Language Processing. MIT Press.

Masys, D. R.; Welsh, J. B.; Fink, J. L.; Gribskov, M.; Klacansky, I.; Corbeil, J. (2001). Use of keyword hierarchies to interpret gene expression patterns. Bioinformatics, v.17, n.4, p.319-326.

Matsubara, E. T.; Martins, C. A.; Monard, M. C. (2003). Pretext: uma ferramenta para pré-processamento de textos utilizando a abordagem bag-of-words. Relatório Técnico 209, Instituto de Ciências Matemáticas e de Computação.

Mavroudi, S.; Papadimitriou, S.; Bezerianos, A. (2002). Gene expression data analysis with a dynamically extended self-organized map that exploits class information. Bioinformatics, v.18, n.11, p.1446-1453.

McCallum, A. K. (1996). Bow: A toolkit for statistical language modeling, text retrieval, classification and clustering. http://www.cs.cmu.edu/ mccallum/bow.

McCallum, A. K. (2002). Mallet: A machine learning for language toolkit. http://mallet.cs.umass.edu. 
Medeiros, D. M. R.; Carvalho, A. C. P. L. F. (2004). Gene clusters analysis using text mining. WOB - Third Workshop on Bioinformatics, p. 141-144.

Medeiros, D. M. R.; Carvalho, A. C. P. L. F. (2005). Applying text mining and machine learning techniques to gene clusters analysis. ICCIMA '05: Proceedings of the Sixth International Conference on Computational Intelligence and Multimedia Applications (ICCIMA'05), p. 23-28, Washington, DC, USA. IEEE Computer Society.

Medeiros, D. M. R.; Carvalho, A. C. P. L. F. (2010). Dpso - dynamic particle swarm optimization. CSI Communications, v.34, n.9, p.8-11.

Mitchell, T. M. (1997). Machine Learning. McGraw-Hill.

Newman, D. J.; Hettich, S.; Blake, C.; Merz, C. (1998). UCI repository of machine learning databases.

Oliveros, J.; Blaschke, C.; Herrero, J.; Dopazo, J.; Valencia, A. (2000). Expression profiles and biological function. Genome Inform Ser Workshop Genome Inform, v.11, p.106-117.

Pal, N.; Bezdek, J. (1995). On cluster validity for the fuzzy c-means model. Fuzzy Systems, IEEE Transactions on, v.3, n.3, p.370 -379.

Papadimitriou, S.; Mavroudi, S.; Vladutu, L.; Bezerianos, A. (2001). Ischemia detection with a self-organizing map supplemented by supervised learning. IEEE Transactions on Neural Networks, v.12, n.3, p.503-515.

Pedrycz, W.; Loia, V.; Senatore, S. (2004). P-fcm: a proximity - based fuzzy clustering. Fuzzy Sets and Systems, v.148, n.1, p.21-41.

Pedrycz, W.; Oliveira, J. V. (2008). A development of fuzzy encoding and decoding through fuzzy clustering. IEEE Transactions on Instrumentation and Measurement, v.57, n.4, p.829-837.

Pedrycz, W.; Waletzky, J. (1997). Fuzzy clustering with partial supervision. IEEE Transactions on Systems Man and Cybernetics, v.B 27, n.5, p.787-795.

Porter, M. (1980). An algorithm for suffix stripping. Program, v.14, n.3, p. 130-137.

Prati, R. C. (2003). O framework de integração do sistema discover. Dissertação (Mestrado), Instituto de Ciências Matemáticas e de Computação - USP.

Quinlan, J. R. (1988). C4.5 Programs for Machine Learning. Morgan Kaufmann. 
Rajman, M.; Besancon, R. (1997). Text mining: Natural language techniques and text mining applications. Proceedings of the 7th IFIP 2.6 Working Conference on Database Semantics, DS-7.

Raychaudhuri, S.; Altman, R. B. (2003). A literature-based method for assessing the functional coherence of a gene group. Bioinformatics, v.19, n.3, p.396-401.

Raychaudhuri, S.; Chang, J. T.; Imam, F.; Altman, R. B. (2003). The computational analysis of scientific literature to define and recognize gene expression clusters. Nucleic Acids Research, v.31, n.15, p.4553-4560.

Raychaudhuri, S.; J. T. Chang, P. D. S.; Altman, R. B. (2002). Associating genes with gene ontology codes using a maximum entropy analysis of biomedical literature. Genome Research, v.12, p.203-214.

Rezende, S. O. (2003). Sistemas Inteligentes: Fundamentos e Aplicações. Manole.

Rijsbergen, C. J. V. (1979). Information Retrieval. Dept. of Computer Science, University of Glasgow, 2nd edição.

Rindflesch, T. C.; Tanabe, L.; Weinstein, J. N.; Hunter, L. (2000). Edgar: extraction of drugs, genes and relations from the biomedical literature. Pacific Symposium on Biocomputing, p. 517-528.

Rousseeuw, P. (1987). Silhouettes: a graphical aid to the interpretation and validation of cluster analysis. J. Comput. Appl. Math., v.20, n.1, p.53-65.

Sanches, M. K. (2003). Aprendizado de máquina semi-supervisionado: proposta de um algoritmo para rotular exemplos a partir de poucos exemplos. Dissertação (Mestrado), ICMC-USP.

Shatkay, H.; Edwards, S.; Wilbur, W.; Boguski, M. (2000). Genes, themes and microarrays: using information retrieval for large-scale gene analysis. Proc Int Conf Intell Syst Mol Biol., v. 8, p. 317-328.

Shatkay, H.; Feldman, R. (2003). Mining the biomedical literature in the genomic era: An overview. Journal of Computational Biology, v.10, n.6, p.821-855.

Shi, Y.; Eberhart, R. (1998). A modified particle swarm optimizer. Evolutionary Computation Proceedings, 1998. IEEE World Congress on Computational Intelligence., The 1998 IEEE International Conference on, p. 69 -73.

Slonim, D. K. (2002). From patterns to pathways: gene expression data analysis comes of age. Nature Genetics, v.32, p.502-508. Supplement. 
Spellman, P. T.; Sherlock, G.; Zhang, M. Q.; Iyer, V. R.; Anders, K.; M. B. Eisen, P. O. B.; Botstein, D.; Futcher, B. (1998). Comprehensive identification of cell cycle-regulated genes of the yeast sacchromyces cerevisiae by microarray hybridization. Molecular Biology of the Cell, v.9, p.3273-3297.

Tamames, J.; Clark, D.; Herrero, J.; Dopazo, J.; Blaschke, C.; Fernandez, J. M.; Oliveros, J. C.; Valencia, A. (2002). Bioinformatics methods for the analysis of expression arrays: data clustering and information extraction. $J$ Biotechnol, v.98, n.2-3, p.269-283.

Tanabe, L.; Scherf, U.; Smith, L. H.; Lee, J. K.; Hunter, L.; Weinstein, J. N. (1999). Medminer: an internet text-mining tool for biomedical information, with application to gene expression profiling. Biotechniques, v.27, n.6, p. 1210-1217.

The Gene Ontology Consortium (2000). Gene ontology: tool for the unification of biology. Nature Genetics, v.25, p.25-29.

Van Le, T. (1995). Evolutionary fuzzy clustering. Evolutionary Computation, 1995., IEEE International Conference on, p. 753-758.

Wagstaff, K.; Cardie, C.; Rogers, S.; Schoredl, S. (2001). Constrained k-means clustering with background knowledge. Proceedings of the Eighteenth International Conference on Machine Learning - ICML-2001, p. 577-584.

Weiss, M.; Indurkhya, N. (1998). Predictive Data-Mining. Morgan Kaufmann.

Witten, I. H.; Frank, E. (2005). Data Mining: Practical machine learning tools and techniques. Morgan Kaufmann, 2nd edição.

Xenarios, I.; Rice, D. W.; Salwinski, L.; Baron, M. K.; Marcotte, E. M. (2000). Dip: the database of interacting proteins. Nucleic Acids Res., v.28, p.289-291.

Xie, X.; Beni, G. (1991). A validity measure for fuzzy clustering. Pattern Analysis and Machine Intelligence, IEEE Transactions on, v.13, n.8, p.841 $-847$.

Xing, E. P.; Ng, A. Y.; Jordan, M. I.; Russel, S. (2003). Distance metric learning with application to clustering with side-information. Thrun, S.; Becker, S.; Obermayer, K., editores, Advances in Neural Information Processing Systems 15, p. 505-512. MIT Press.

Yandell, M. D.; Majoros, W. H. (2002). Genomics and natural language processing. Nature Reviews Genetics, v.3, p.601-610. 
Yi, W.; Yao, M.; Jiang, Z. (2006). Fuzzy particle swarm optimization clustering and its application to image clustering. Zhuang, Y.; Yang, S.; Rui, Y.; He, Q., editores, Advances in Multimedia Information Processing - PCM 2006, v. 4261 de Lecture Notes in Computer Science, p. 459-467. Springer Berlin / Heidelberg. 10.1007/11922162_53.

Zeng, H.-J.; Wang, X.-H.; Chen, Z.; Lu, H.; Ma, W.-Y. (2003). Cbc: Clustering based text classification requiring minimal labeled data. Third IEEE International Conference on Data Mining, p. 443-450.

Zhu, X.; Kandola, J.; Ghahramani, Z.; Lafferty, J. (2005). Nonparametric transforms of graph kernels for semi-supervised learning. Advances in Neural Information Processing Systems, v.17, p.1641-1648.

Zipf, G. K. (1949). Human Behavior and the Principle of Least-Effort. Addison-Wesley. 
APÊNDICE

A

\section{Resultados completos dos experimentos em AD semi-supervisionado}

Nas Figuras A.1-A.3 são apresentados os erros de classificação obtidos nos experimentos comparando os algoritmos SSL+P, Bouchachia e Pedrycz (Bouchachia e Pedrycz, 2003), Constrained e Seeded $k$-médias considerando as bases de dados Sintética-1, Sintética-3 e Sintética-4.

As Figuras A.4,A.5, A.6 e A.7 apresentam os erros de classificação quando o algoritmo SSL+P* é utilizado no lugar do SSL+P nas bases de dados Iris, Sintética-3, Sintética-4 e Wine, respectivamente. O número de clusters estimados pelo SSL+P* para cada base de dados são apresentados nas Figuras A.8, A.9, A. 10 e A. 11 
APENNDICE A. RESULTADOS COMPLETOS DOS EXPERIMENTOS EM AD

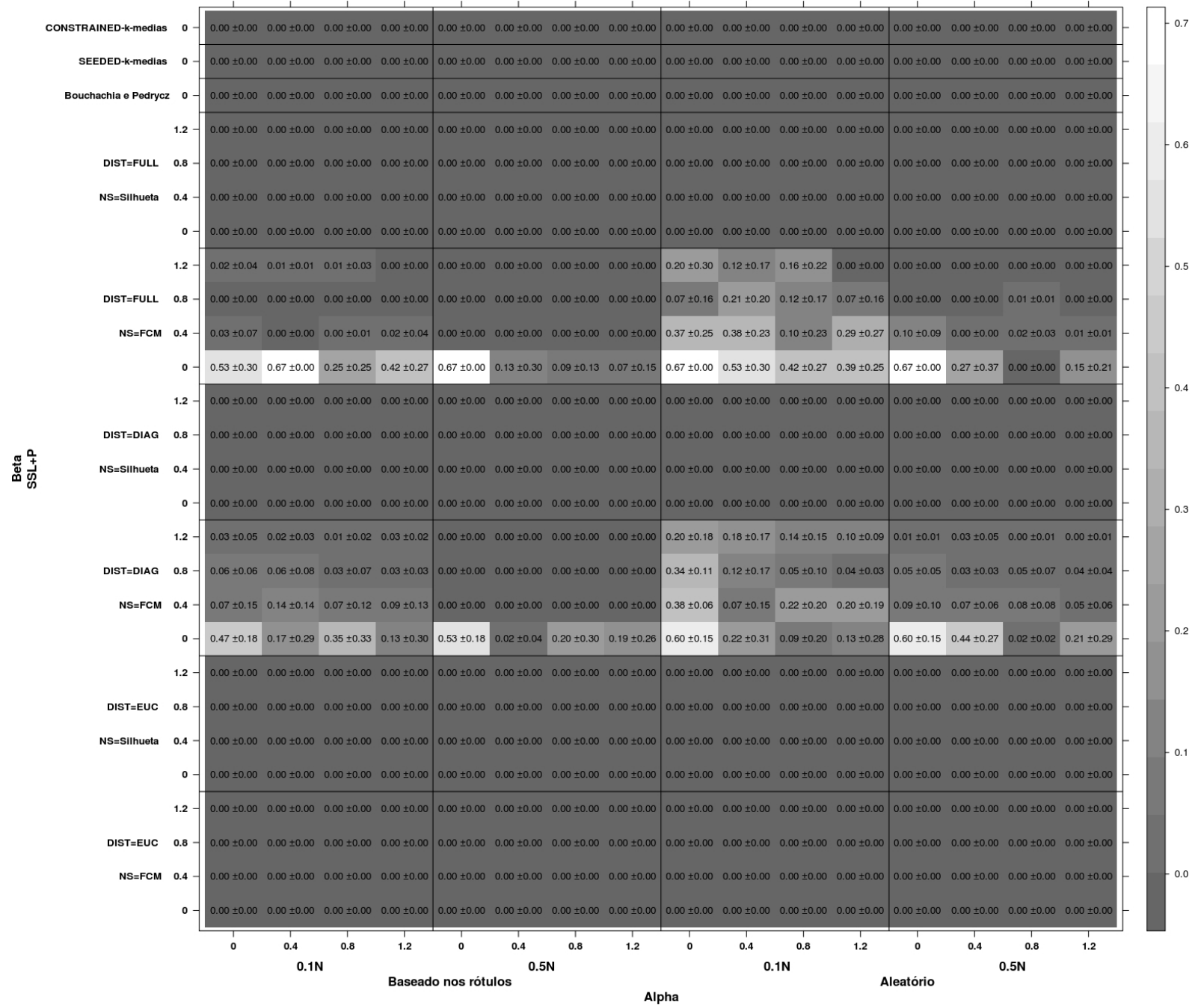

Figura A.1: Comparação do erro de classificação entre os algoritmos Bouchachia e Pedrycz (Bouchachia e Pedrycz, 2006a), Constrained e Seeded k-médias com SSL+P na base de dados Sintética-1. 


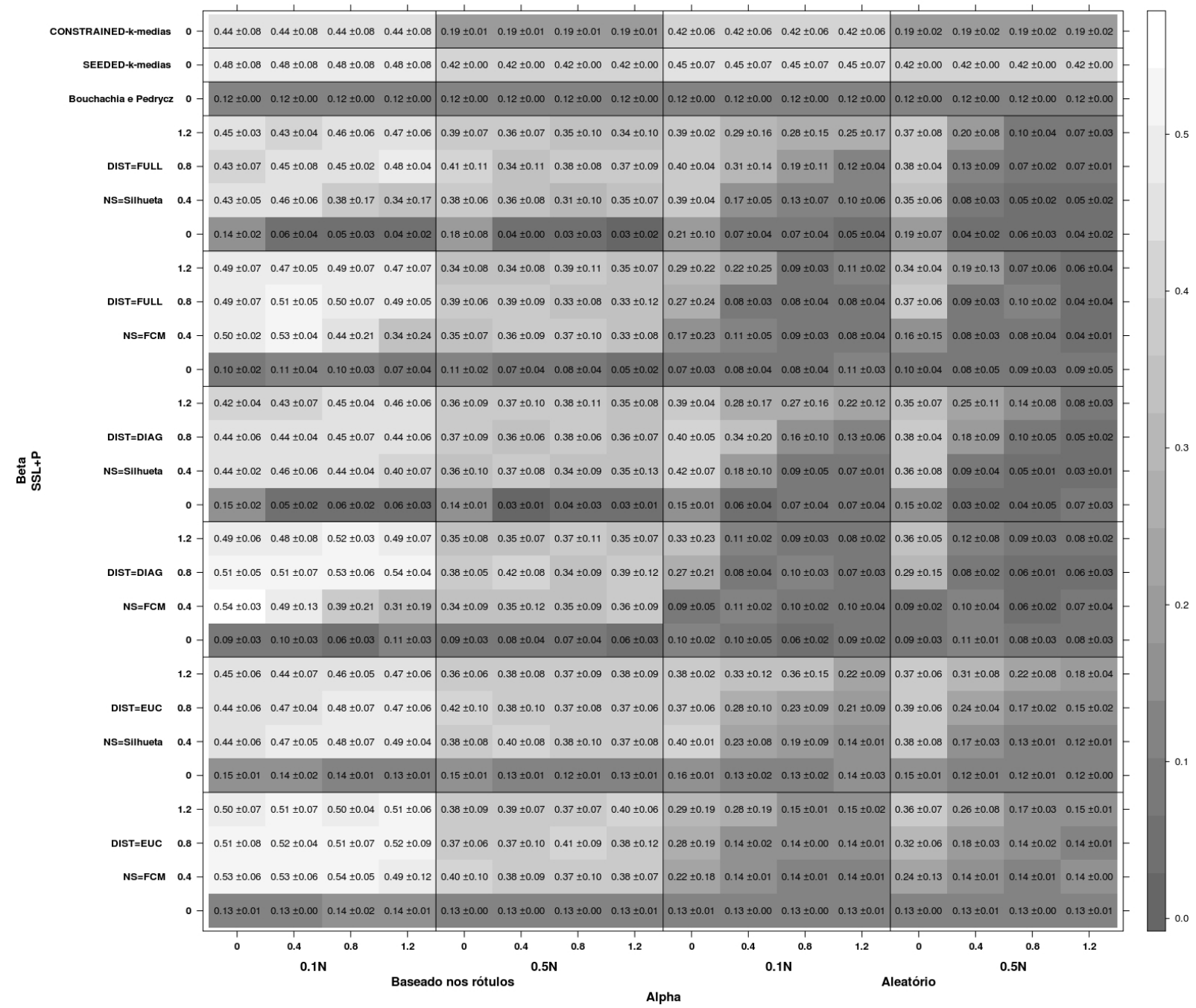

Figura A.2: Comparação do erro de classificação entre os algoritmos Bouchachia e Pedrycz (Bouchachia e Pedrycz, 2006a), Constrained e Seeded $k$-médias com SSL+P na base de dados Sintética-3. 
APÊNDICE A. RESULTADOS COMPLETOS DOS EXPERIMENTOS EM AD

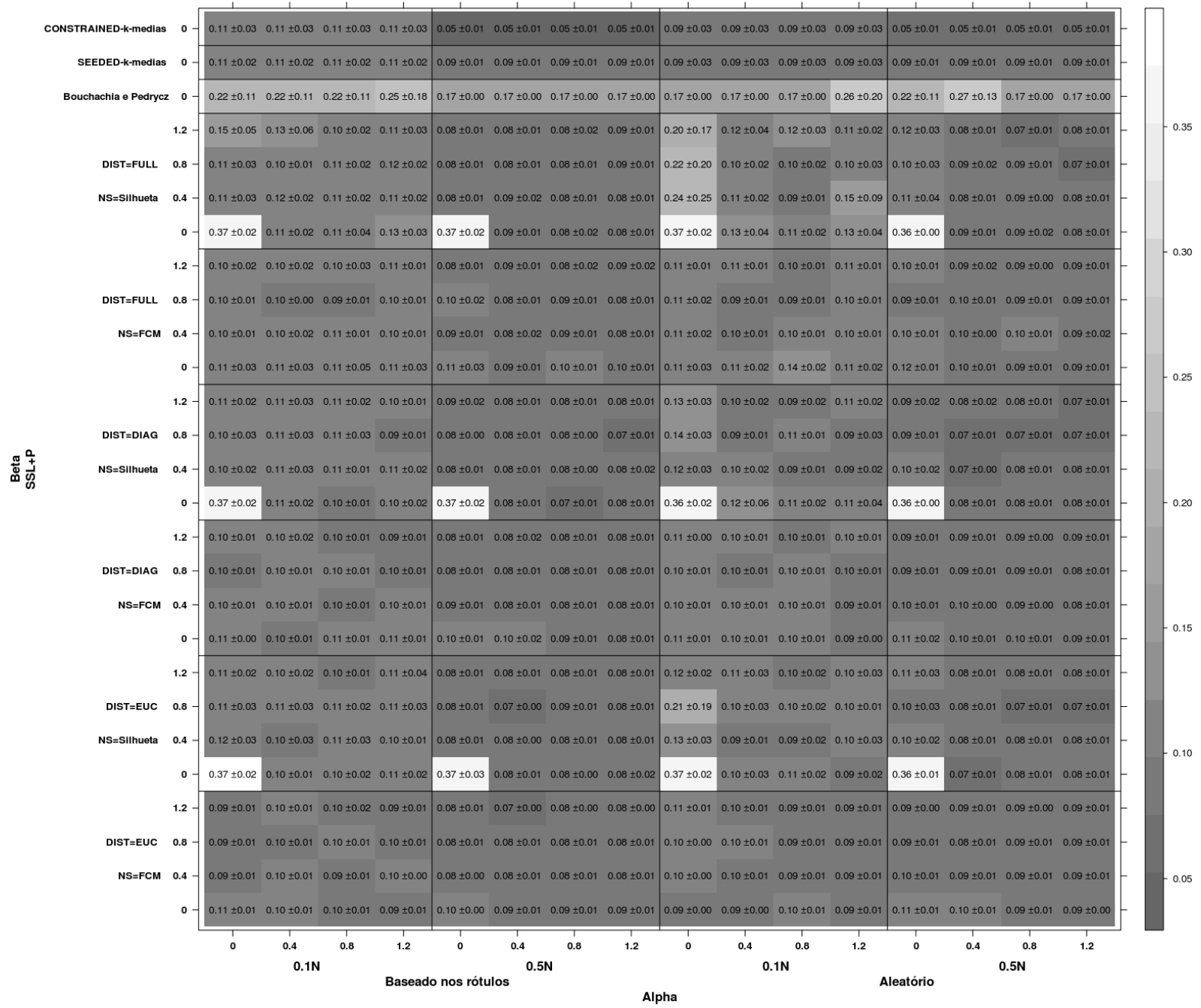

Figura A.3: Comparação do erro de classificação entre os algoritmos Bouchachia e Pedrycz (Bouchachia e Pedrycz, 2003), Constrained e Seeded k-médias com SSL+P na base de dados Sintética-4. 


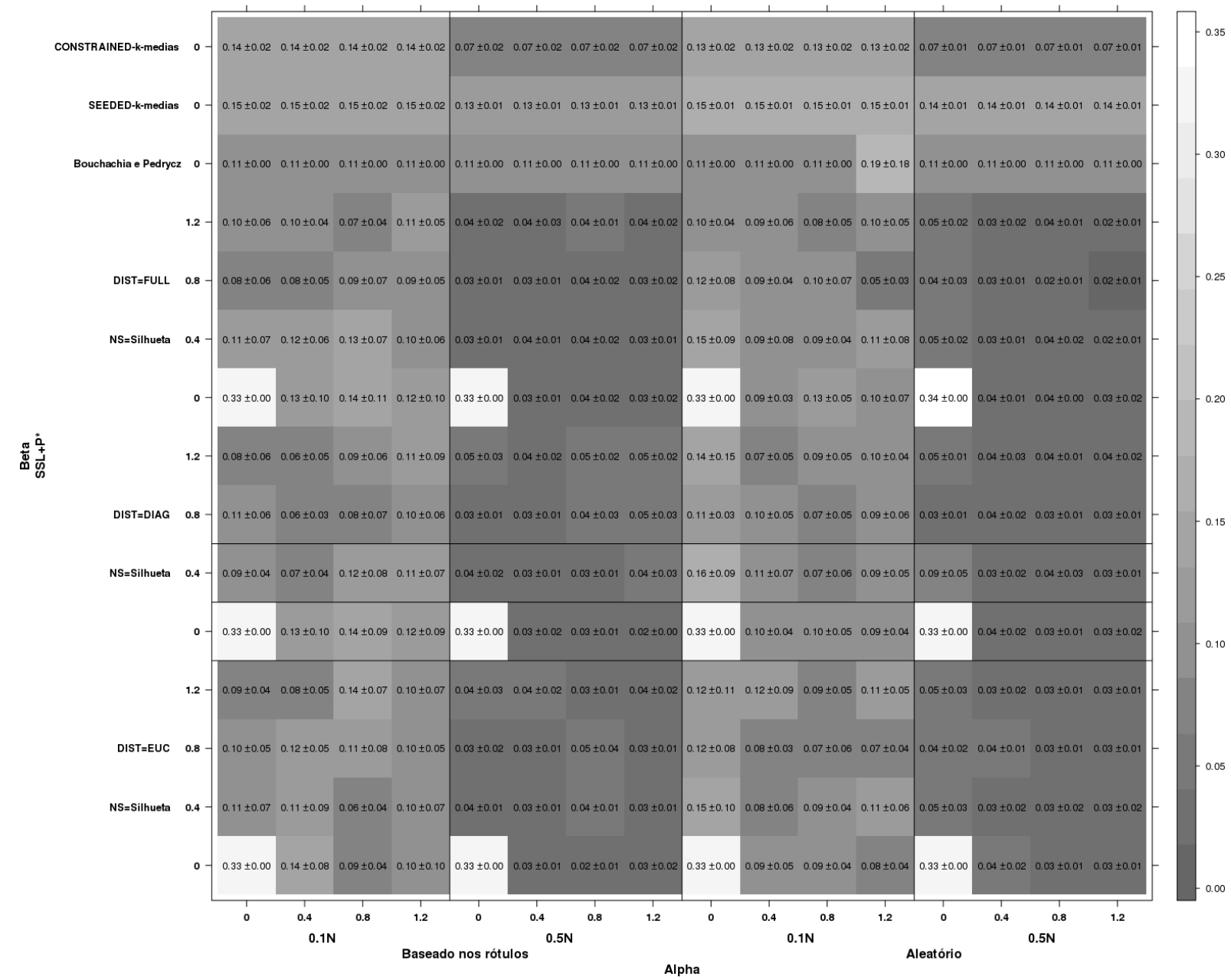

Figura A.4: Comparação do erro de classificação entre os algoritmos Bouchachia e Pedrycz (Bouchachia e Pedrycz, 2003), Constrained e Seeded $k$-médias com SSL+P* na base de dados Iris. 


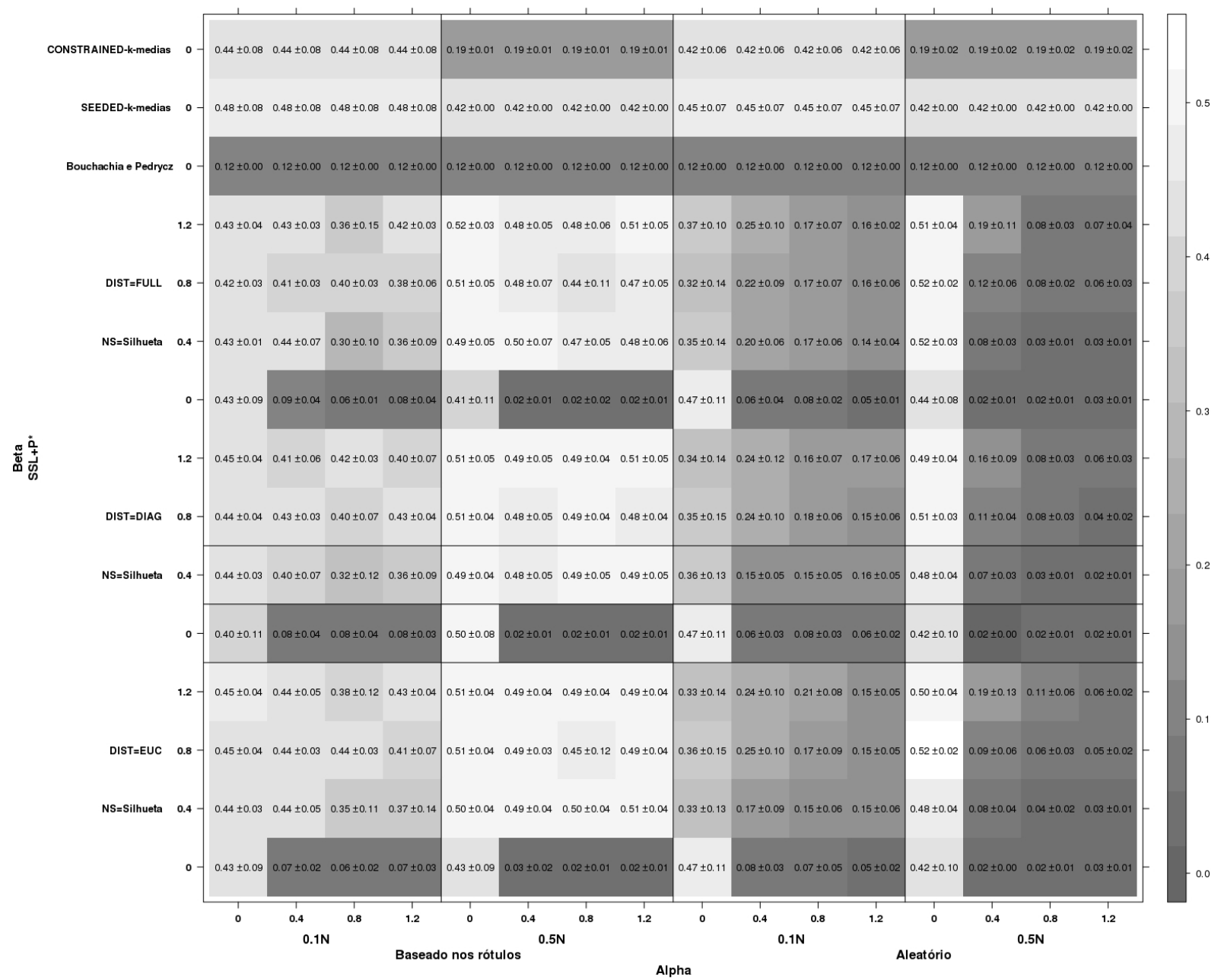

Figura A.5: Comparação do erro de classificação entre os algoritmos Bouchachia e Pedrycz (Bouchachia e Pedrycz, 2003), Constrained e Seeded k-médias com SSL+P* na base de dados Sintética-3. 


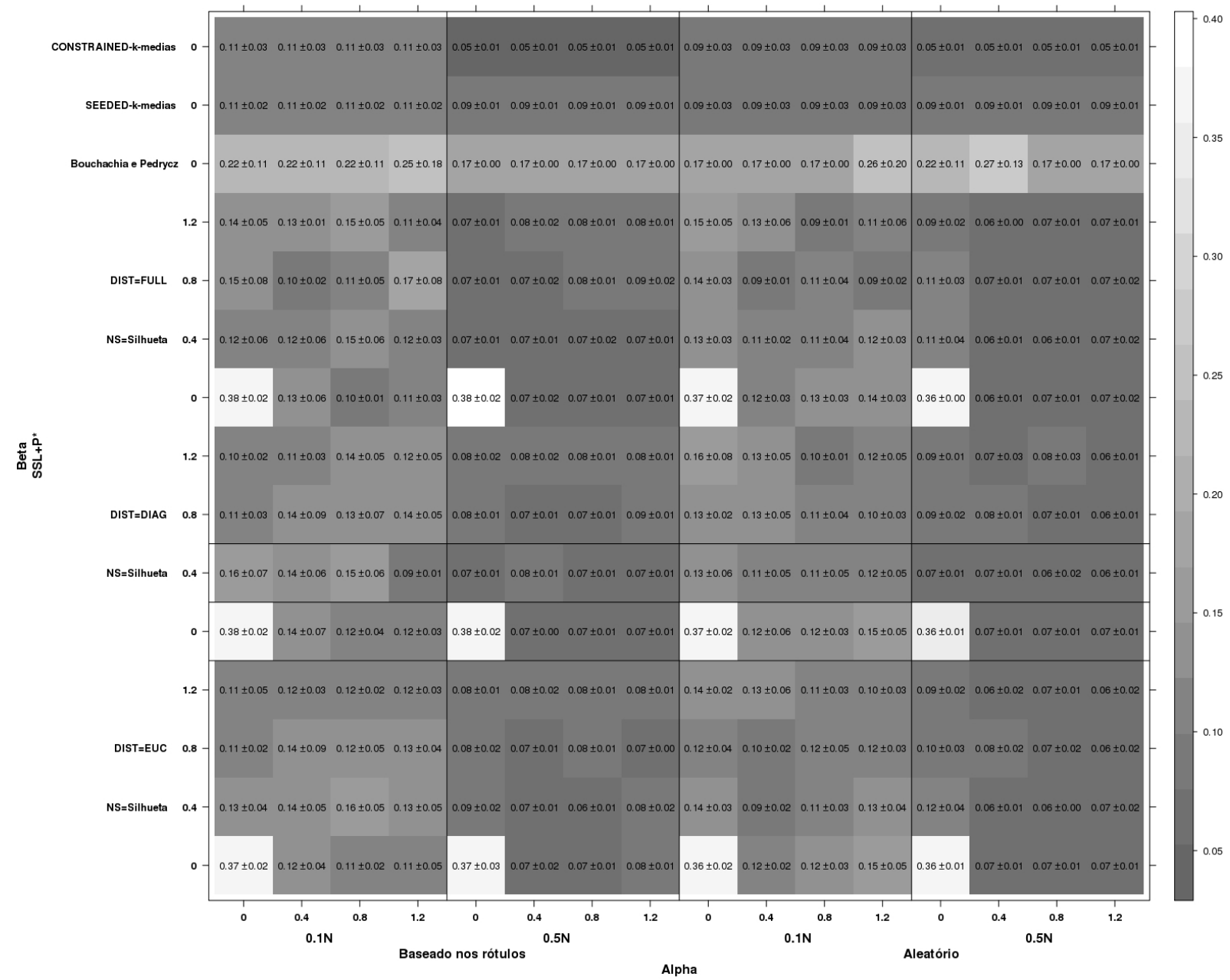

Figura A.6: Comparação do erro de classificação entre os algoritmos Bouchachia e Pedrycz (Bouchachia e Pedrycz, 2003), Constrained e Seeded $k$-médias com SSL+P* na base de dados Sintética-4. 
APÊNDICE A. RESULTADOS COMPLETOS DOS EXPERIMENTOS EM AD

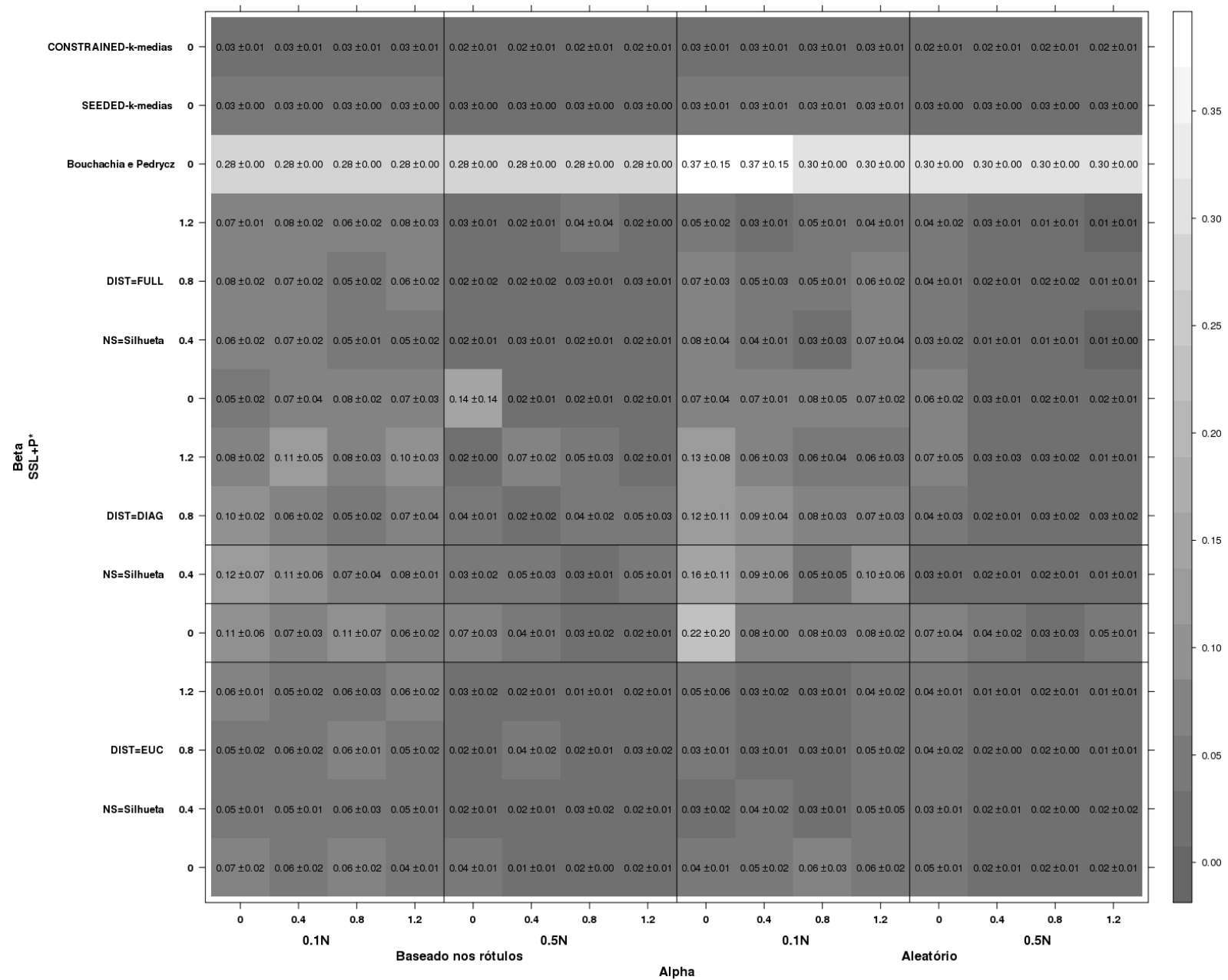

Figura A.7: Comparação do erro de classificação entre os algoritmos Bouchachia e Pedrycz (Bouchachia e Pedrycz, 2003), Constrained e Seeded $k$-médias com SSL+P* na base de dados Wine.

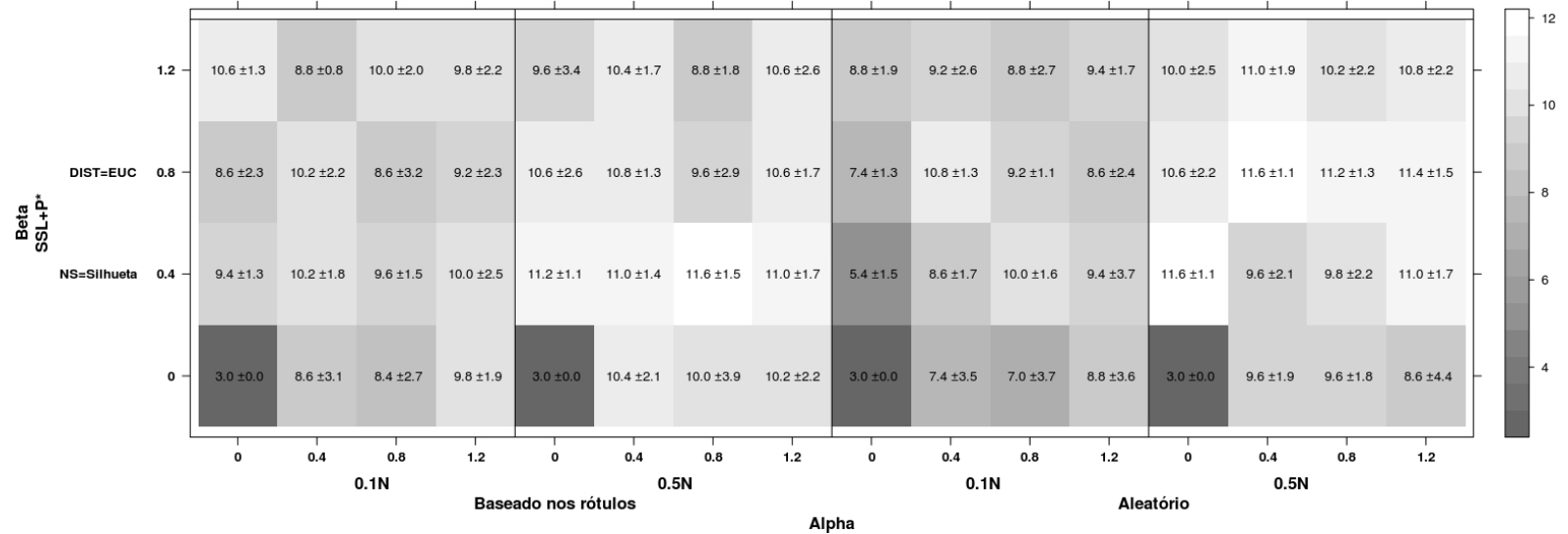

Figura A.8: Número de clusters estimados pelo algoritmo SSL+P* na base de dados Iris. 


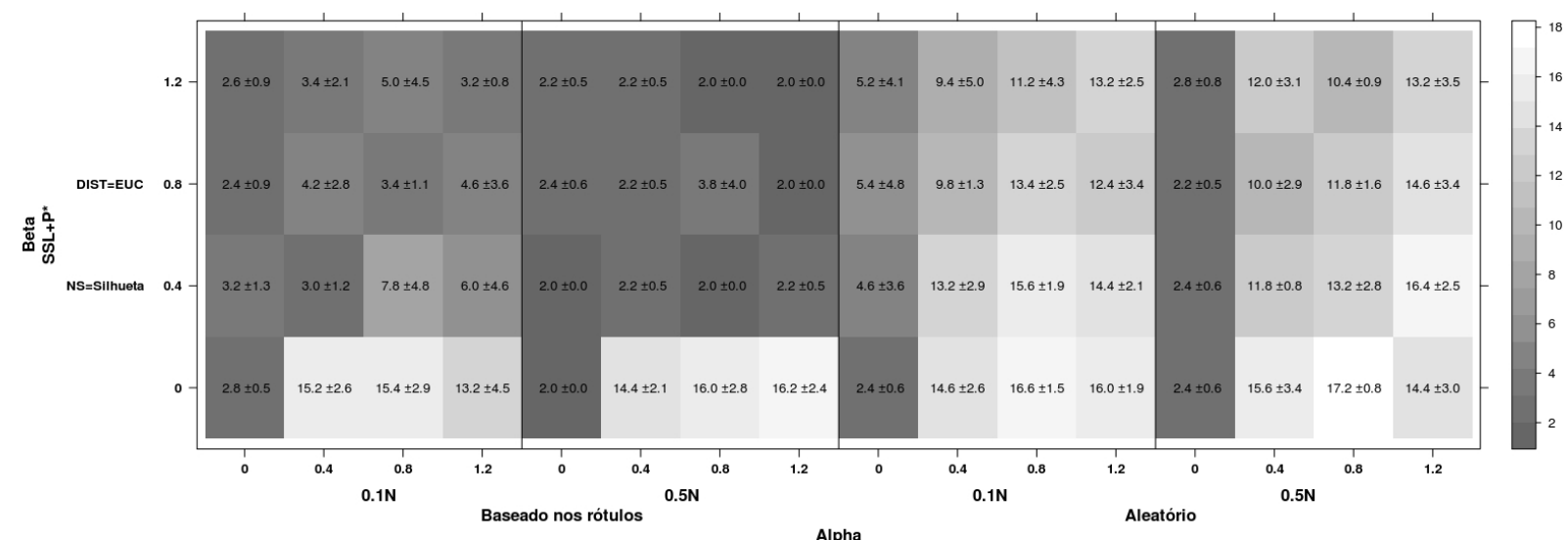

Figura A.9: Número de clusters estimados pelo algoritmo SSL+P* na base de dados Sintética-3.

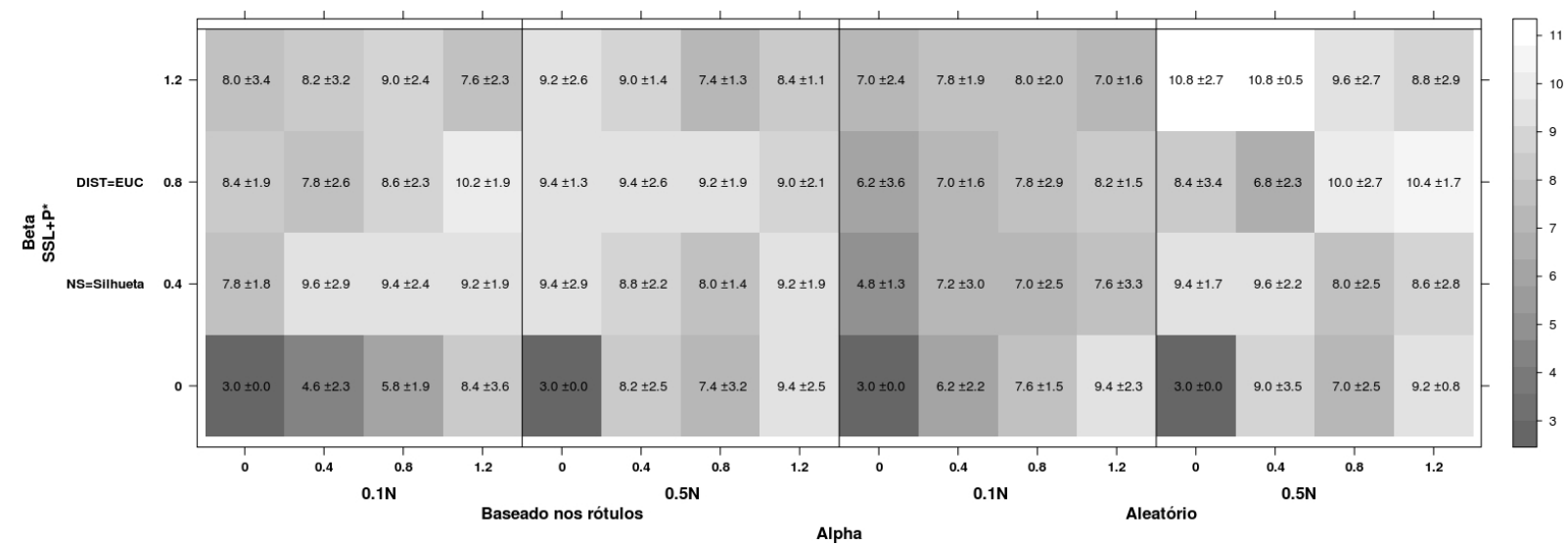

Figura A.10: Número de clusters estimados pelo algoritmo SSL+P* na base de dados Sintética-4.

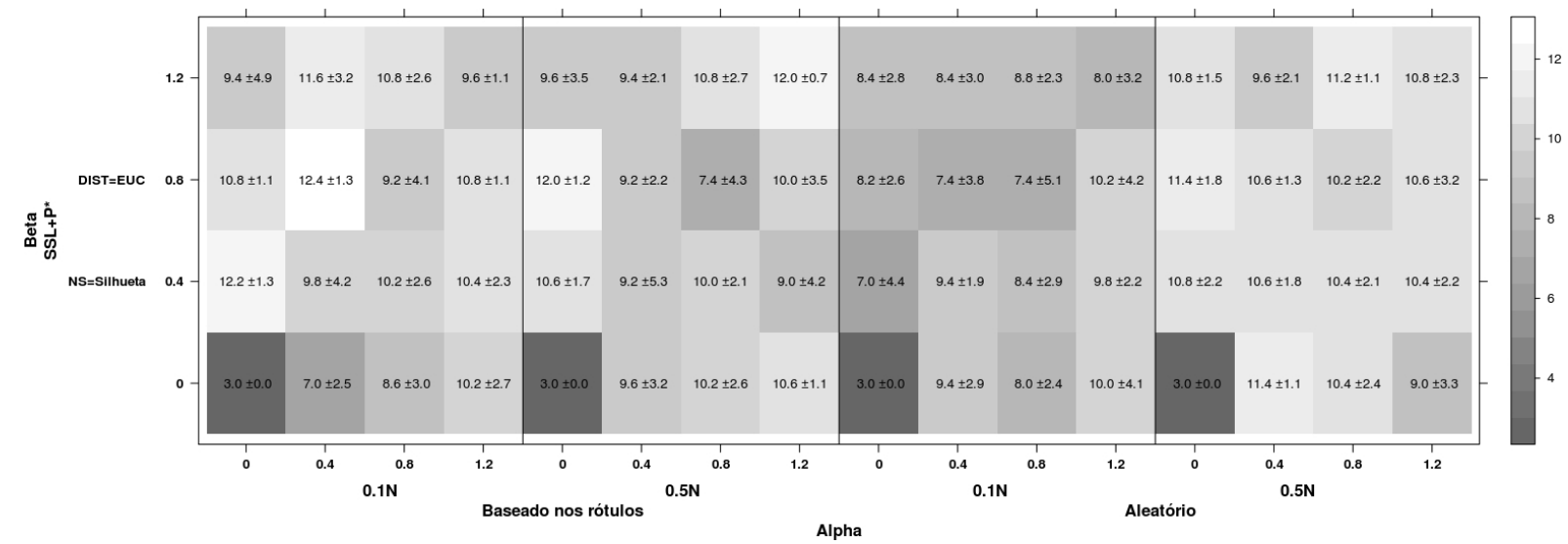

Figura A.11: Número de clusters estimados pelo algoritmo SSL+P* na base de dados Wine. 
APÊNDICE A. RESULTADOS COMPLETOS DOS EXPERIMENTOS EM AD 110 
APÊNDICE

\section{Resumo sobre o algoritmo PSO (Particle Swarm Optimization)}

O PSO (Kennedy e Eberhart, 1995, 2001) utiliza uma população de partículas, $e_{i}$, e uma velocidade associada a cada uma delas $q_{i}$, que controla sua movimentação no espaço de soluções. Essa velocidade é calculada com base na melhor posição que cada partícula já assumiu, $p_{i}$, e a melhor posição, $g$, já atingida pelas partículas de toda população, de acordo com a Equação (B.1):

$$
\begin{array}{r}
e_{i}=e_{i}+q_{i} \\
q_{i}=w q_{i}+c_{1} r_{1}\left(p_{i}-e_{i}\right)+c_{2} r_{2}\left(g-e_{i}\right)
\end{array}
$$

onde $r_{1}$ e $r_{2}$ são valores aleatórios no intervalo [0,1], $c_{1}$ e $c_{2}$ são coeficientes de confiança e $w$ é um parâmetro de inércia que controla o equilíbrio entre a busca local e a busca global. 